Research, part of a Special Feature on Urban ecological and social-ecological research in the City of Cape Town

\title{
Development of a Compendium of Local, Wild-Harvested Species Used in the Informal Economy Trade, Cape Town, South Africa
}

\author{
L.M. Petersen $^{1,2}$, E. J. Moll ${ }^{3}$, R. Collins $^{4}$, and Marc T. Hockings ${ }^{5}$
}

\begin{abstract}
Wild harvesting has taken place over millennia in Africa. However urbanization and cash economies have effectively altered harvesting from being cultural, traditional, and subsistence activities that are part of a rural norm, to being a subculture of commonly illicit activities located primarily within the urban, cash-based, informal economy. This paper focuses on Cape Town, South Africa where high levels of poverty and extensive population growth have led to a rapidly growing informal industry based on the cultural, subsistence, and entrepreneurial harvesting and consumption of products obtained from the local natural environment. Through a process of literature reviews, database analysis, and key informant interviews, a compendium of harvested species was developed, illustrating the breadth of illicit harvesting of products from nature reserves, public open space, and other commonage within the City. The compendium records 448 locally occurring species (198 animals and 250 plants) that are extracted for medicinal, energy, ornamental, sustenance, nursery, and other uses. The sustainability of harvesting is questionable; nearly $70 \%$ of all harvested flora and $100 \%$ of all collected fauna are either killed or reproductively harmed through the harvesting processes. Furthermore, for the 183 indigenous flora species currently recorded on the International Union for Conservation of Nature (IUCN) Red List, 28\% (51) hold assessments ranging from Declining through to Critically Endangered. With respect to the more poorly assessed fauna (46 spp.), approximately 24\% (11) have Declining or Threatened status.
\end{abstract}

Key Words: biodiversity; Cape Town, South Africa; cash-based economy; compendium; conservation; illicit harvesting; informal economy; urbanization; wild harvesting; wild harvest trade

\section{INTRODUCTION}

Despite there being a limited formal record, the procurement and trade of wild-harvested products in South Africa is believed to be considerable (Shackleton 2009). It has been established that up to $80 \%$ of South African households use herbs for medicinal and cultural purposes (Mander 1998, Shackleton 2005) and there is strong reliance on wildharvested products for household items, income generation (Shackleton and Shackleton 2004), fuelwood (Twine et al. 2003), foods (Clark et al. 2002, Shackleton 2002, UNDP 2006), and veterinary medicines (Dold and Cocks 2001). Communally managed areas that were formalized as " homelands" by the apartheid regime, and coastal zones, are among the South African landscapes where wild harvesting has traditionally taken place.

As South Africa's homelands dissolved following the democratic elections of 1994, a mass process of internal migration took place whereby impoverished residents relocated to major South African cities, in accordance with broader African urbanization trends (UN Habitat 2008). Subsequently, urban-based cash markets for traditional medicines, foods, building materials, and fuel increased. The combined trends of urbanization and cash-driven demand for natural resources brings about profound consequences for conservation and the management of biodiversity, not least of which is, anecdotally, the growing trend of illicit wild harvesting from formally proclaimed protected areas. This may be particularly the case for Cape Town - the urban centerpiece of the unique Cape Floristic Region (CFR), which is home to $>9000$ flora species, of which $70 \%$ are endemic (Goldblatt and Manning 2002) and in close proximity to a conurbation of over 3.5 million people. Within the municipal area these natural habitats are represented in many protected areas (including the World Heritage Table Mountain National Park and some 23 smaller City-operated conservation reserves), catchments, parklands, commonage, beaches, and marine environments.

The purpose of the research presented in this paper was to better understand the extent of wild harvesting and its reliance on the City of Cape Town's ecological resources.

\section{Research site}

The coastal City of Cape Town (municipal area $2487 \mathrm{~km}^{2}$ ) is effectively bounded by the South Atlantic Ocean and the Hottentots Holland mountains. The City center is dominated by the Table Mountain range (1092 m elev.) extending southwards in a largely undeveloped peninsula forming the bulk of the Table Mountain National Park. Historically, the City has occupied the land between the foot slopes of the park and the sea, which now comprises well-established middle and upper class residential areas. Moving eastwards, the urban

\footnotetext{
${ }^{1}$ University of Queensland, Australia, ${ }^{2}$ Sustainable Livelihoods Foundation, South Africa, ${ }^{3}$ Department of Biodiversity and Conservation Biology, University of the Western Cape, South Africa, ${ }^{4}$ School of Agriculture and Food Sciences, University of Queensland, Australia, ${ }^{5}$ Department of Geography, Planning and Environmental Management, University of Queensland, Australia
} 
landscape sprawls over $50 \mathrm{~km}$ onto a large, sandy, low plain colloquially known as the Cape Flats; it is primarily occupied by working class residences. Cape Town's population is culturally diverse, with the main groups officially recognized as $\sim 48 \%$ Colored (Khoi/mixed descent), $\sim 32 \%$ Black (primarily isiXhosa affiliated), $\sim 18 \%$ White, and $~ 2 \%$ Other (City of Cape Town 2009). As a legacy of the apartheid regime, these groups primarily reside geographically separately, with White South Africans generally living closer to the City center and fringing the mountains and beaches, and predominantly Black and Colored South Africans inhabiting the Cape Flats.

The City is estimated to accommodate 3.67 million people (City of Cape Town 2010) in at least 904,000 households (City of Cape Town 2005). Cape Town is a fast-growing center; between 1996 and 2007 the City grew by an average of 93,400 persons (extensive migration plus births) each year (City of Cape Town 2010). Migration is manifested in rapidly expanding informal settlements on the fringes of the Cape Flats, containing 108,899 nontitled informal dwellings, i.e., shacks (City of Cape Town 2007).

Poverty is commonplace. Over $38 \%$ of Cape Town households earned less than the Minimum Living Level for an average household of 4.7 people (US\$230 per month in 2010) (City of Cape Town 2007). Unemployment in the migrant settlement of Khayelitsha stands at approximately 54\% (Department of Social Development 2007), in contrast to just over 20\% for the Province (Statistics South Africa 2010). Education levels are generally low, with $58 \%$ of the adult population educated below matriculation (Grade 12) and a further $8.5 \%$ educated to Grade 5 level only (Statistics South Africa 2010).

Within the City, limited formal employment opportunities, poverty, and poor education have spawned the rise of a relatively large and expanding "cash" or informal economy. This economy is broadly characterized as "unregulated economic enterprises or activities" (Hart 1973), including "businesses that are not registered in any way ... small in nature ... operated from homes, street pavements and other informal arrangements" (Statistics South Africa 2010). Though historically characterized as separate, this economy displays various backward and forward linkages to South Africa's formal sector (Devey et al. 2006), although such linkages can be opaque. In this case the urban poor enter the largely informal industry of harvesting, processing, and/or trading wild-harvested products as livelihood activities to fulfill existing cultural and economic demands, and to utilize traditional knowledge and make rural linkages in an urban economy with otherwise high barriers to entry.

\section{Cape Town's informal wild-harvesting industry}

Relatively little has been researched or published on the local informal industry of wild harvesting within the Cape Floristic Region. Loundou (2008), in his thesis of medicinal plant trade, noted the retailing of 170 medicinal plant species within the Cape Town metropolitan area, the majority of which were harvested from the Western or Eastern Cape regions. In a related study, Nzue (2009) recorded harvest of 52 Cape Floristic Region species as medicines. Concerning the informal cut flower industry, Rebelo (1996) revealed that rare Proteaceae species were being wild harvested at low levels on the Cape Peninsula. Prominent foods harvested from Cape Floristic Region landscapes included sour figs (Carpobrotus spp.), honeybush tea (Cyclopia spp.), and buchu (Agathosma spp.) for essential oils (Cowling and Richardson 1995); however, Cowling and Richardson did not specifically describe the informal gathering and trade of these items. In a natural resource valuation study of the Cape Floristic Region, Turpie et al. (2003) estimated that the average net income from harvesting and informal trade of firewood (introduced Acacia spp.) was R148/ha/year. The informal use of marine resources has been more thoroughly investigated, in particular subsistence fisheries (Clark et al. 2002). This usage and trade are acknowledged by the South African government which, via the Marine and Coastal Management (MCM) Directorate, issues permits for subsistence harvesting of bait, shellfish, and other marine and coastal organisms. Furthermore, areas of government and academic focus are the rise of illicit harvesting of abalone (Haliotis spp.) and its export to the far east (Steinberg 2005, Hauck and Kroese 2006).

Other than sporadic research interventions that hint at the phenomenon and scale of the informal wild-harvesting industry in Cape Town, there has been no consolidated effort to record the breadth of this reliance. In the context of growing urbanization and poverty, it is likely that reliance on local biodiversity to support livelihoods is considerable. The development of a contemporary compendium of harvested species would establish a baseline for improved understanding of this activity and it would inform future conservation management actions.

\section{METHODS}

The compendium was developed through four stages that were designed to integrate data and materials from a wide variety of stakeholders and participants.

\section{Stage 1: developing a master list of all locally occurring biodiversity}

Firstly, a master list of all recorded Cape Town biodiversity was developed using the South African National Biodiversity Institute's (SANBI) Integrated Biodiversity Information System (SIBIS). SIBIS is an internet-based platform (http:// www.sibis.sanbi.org) consisting of 1.6 million recorded flora and fauna species sightings throughout South Africa, georeferenced to exact localities (SANBI 2009). The database was publicly accessible through a map interface, allowing the authors to select broad map coordinates of the City municipal area and generate a comprehensive inventory of local species. 
This approach generated an initial record of more than 300,000 site entries of local species. Upon removal of duplicate records from multiple sightings, the list was greatly reduced to 4464 flora species and 1878 fauna species, thus totaling 6642 species. The list is inclusive of marine, freshwater, and terrestrial landscapes, and lists local and Cape Floristic Region endemics, South African indigenous and alien species and subspecies, and plant hybrids. Some weaknesses were noted, including an emphasis on flora, and the local extinction or emigration of various species since the time of original data collection (these are acknowledged by the SIBIS authors). Marine and littoral species were bolstered with literature from the Marine and Coastal Management Directorate. The final list was confirmed by various local ecologists and the SIBIS database manager to represent the totality of local species.

\section{Stage 2: compiling a provisional harvested species compendium}

In a separate process, a literature review of South African subsistence and traditional utilization of wild-harvested products was conducted. From a range of peer-reviewed literature (circa 1998 to present), all recorded harvested species were documented. The harvested species from the literature were then cross-checked with the master list of species. Where harvested species were present on the master list they were extracted into a provisional harvested species compendium, by recording family, genus and species, common names, indicative anthropogenic uses, and references.

\section{Stage 3: ground assessment of the provisional harvested species compendium}

Over the period November 2010 to April 2011, the provisional harvested species compendium was field tested in 62 semistructured interviews with conservation and lawenforcement professionals, informal economy harvesters/ processors of local species, and retailers at various points in the value/supply chain. Where interviews revealed local harvested species, they were confirmed or included in the compendium. This approach was utilized to better understand the broader system of harvesting and trade aspects (described in Bonney et al. 2007), and to allow for a variety of perspectives and inputs. Further details on participant ethnicity, product demands, and harvest trends were recorded. Participants included:

- Conservation professionals in South African national parks and the City of Cape Town. These 25 individuals were able to reveal harvesting and resource pressures within the following areas: Table Mountain National Park (terrestrial and marine sections), Edith Stephens Nature Reserve, Harmony Flats Nature Reserve, Rondevlei Nature Reserve (and encompassing False Bay Ecology Park), Macassar Dunes Nature Reserve, Tygerberg Nature Reserve, Wolfgat Nature Reserve,
Atlantis Conservation Area, and the Blaauberg Conservation Area.

- Marine and terrestrial law-enforcement officers. These 11 officers were working primarily within the Table Mountain National Park and the City of Cape Town.

- Harvesters/processors of local species. The researcher accompanied 11 harvesters on collection exercises and observed processing (generally in informal markets).

- Resource retailers/users. Fifteen individuals in eight informal markets throughout the City were visited and interviewed. Ethnic, traditional healer groups (such as spiritual doctors, herbalists, and Rastafarians), cut flower traders, and ad hoc roadside vendors were interviewed, and their natural resource trading stock was examined.

To elicit accurate and reflective responses, a multiracial and culturally representative investigatory team with practical understanding of informal trade operations was trained by the lead researcher, and the team participated in all interviews. The 6-month interview and data collection process (across three seasons) allowed for temporal factors of harvest and trade, such as highly seasonal cut flower collections. Responses were further compared with law-enforcement and other official data to reflect accuracy.

\section{Stage 4: finalization of the compendium}

At the conclusion of field work, the locally harvested species compendium was populated and finalized. The finalization included a review of the International Union for Conservation of Nature's (IUCN) Red List status (Raimondo et al. 2009) of each harvested species, in order to support sustainability assessments and to categorize each species in terms of endemism. Where possible, references to data sources were added, although in many cases informal economy participants wished to remain anonymous.

\section{RESULTS}

\section{Summary}

The compendium records a total harvest of 454 separate species/items (flora, fauna, fungi, and inert) from within the City of Cape Town. Of the 454 locally collected records, 250 $(55.1 \%)$ are locally occurring flora from 70 different taxonomic families (inclusive of three fungi species); 198 (43.4\%) are marine, littoral, and terrestrial fauna from 17 taxonomic classes; and a further six "inert" wild-harvested items (including stones and seawater) are collected for trade. These are documented in Appendices 1 and 2. Appendix 1 lists locally harvested/traded flora (including fungi) for the informal economy, and Appendix 2 lists locally collected/ traded fauna. A further 121 species-reportedly wild harvested from outside the City-are imported for retail sale. For all uses, the trade of biodiversity within the City extends to 575 separate items (of which 569 are biological organisms). 


\section{Anthropogenic uses of local, wild-harvested products} Of the 250 species of flora (and taking into account multiple uses), $129(51.6 \%)$ are harvested from within the City boundary for medicinal purposes, $96(38.4 \%)$ are harvested for the cut flower trade, 10 are harvested for fiber, and 4 are harvested as fuelwood. The medicinal plant trade was substantially bolstered by an additional 121 imported species (medicinal plants thus account for $67.3 \%$ of total local informal flora trade). These are sold by informal retailers as individual plant parts, or in a variety of plant component blends and prescribed mixes. This study confirms and broadens Loundou's (2008) work from 170 to 250 species of medicinal plants traded within the City. With respect to medicinal plant species, the compendium compares to other areas as follows: in the Eastern Cape where 166 plant species are regularly traded (Dold and Cocks 2002); in Mpumalanga where 176 species are harvested/traded (Botha et al. 2004), in KwaZulu Natal where up to 400 species are regularly utilized for medicinal purposes (Mander 1998); and in Gauteng where 511 species are traded (Williams et al. 2007). The informal collection of flora species for the cut flower trade is likely greater than other biomes, but the harvest of four Cape Town flora species as food sources (including Carpobrotus spp.) is substantially less than in other regions. Table 1 summarizes the ten floral families of greatest harvest impact.

Table 1. Relative effects of wild-harvesting on the ten most affected plant species, by flora family: summary.

\begin{tabular}{ccc}
\hline Family & $\begin{array}{c}\text { No. of species } \\
\text { harvested }\end{array}$ & Common usage \\
\hline Proteaceae & 52 & Cut flower trade \\
Iridaceae & 15 & Cut flower trade / \\
& & medicinal \\
Asteraceae & 14 & Medicinal \\
Lamiaceae & 10 & Medicinal \\
Poaceae & 11 & Fiber / nursery \\
Restionaceae & 9 & Fiber \\
Fabaceae & 8 & Fiber / medicinal \\
Scrophulariaceae & 7 & Medicinal \\
Amaryllidaceae & 7 & Medicinal \\
Malvaceae & 7 & Medicinal
\end{tabular}

Conversely, with respect to 198 harvested fauna species, 120 $(60.6 \%)$ are harvested for human consumption; these are primarily marine mollusks, but included are four terrestrial mammals and potentially 16 terrestrial/wetland birds. A further 77 species (exclusively marine) are harvested for use as bait for catching food for human consumption, although 73 of these are also traded or eaten as a primary food. Fifty-six species (28.2\%)—including reptiles (primarily snakes), all locally occurring butterflies, arachnids, and Colophon beetles - are gathered by (potentially affluent) collectors or pet traders. A further 33 species $(16.7 \%)$ - primarily reptiles, including snakes and chameleons - are harvested for the purpose of medicinal use. The majority of larger mammals are hunted for sport or gambling purposes (including "blood sports"). Table 2 highlights the relative effects of wild harvesting on animal species, by faunal class.

Table 2. Relative effects of wild harvesting on animal species, by faunal class: summary.

\begin{tabular}{ccc}
\hline \hline Class & $\begin{array}{c}\text { No. of species } \\
\text { harvested }\end{array}$ & Common usage \\
\hline Gastropoda & 53 & Bait / food \\
Insecta & 36 & Collectors \\
Reptilia & 28 & Medicinal / pet trade \\
Aves & 19 & Food \\
Osteichthyes & 15 & Food \\
Polyplacophora & 11 & Bait / food \\
Mammalia & 10 & Sport / food \\
Bivalvia & 7 & Bait / food \\
Pteriomorphia & 5 & Food \\
Arachnida & 3 & Pet trade \\
Maxillopoda & 3 & Bait / food \\
Amphibia & 2 & Pet trade \\
Malacostraca & 2 & Bait / food \\
Ascidiacea & 1 & Bait \\
Cephalopoda & 1 & Food \\
Crustacea & 1 & Bait \\
Polychaeta & 1 & Bait \\
\hline
\end{tabular}

\section{People and local, wild-harvested products}

The harvesters, retailers, and users of wild-harvested species come from a variety of cultural and socioeconomic backgrounds. There are no known estimates as to their numbers, although three groups of role players are prominent.

\section{Medicinal}

This includes harvesters/traders of Colored and Black ethnicity who describe themselves as Rastafarians and longstanding residents with strong traditional links to Cape biodiversity. Harvesters/traders of Black (isiXhosa) ethnicity include spiritual doctors (sangomas), traditional herbalists (nyangas), faith healers, and birth attendants. Medicinal actors harvest and trade 166 species of local flora and fauna $(36.7 \%$ of all locally harvested species) for personal use or sale. When taking into account product imports from outside the City, this group accounts for $50.6 \%$ of all wild-harvested species traded.

\section{Utility}

This group includes harvesters who are primarily Colored and Black in origin, and who are seeking resources to bolster food or income security. This group ranges from firewood gatherers and seasonal cash-driven flower and reed harvesters, to shellfish harvesters and small-scale commercial fishermen. This group harvests 239 flora and fauna species (52.6\% of all harvested species) and accounts for $41.6 \%$ of local species that are traded. 
Niche

Niche operators are the smallest group of users. They are not necessarily economically marginalized and include collectors with specialist knowledge who harvest items such as insect or nursery specimens from a personal or financial interest. Another group includes syndicated gamblers illicitly hunting herbivorous mammals with dogs in protected areas. This group is responsible for the harvest of 60 flora and fauna species from within the City ( $13.2 \%$ of total species count).

\section{Spread of harvesting incidences in Cape Town}

The overwhelming majority of flora and terrestrial fauna are illicitly harvested from formal protected areas within the City, with the majority of marine species either collected or fished (either permit-based or illicitly) from the intertidal zone. Although not all nature reserves and public open spaces were investigated, where the data were available the research revealed a widespread anthropogenic involvement in harvest and trade activities throughout the City. Fig. 1 is an indicative spread of these activities in key researched areas, as compiled through the field investigation and harvester information.

It is evident that harvesting incidences are spread throughout the City, with larger impacts occurring closer to the urban footprint. The clustering of harvesting incidents in formal conservation areas reflects close proximity to lower income residential areas. Whilst not exhaustive, recorded are a number of sites where wild-harvested products are retailed, the most prominent being street traders selling medicinal plants on main commercial streets. A number of informal traders of food (such as fish, sour figs) and firewood vendors were documented; these individuals are commonly positioned along roadways and traffic intersections.

\section{Harvest demand}

To better understand the depth of wild harvesting, lawenforcement data for the Tygerberg Nature Reserve were interrogated. These data, presented in Table 3, are based on biodiversity confiscations from illicit harvesters during office hours from April to December 2010 and they give some indication of harvester demand for biodiversity in the reserve.

In this example, the primary purpose of illicit harvesting was for medicinal use, reportedly by Rastafarian persons. Eighty percent of harvested species are killed or reproductively maimed. Research participants noted that the extremely high numbers of Tulbaghia capensis rhizomes confiscated are indicative of recent demand trends intersecting with harvester "discovery" of this resource within the reserve. Harvesting activity is responsive to demand trends, with consolidated lawenforcement data revealing a similar contemporary spike in medicinal harvesting of various tortoise species within a number of City reserves.
Fig. 1. An indicative spread of biodiversity harvesting and retailing localities, based on reports by harvester and conservation manager informants, within the City of Cape Town.

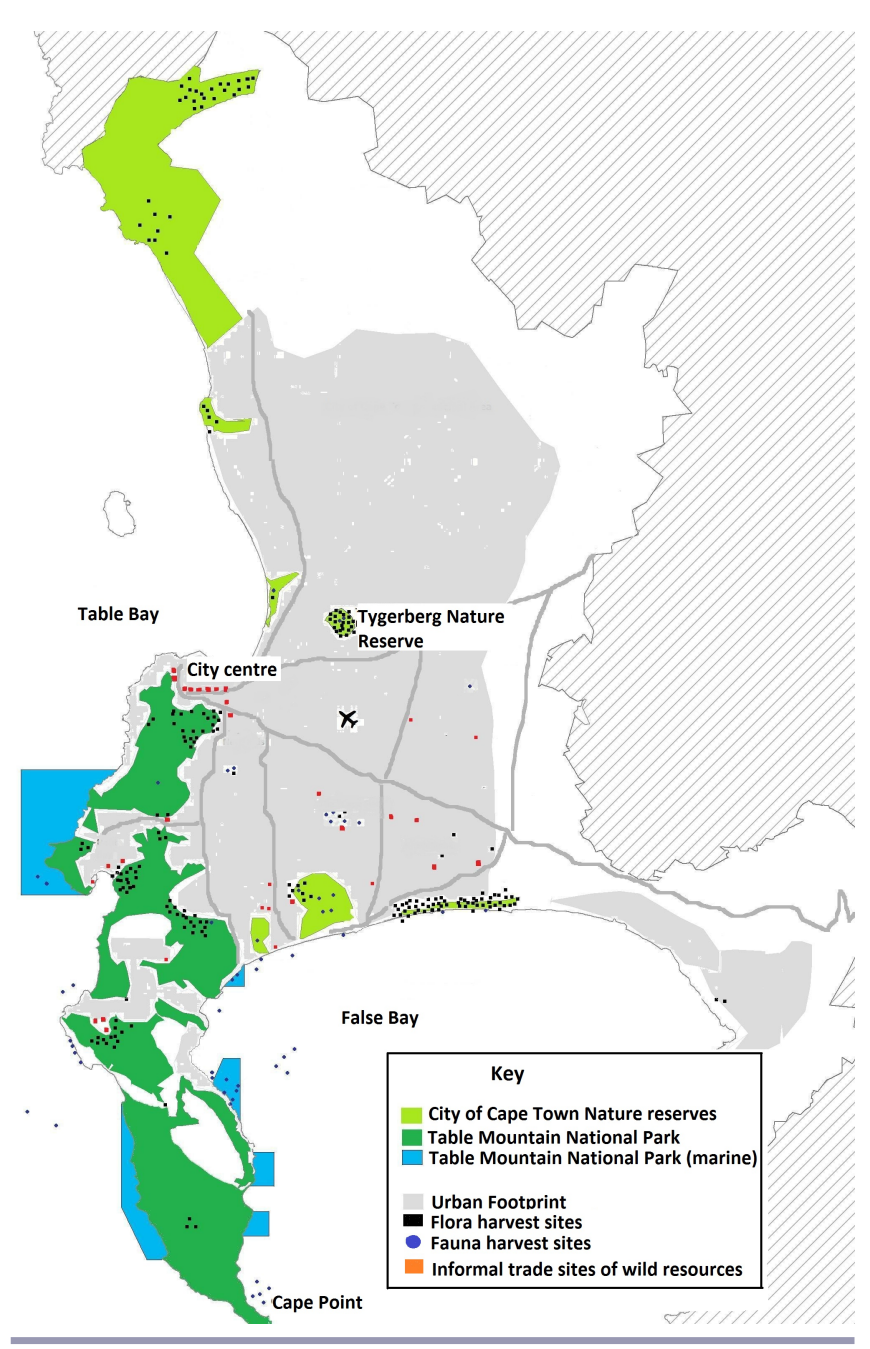

\section{Sustainability of harvesting local wild species Harvest modalities}

Nearly all of the 250 flora species ( 242 or $96.8 \%$ ) are harvested by hand using simple tools, i.e., spades, hand pruners (clippers), or knives. Medicinal and utility actors primarily collect on foot, storing harvested items in bags and utilizing public transport. The remaining 14 species are harvested with an axe or a saw, which are used primarily for removing bark or cutting fuelwood; these are generally transported to markets in commandeered supermarket trolleys. 
Table 3. The ten most-commonly harvested flora species from the Tygerberg Nature Reserve (300 ha), City of Cape Town, from April to December 2010, as reflected in law-enforcement confiscations (personal communication Glanville 2011).

\begin{tabular}{|c|c|c|c|c|c|}
\hline Rank & Species & Common name & Common usage & Harvest target & $\begin{array}{c}\text { Quantity confiscated (units } \\
\text { / bunches) }\end{array}$ \\
\hline 1 & Tulbaghia capensis $\mathrm{L}$. & $\begin{array}{c}\text { Wild garlic / Wilde } \\
\text { Knoffel }\end{array}$ & Medicinal & Rhizome & 9936 \\
\hline 2 & Helichrysum patulum (L.) D. Don & Imphepho & Medicinal & $\begin{array}{l}\text { Harvest of reproductive } \\
\text { structures / systems }\end{array}$ & 223 \\
\hline 3 & Elytropappus rhinocerotis L.f. & $\begin{array}{l}\text { Rhenoster bush / } \\
\text { Renosterbos }\end{array}$ & Medicinal & Leaf and stem & 192 \\
\hline 4 & Chironia baccifera $\mathrm{L}$. & $\begin{array}{l}\text { Christmas berry / } \\
\text { Bitterbossie }\end{array}$ & Medicinal & $\begin{array}{l}\text { Harvest of reproductive } \\
\text { structures / systems }\end{array}$ & 183 \\
\hline 5 & Haemanthus coccineus $\mathrm{L}$. & March flower / rooikwas & $\begin{array}{c}\text { Flowers / foliage / } \\
\text { medicinal }\end{array}$ & Bulb, flower & 116 \\
\hline 6 & $\begin{array}{c}\text { Drimia capensis Burm. f. } \\
\text { Wijnands }\end{array}$ & Brandui & Medicinal & Bulb & 61 \\
\hline 7 & $\begin{array}{l}\text { Helichrysum cymosum Sch.Bip. } \\
\text { subsp. Cymosum }\end{array}$ & Everlasting / Kooigoed & Medicinal & $\begin{array}{l}\text { Harvest of reproductive } \\
\text { structures / systems }\end{array}$ & 60 \\
\hline 8 & Arctopus echinatus L. & $\begin{array}{l}\text { Bear foot / Kaapse } \\
\text { platdoring }\end{array}$ & Medicinal & Bulb & 44 \\
\hline 9 & Drimia elata Jacq. ex Willd. & Brandui & Medicinal & Bulb & 23 \\
\hline 10 & Agathosma crenulata (L.) Pillans & Boegoe & Medicinal & $\begin{array}{l}\text { Leaves / stems } \\
\text { Total items }\end{array}$ & $\begin{array}{c}12 \\
10,850\end{array}$ \\
\hline
\end{tabular}

A total of 119 of the 198 fauna species $(60.1 \%)$ are harvested by hand or with simple tools. For intertidal mollusks, the use of paint scrapers and plastic containers was commonly described. Nets are used for the capture of up to 44 species $(22.2 \%)$, including various insects and fish. Twenty-six species $(13.1 \%)$ are captured with traps and/or dogs. Six species (predominantly fish) required the use of a boat in procurement.

\section{Life forms targeted}

Of the 250 flora species, the reproductive componentsgenerally flowers for the cut flower or medicinal plant trade - are removed for 99 species (39.6\%). Bulbs, tubers, and roots are targeted for 58 species (23\%) of plants, and these are used primarily for medicinal purposes. For a further 18 species $(7.1 \%)$ the entire plant was targeted for the medicinal or nursery trade. In all, a total of $70 \%$ of the entire harvest of flora required the reproductive maiming, removal, or death of the plant. These findings compare to those of Dold and Cocks (2002) in the Eastern Cape, and Mander et al., (2007) in KwaZulu Natal, who noted respectively that more than $75 \%$ and $86 \%$ of harvested plant parts in their studies were associated with the death of the plant. Within this study, for a further 53 species (21\%) the leaves and stems are targeted, that is, for medicinal use, fiber, and the cut flower trade. Seven tree species (2.8\%) are harvested for bark that is exclusively for medicinal use; this is proportionally less than in the Eastern Cape (17\%) and the KwaZulu Natal (27\%) due to the limited forest habitats in the City. A further five tree species (alien to South Africa) are commonly harvested for fuelwood.

Of the total harvest of fauna, all (100\%) required the death or extraction of the animal.

\section{Conservation status}

With respect to the harvest of the 250 flora species, 132 $(52.8 \%)$ are of Least Concern on the IUCN Red Data List. Insufficient data were available for conservation assessments for 69 species $(27.6 \%)$. Of the 181 species under assessment, $49(27.1 \%)$ are of concern.

- Six species are Declining. Five are medicinal plants; one is harvested for the nursery trade.

- Thirteen species are assessed as Near Threatened. These comprise nine species utilized for the cut flower trade, and two species each for the medicinal and nursery trades.

- Thirteen species are considered to have Vulnerable status. Of these, ten are harvested as cut flowers.

- Fourteen species have Endangered status. Of these, 13 are traded as cut flowers. A further species (Ocotea bullata) undergoes regular bark stripping for medicinal purposes.

- Three species are considered to be Critically Endangered. Reportedly these are harvested for the cut flower trade.

Of the 49 species recorded on the Red List, 33 incur reproductive harm from harvesting (67.3\%) and 11 die $(22.4 \%)$ as a result of harvesting. A further three tree taxa incur bark stripping damage for medicinal use; the cumulative impacts pose a threat to tree survival. Forty Red List species are locally indigenous (naturally occurring in Cape Town), and the remainder are indigenous to the Cape Floristic Region (not necessarily the City). 
Species conservation assessments for local fauna are less comprehensive. For the 198 species of animals harvested, a total of $46(23.2 \%)$ have been assessed. Thirty five $(76 \%)$ of these are of Least Concern. Eleven species (23.9\%) are recorded as being of concern. Psammobates geometricus is harvested for medicinal purposes and the pet/collector trade and is considered Endangered. Similarly Endangered Colophon beetles are also used in the collector trade, as are five butterflies of conservation concern. One marine fish, Lithognathus lithognathus, is of lower risk status, and one freshwater fish, Cyprinus carpio (an alien), is considered Vulnerable within its originating habitat. Four harvested animal species are considered alien to South Africa, and one, Numida meliagris (Guinea fowl), is considered alien to Cape Town. The unassessed species are comprised mostly of harvested marine shellfish (almost all species), reptiles, and birds.

\section{DISCUSSION}

Our study highlights that wild harvesting has considerable spread and impact throughout the City of Cape Town. Driving this commonly illicit industry are growing numbers of resource extractors of diverse ethnic origin (anecdotally also including more affluent sectors of the local population), who benefit from low barriers to entry (>96\% of flora and $60 \%$ of fauna are harvested by hand), and who consume a wide variety of species. These groups vary in their reliance on the trade of wild-harvested products, although it appears that many harvesters could be best described as small-scale, informal, commercial operators who fulfill fluctuating demands for wild-harvested products. In many cases these individuals appear to be justified by culture but motivated by cash income as they fulfill growing and diverse market demands.

The ecological sustainability of the ongoing, mainly illicit, harvest of floral species is questionable. Collectively, medicinal plants and cut flowers comprise $90 \%$ of the total flora harvest from within City conservation areas, of which $>70 \%$ are either killed or reproductively maimed. The precedent for current harvesting damage to become more pronounced can be seen in re-analysis of Dold and Cocks' (2002) Eastern Cape research which noted that 3 of 34 commonly harvested species were of conservation concern. Upon re-evaluation, the same list now includes at least 11 species of concern (although the causes of their subsequent decline may vary). This research, by investigating harvesting in an urban context, has demonstrated similarly pronounced sustainability impacts within formal protected areas for species of conservation concern. Furthermore, these impacts extend to all harvested species within proximity to human settlements, and to specific individuals (such as Tulbaghia capensis) where the extent of harvesting demand is pronounced.

With respect to wild-harvested cut flowers, an historic study by Rebelo (1996) recorded 22 local Proteaceae spp. as being picked at varying levels and as being of IUCN conservation concern. The number of taxa of concern being picked has since grown to 31 , as determined from, primarily, deteriorating species assessments. In light of the population growth and informal settlement growth that have occurred since Rebelo's study, and in conjunction with the potentially high reproductive damage caused by flower harvesting and the anecdotally indiscriminate utilization of species for the cut flower trade, the scope for ecological damage inflicted by illicit harvesters is of concern. A tendency for indiscriminate flower gathering was reflected in the feedback from one respondent: "My brother collects his medicines in the park, and then at the end of the day he will cut a bunch of flowers to sell for transport money to get home." Similarly, a trend of medicinal plant substitution was also encountered. In cases of shortages of a particular wild-harvested product, various harvester informants were sourcing wild substitutes. Indiscriminate harvesting and species substitution bodes poorly for conservation efforts, and presents a scenario of resource stripping from protected areas.

With respect to fauna, the subsistence harvest of marine organisms reveals lower impacts (although $>75 \%$ of species await conservation assessments). A resource-rich local marine environment, an emphasis on harvesting commonplace and highly fecund mollusks, a permit-monitoring system, and relatively lax policing may contribute to the potential for improved sustainability. Of greater concern is the potential ecological damage from invertebrate and reptile harvesters extracting species for the pet, collector, and medicinal markets.

The growth of human settlement in the City is reflected in increased harvesting pressures in local conservation areas, which is most pronounced in areas adjacent to poor socioeconomic settlements. Yet, if confiscations data from the Tygerberg Nature Reserve (which is both fenced and surrounded by middle class suburbia) reflect trends in the demand for local flora and fauna, there is an urgent requirement for all conservation reserves to enhance measures to protect biodiversity.

This research highlights the imperative for creative management, and economic and enforcement solutions that address various harvester groups.

Firstly, there is a need to improve the overall understanding of the informal economy's demand for local wild-harvested species. The effort to understand the demand is ongoing in this research, through analysis of the value chains in the informal wild-harvesting economy. Understanding these trends through value chain analysis will improve scope for developing conservation programs that are culturally acceptable and economically beneficial for Cape Town's poor residents. Growing numbers of economically marginalized residents within the City, and the varied and evolving cultural 
dynamics, require increasingly people-centered solutions for community and conservation relevance.

Secondly, in localities where uncontrolled harvesting is known to occur, mapping community structure and form as a baseline for possible future restoration efforts should take place. Simultaneously, comprehensive reserve-level risk assessments that integrate current and new management approaches are required. Understanding and prioritizing actual and potential illicit harvesting risk and impacts at the protected area level will improve conservation management approaches. In highrisk reserves, enhanced surveillance and enforcement are essential, although 24-h enforcement is impractical for areas such as the $470 \mathrm{~km}^{2}$, open-access Table Mountain National Park. Despite potential legal and bureaucratic hurdles, further investigation of suitable permit systems for select species (as is presently utilized for various marine organisms) is required; although, according to anecdotes, permits can serve as gateways for indiscriminate resource extraction, and would not only require considerable policing but in some cases would require highly specialist biodiversity knowledge to enforce. With respect to medicinal plant and cut flower activities, the centralized control of community-based plant nurseries shows incompatibilities with the nature of informal entrepreneurship. However, in agreement with Botha, Witkowski et al. (2004) note that wholesale nurseries or cultivation efforts (ideally driven by conservation agencies) may assist in fulfilling local demands.

\section{CONCLUSIONS}

This paper extends the state of knowledge of flora and fauna harvesting from the City of Cape Town within the Cape Floristic Region. Our research has generated a comprehensive species inventory that will inform management decision making. It highlights the sum of wild-harvested products, of which plants and terrestrial animals in particular are commonly extracted illicitly and unsustainably. In terms of developing effective solutions (such as potential conservation/ economic development projects), there is a requirement for conservation managers to recognize the diverse biodiversity demands of the informal sector and the complex, growing, informal markets they serve. The research highlights an issue of growing prominence within the City which has incremental potential to become a major threat to future biodiversity conservation.

Responses to this article can be read online at: http://www.ecologyandsociety.org/vol17/iss2/art26/ responses/

\section{Acknowledgments:}

With thanks to the Sustainable Livelihoods Foundation, City of Cape Town Biodiversity Management; Mr Dalton Gibbs;
Drs Tony Rebelo, Patricia Holmes, and Andrew Charman; anonymous informal sector informants; and anonymous reviewers. This paper is a product of the Urban Ecology CityLab, which is part of the CityLab programme of the African Centre for Cities at the University of Cape Town. The African Centre for Cities' CityLab programme is funded through the Mistra Urban Futures network (which is funded by Mistra the Foundation for Strategic Environmental Research and the Swedish International Development Cooperation Agency), the Provincial Government of the Western Cape (Department of Human Settlements), and the City of Cape Town.

\section{LITERATURE CITED}

Bonney, L., R. Collins, A. Fearne, and R. Clarke. 2007. Proceedings of the fifth international conference on supply chain management and information systems, 9-12 December, Melbourne, Australia. Presented by a consortium of Australian universities and industry associations.

Botha, J., E. T. F. Witkowski, and C. Shackleton. 2004. Market profiles and medicinal plants in the Lowveld, South Africa. Environmental Conservation 31(1):38-46. http://dx.doi.org/1 $\underline{0.1017 / \mathrm{S} 0376892904001067}$

Campbell, T. A. 2006. The effects of fire and harvesting on Restionaceae spp. (Thamnochortus insignus and $\mathrm{T}$. erectus) with different life histories: a matrix modelling approach. Dissertation. University of Stellenbosch, South Africa.

City of Cape Town. 2005. City statistics and population census: city statistics. Strategic Information, Strategic Development Information and GIS Department, City of Cape Town, South Africa.

City of Cape Town. 2007. City statistics and population census: city statistics. Strategic Information, Strategic Development Information and GIS Department, City of Cape Town, South Africa.

City of Cape Town. 2009. State of Cape Town 2008: development issues in Cape Town. Strategic Development Information and GIS Department, City of Cape Town, South Africa. [online] URL:

http://www.capetown.gov.za/en/stats/CityReports/Documents/ IDP/State\%20of\%20Cape\%20Town\%202008\%20Final\%20low\% 20res.pdf.

City of Cape Town. 2010. City of Cape Town discussion paper, 27th August, 2010: demographics scenario. Strategic Development Information and GIS Department, City of Cape Town, South Africa. [online] URL: http://www.capetown.gov.za/en/sdf/Documents/Nov2010/ DemographicsDiscussionPaperAugust2010.pdf.

Clark, B. M., M. Hauck, J. M. Harris, K. Salo, and E. Russell. 2002. Identification of subsistence fishers, fishing areas, resource use and activities along the South African coast. 
South African Journal of Marine Science 24(1):425-437. http ://dx.doi.org/10.2989/025776102784528574

Cowling, R. M., and D. M. Richardson. 1995. Fynbos: South Africa's unique floral kingdom. Fernwood Press, Cape Town, South Africa. http://dx.doi.org/10.1016/0006-3207(91)90094$\underline{\mathrm{P}}$

Department of Social Development. 2007. Khayelitsha: livelihood profile of Khayelitsha and situational analysis of DSD services in the node. Government Report, Pretoria, South Africa.

Devey, R., C. Skinner, and I. Valodia. 2006. Second best? Trends and linkages in the informal economy in South Africa. Paper presented at DPRU/TIPS Conference on Accelerated and Shared Growth in South Africa: Determinants, Constraints and Opportunities, The Birchwood Hotel and Conference Centre, Johannesburg, South Africa, 18-20 October 2006. [online] URL:http://www.tips.org.za/files/forum/2006/papers/ SecondBest_Devey_Skinner_Valodia.pdf.

Dold, A. P., and M. L. Cocks. 2001. Traditional veterinary medicine in the Alice district of the Eastern Cape Province, South Africa. South African Journal of Science 97:375-379.

Dold, A. P., and M. L. Cocks. 2002. The trade in medicinal plants in the Eastern Cape Province, South Africa. South African Journal of Science 98:589-597.

Geertsema H. 2004. An avifauna impact study for proposed N21 (R300) Cape Town ring road toll project. City of Cape Town, South Africa. [online] URL:http://www.peninsula-exp ressway.org.za/draft_docs/Avifauna.pdf.

Goldblatt, P., and J. C. Manning. 2002. Plant diversity of the Cape Region of Southern Africa. Annals of the Missouri Botanical Garden 89:281-302. http://dx.doi.org/10.2307/3298566

Hart, K. 1973. Informal income opportunities and urban employment in Ghana. Journal of Modern African Studies 11 (1):61-89. http://dx.doi.org/10.1017/S0022278X00008089

Hauck, M., and M. Kroese. 2006. Fisheries compliance in South Africa: A decade of challenges and reform 1994-2004. Marine Policy 30(1):74-83. http://dx.doi.org/10.1016/j.marpo $\underline{1.2005 .06 .007}$

Keirungi, J., and C. Fabricius. 2005. Selecting medicinal plants for cultivation at Nqabara on the Eastern Cape Wild Coast, South Africa. South African Journal of Science 101:497-501.

Lewu, F. B., and A. J. Afolayan. 2009. Ethnomedicine in South Africa: the role of weedy species. African Journal of Biotechnology 8(6):929-934.

Loundou, P. 2008. Medicinal plant trade and opportunities for sustainable management in South Africa. Dissertation. University of Stellenbosch, South Africa.
Mander, M. 1998. Marketing of indigenous medicinal plants in South Africa. Food and Agriculture Organisation, Rome, Italy.

Mander, M., L. Ntuli, N. Diedrichs, and K. Mavundla. 2007. Chapter 13: economics of the traditional medicine trade in South Africa. Pages 189-200 in S. Harrison, R. Bhana, and A. Ntuli, editors. South African health review 2007. Health Systems Trust, Durban, South Africa. [online] URL: http://w ww.hst.org.za/uploads/files/chap13 07.pdf.

Marine and Coastal Management. 2008. Harvest permit seeker data and forms. Department of Environmental Affairs and Tourism, Pretoria, South Africa.

Nzue, A. P. M. 2009. Use and conservation status of medicinal plants in the Cape Peninsula, Western Cape Province of South Africa. Dissertation. University of Stellenbosch, South Africa.

Raimondo, D., L. von Staden, W. Foden, J. E. Victor, N. A. Helme, R. C. Turner, D. A. Kamundi, and P. A. Manyama (editors). 2009. Red List of South African plants. Strelitzia 25. South African National Biodiversity Institute, Pretoria, South Africa. http://dx.doi.org/10.4102/sajs.v107i5/6.653

Rebelo, T. 1996. The utilisation of proteas. Unpublished report. Protea Atlas Project, Cape Town, South Africa.

Shackleton, C. 2009. Will the real custodian of natural resource management please stand up. South African Journal of Science 105:91-93.

Shackleton, C., and S. Shackleton. 2004. The Pterocarpus angolensis DC. based woodcraft industry in the Bushbuckridge District, South Africa. Pages 203 to 228 in T. Sunderland and O. Ndoye, editors. Forest products, livelihoods and conservation. Centre for International Forest Management, Bogor-Barat, Indonesia.

Shackleton, S. 2002. The informal marula beer traders of Bushbuckridge, Limpopo Province, South Africa. Internal report. Department of Environmental Science, Rhodes University, Grahamstown, South Africa.

Shackleton, S. 2005. The significance of the local trade in natural resource products for livelihoods and poverty alleviation in South Africa. Dissertation. Rhodes University, Grahamstown, South Africa.

South African National Biodiversity Institute (SANBI). 2005. Plants of southern Africa: an online checklist. Pretoria, South Africa. [online] URL: http://posa.sanbi.org/intro.php.

South African National Biodiversity Institute (SANBI). 2009. SIBIS user manual. Pretoria, South Africa. [online] URL: $\underline{\text { htt }}$ p://sibis.sanbi.org/resources/SIBIS_Manual_2009.pdf.

Statistics South Africa. 2010. Quarterly labour force survey: quarter 1. Pretoria, South Africa. 
Steinberg, J. 2005. The illicit abalone trade in South Africa. Paper 105. Institute for Security Studies, Cape Town, South Africa.

Turpie, J. K., B. J. Heydenrych, and S. J. Lamberth. 2003. Economic value of terrestrial and marine biodiversity in the Cape Floristic Region: implications for defining effective and socially optimal conservation strategies. Biological Conservation 112:233-251. http://dx.doi.org/10.1016/S0006-3207 $\underline{(02) 00398-1}$

Twine, W. C., D. Moshe, T. Netshiluvhi, and V. Siphugu. 2003. Consumption and direct-use values of savanna bioresources used by rural households in Mametja, a semi-arid area of Limpopo Province, South Africa. South African Journal of Science 99:467-473.

United Nations Development Programme (UNDP). 2006. South Africa showcase. Global Environment Facility, New York, New York, USA.

UN-Habitat. 2008. The state of African cities 2008: a framework for addressing urban challenges in Africa. United Nations Human Settlements Programme, Nairobi, Kenya.

Williams, V., E. T. F. Witkowski, and K. Balkwill. 2007. Volume and financial value of species traded in the medicinal plant markets of Gauteng, South Africa. International Journal of Sustainable Development and World Ecology 14:584-603. http://dx.doi.org/10.1080/13504500709469757 
Appendix 1. Compendium of locally harvested/traded flora (including fungi) within the City of Cape Town.

\begin{tabular}{|c|c|c|c|c|c|c|c|c|c|c|}
\hline Family & Scientific Name & $\begin{array}{c}\text { Common Names } \\
\text { (English / } \\
\text { Afrikaans) } \\
\end{array}$ & & $\begin{array}{c}\text { Harvest } \\
\text { target }\end{array}$ & $\begin{array}{c}\text { Common } \\
\text { usage }\end{array}$ & Capture & $\begin{array}{c}\text { Red List } \\
\text { status }\end{array}$ & Indigenous-ness & $\begin{array}{l}\text { Source } \\
\text { locality }\end{array}$ & Reference \\
\hline FABACEAE & $\begin{array}{l}\text { Acacia cyclops A. } \\
\text { Cunn. ex G. Don. }\end{array}$ & Rooikrans & 1 & Timber & Fuel & $\begin{array}{l}\text { Axe / } \\
\text { saw }\end{array}$ & Not listed & $\begin{array}{l}\text { Alien to South } \\
\text { Africa }\end{array}$ & $\begin{array}{l}\text { Cape Town - } \\
\text { general }\end{array}$ & $\begin{array}{l}\text { H. Mananga, } \\
\text { personal } \\
\text { communication }\end{array}$ \\
\hline FABACEAE & $\begin{array}{l}\text { Acacia longifolia } \\
\text { (Andr.) Willd. }\end{array}$ & $\begin{array}{l}\text { Long leafed } \\
\text { wattle }\end{array}$ & 1 & $\begin{array}{l}\text { Timber / } \\
\text { leaves / } \\
\text { foliage }\end{array}$ & $\begin{array}{l}\text { Fuel / } \\
\text { Fiber }\end{array}$ & $\begin{array}{l}\text { Axe / } \\
\text { saw }\end{array}$ & Not listed & $\begin{array}{l}\text { Alien to South } \\
\text { Africa }\end{array}$ & $\begin{array}{l}\text { Cape Town - } \\
\text { general }\end{array}$ & SANBI (2005) \\
\hline FABACEAE & $\begin{array}{l}\text { Acacia mearnsii de } \\
\text { Wild. Syn. }\end{array}$ & Black wattle & 1 & $\begin{array}{l}\text { Timber / } \\
\text { leaves / } \\
\text { foliage }\end{array}$ & $\begin{array}{l}\text { Fuel / } \\
\text { Fiber }\end{array}$ & $\begin{array}{l}\text { Axe / } \\
\text { saw }\end{array}$ & Not listed & $\begin{array}{l}\text { Alien to South } \\
\text { Africa }\end{array}$ & $\begin{array}{l}\text { Cape Town - } \\
\text { general }\end{array}$ & SANBI (2005) \\
\hline FABACEAE & $\begin{array}{l}\text { Acacia melanoxylon } \mathbf{R} \text {. } \\
\text { Br. }\end{array}$ & $\begin{array}{l}\text { Australian } \\
\text { blackwood }\end{array}$ & 1 & $\begin{array}{l}\text { Timber / } \\
\text { leaves / } \\
\text { foliage }\end{array}$ & $\begin{array}{l}\text { Fuel / } \\
\text { Fiber }\end{array}$ & $\begin{array}{l}\text { Axe / } \\
\text { saw }\end{array}$ & Not listed & $\begin{array}{l}\text { Alien to South } \\
\text { Africa }\end{array}$ & $\begin{array}{l}\text { Cape Town - } \\
\text { general }\end{array}$ & - SANBI (2005) \\
\hline FABACEAE & $\begin{array}{l}\text { Acacia saligna (Labill.) } \\
\text { H.L.Wendl. }\end{array}$ & Port Jackson & 1 & $\begin{array}{l}\text { Timber / } \\
\text { leaves / } \\
\text { foliage }\end{array}$ & $\begin{array}{l}\text { Fuel / } \\
\text { Fiber }\end{array}$ & $\begin{array}{l}\text { Axe / } \\
\text { saw }\end{array}$ & Not listed & $\begin{array}{l}\text { Alien to South } \\
\text { Africa }\end{array}$ & $\begin{array}{l}\text { Cape Town - } \\
\text { general }\end{array}$ & $\begin{array}{c}\text { SANBI (2005), } \\
\text { D. Drooste } \\
\text { personal } \\
\text { communication }\end{array}$ \\
\hline AMARANTHACEAE & $\begin{array}{l}\text { Achyranthes aspera } \mathbf{L} \text {. } \\
\text { var. aspera }\end{array}$ & Klits & 1 & Whole plant & $\begin{array}{l}\text { Flowers / } \\
\text { foliage / } \\
\text { Nursery }\end{array}$ & Hand & Not listed & $\begin{array}{c}\text { South Africa } \\
\text { indigenous }\end{array}$ & $\begin{array}{l}\text { Cape Town - } \\
\text { general }\end{array}$ & $\begin{array}{c}\text { Lewu and } \\
\text { Afolayan (2009) }\end{array}$ \\
\hline APOCYNACEAE & $\begin{array}{l}\text { Acokanthera } \\
\text { oppositifolia (Lam.) } \\
\text { Codd. }\end{array}$ & $\begin{array}{c}\text { Bushmans } \\
\text { poison }\end{array}$ & 1 & Leaves & Medicine & Hand & $\begin{array}{c}\text { Least } \\
\text { Concern }\end{array}$ & $\begin{array}{c}\text { Locally } \\
\text { indigenous }\end{array}$ & $\begin{array}{l}\text { Cape Town - } \\
\text { general }\end{array}$ & $\begin{array}{l}\text { Dold and Cocks } \\
\text { (2001) }\end{array}$ \\
\hline RUTACEAE & $\begin{array}{l}\text { Adenandra uniflora (L.) } \\
\text { Willd. }\end{array}$ & $\begin{array}{l}\text { Anys-buchu / } \\
\text { Anysboegoe }\end{array}$ & 1 & $\begin{array}{c}\text { Leaves / } \\
\text { stems }\end{array}$ & Medicine & Hand & Not listed & $\begin{array}{c}\text { Locally } \\
\text { indigenous }\end{array}$ & $\begin{array}{l}\text { Cape Town - } \\
\text { general }\end{array}$ & Nzue (2009) \\
\hline RUTACEAE & $\begin{array}{l}\text { Adenandra villosa } \\
\text { P.J.Bergius Licht. ex } \\
\text { Roem. and Schult }\end{array}$ & $\begin{array}{l}\text { China flower / } \\
\text { buchu }\end{array}$ & 1 & $\begin{array}{c}\text { Leaves / } \\
\text { stems }\end{array}$ & Medicine & Hand & Not listed & $\begin{array}{l}\text { Locally } \\
\text { indigenous }\end{array}$ & $\begin{array}{c}\text { Atlantis } \\
\text { Conservation } \\
\text { Area }\end{array}$ & $\begin{array}{l}\text { T. Abrahams } \\
\text { and C. McKie, } \\
\text { personal } \\
\text { communication }\end{array}$ \\
\hline AGAPANTHACEAE & $\begin{array}{l}\text { Agapanthus africanus } \\
\text { (L.) Hoffmanns }\end{array}$ & & 1 & Bulb & Medicine & Hand & $\begin{array}{c}\text { Least } \\
\text { Concern } \\
\end{array}$ & $\begin{array}{c}\text { Locally } \\
\text { indigenous }\end{array}$ & $\begin{array}{l}\text { Cape Town - } \\
\text { general }\end{array}$ & $\begin{array}{c}\text { Keirungi and } \\
\text { Fabricius (2005) }\end{array}$ \\
\hline RUTACEAE & $\begin{array}{l}\text { Agathosma crenulata } \\
\text { (L.) Pillans }\end{array}$ & Boegoe & 1 & $\begin{array}{c}\text { Leaves / } \\
\text { stems }\end{array}$ & Medicine & Hand & Declining & $\begin{array}{c}\text { Locally } \\
\text { indigenous }\end{array}$ & $\begin{array}{l}\text { Cape Town - } \\
\text { general }\end{array}$ & $\begin{array}{c}\text { H. Mananga, } \\
\text { personal } \\
\text { communication }\end{array}$ \\
\hline HYACINTHACEAE & Albuca sp. & & 3 & Bulb & Medicine & Hand & $\begin{array}{c}\text { Least } \\
\text { Concern }\end{array}$ & $\begin{array}{c}\text { Locally } \\
\text { indigenous }\end{array}$ & $\begin{array}{c}\text { Macassar / } \\
\text { Wolfgat } \\
\text { Nature } \\
\text { Reserves } \\
\end{array}$ & $\begin{array}{c}\text { H. Mananga, } \\
\text { personal } \\
\text { communication }\end{array}$ \\
\hline ALLIACEAE & $\begin{array}{l}\text { Allium dregeanum } \\
\text { Kunth. }\end{array}$ & $\begin{array}{c}\text { Wild onion / } \\
\text { Wildeui } \\
\end{array}$ & 1 & Bulb & Medicine & Hand & Not listed & $\begin{array}{c}\text { Locally } \\
\text { indigenous }\end{array}$ & $\begin{array}{l}\text { Cape Town - } \\
\text { general }\end{array}$ & Nzue (2009) \\
\hline ASPHODELACEAE & $\begin{array}{l}\text { Aloe commixta } \mathbf{A} . \\
\text { Berger }\end{array}$ & & 1 & Whole plant & Nursery & Hand & Vulnerable & $\begin{array}{c}\text { Locally } \\
\text { indigenous }\end{array}$ & $\begin{array}{l}\text { Cape Town - } \\
\text { general }\end{array}$ & $\begin{array}{l}\text { Raimondo et al., } \\
\text { (2009) }\end{array}$ \\
\hline AMARYLLIDACEAE & Amaryllis belladonna $\mathbf{L}$. & & 1 & Flowers & $\begin{array}{l}\text { Flowers / } \\
\text { foliage }\end{array}$ & Hand & Not listed & $\begin{array}{c}\text { Locally } \\
\text { indigenous }\end{array}$ & $\begin{array}{l}\text { Cape Town - } \\
\text { general }\end{array}$ & $\begin{array}{c}\text { D. Gibbs, } \\
\text { personal } \\
\text { communication }\end{array}$ \\
\hline APONOGETONACEAE & $\begin{array}{l}\text { Aponogeton distachyos } \\
\text { L. f. }\end{array}$ & $\begin{array}{c}\text { Cape hawthorn } \\
\text { or Cape } \\
\text { asparagus / } \\
\text { Waterblommetjie }\end{array}$ & 1 & $\begin{array}{l}\text { Flower buds } \\
\text { and stem tips }\end{array}$ & $\begin{array}{c}\text { Food } \\
\text { source }\end{array}$ & Hand & Not listed & $\begin{array}{c}\text { Locally } \\
\text { indigenous }\end{array}$ & $\begin{array}{l}\text { Cape Town - } \\
\text { general }\end{array}$ & Nzue (2009) \\
\hline APIACEAE & Arctopus echinatus $\mathbf{L}$. & $\begin{array}{l}\text { Bear foot / } \\
\text { Kaapse } \\
\text { platdoring }\end{array}$ & 1 & Bulb & Medicine & Hand & Not listed & $\begin{array}{c}\text { Locally } \\
\text { indigenous }\end{array}$ & $\begin{array}{c}\text { Table } \\
\text { Mountain } \\
\text { National } \\
\text { Park } \\
\end{array}$ & $\begin{array}{c}\text { Harvester } \\
\text { informants, } \\
\text { personal } \\
\text { communication }\end{array}$ \\
\hline POACEAE & $\begin{array}{l}\text { Aristea africana }(\mathbf{L} .) \\
\text { Hoffmans }\end{array}$ & Moerbos & 1 & Whole plant & Medicine & Hand & Not listed & $\begin{array}{c}\text { Locally } \\
\text { indigenous }\end{array}$ & $\begin{array}{l}\text { Cape Town - } \\
\text { general }\end{array}$ & Nzue (2009) \\
\hline ASTERACEAE & $\begin{array}{l}\text { Artemisia afra var afra } \\
\text { Jacq.ex Willd }\end{array}$ & $\begin{array}{c}\text { African } \\
\text { wormwood / } \\
\text { Wilde-als }\end{array}$ & 1 & $\begin{array}{c}\text { Leaves / } \\
\text { stems }\end{array}$ & Medicine & Hand & $\begin{array}{c}\text { Least } \\
\text { Concern }\end{array}$ & $\begin{array}{c}\text { Cape } \\
\text { indigenous }\end{array}$ & $\begin{array}{l}\text { Cape Town - } \\
\text { general }\end{array}$ & Nzue (2009) \\
\hline POACEAE & Arundo donax $\mathbf{L}$. & Spanish reed & 1 & $\begin{array}{c}\text { Leaves / } \\
\text { stems }\end{array}$ & Fiber & $\begin{array}{l}\text { Axe / } \\
\text { saw }\end{array}$ & Not listed & $\begin{array}{l}\text { Alien to South } \\
\text { Africa }\end{array}$ & $\begin{array}{l}\text { Cape Town - } \\
\text { general }\end{array}$ & $\begin{array}{c}\text { Harvester } \\
\text { informants, } \\
\text { personal } \\
\text { communication }\end{array}$ \\
\hline ASPARAGACEAE & $\begin{array}{l}\text { Asparagus africanus } \\
\text { Lam. }\end{array}$ & & 1 & Rhizome & Medicine & Hand & $\begin{array}{c}\text { Least } \\
\text { Concern }\end{array}$ & $\begin{array}{l}\text { Locally } \\
\text { indigenous }\end{array}$ & $\begin{array}{l}\text { Macassar / } \\
\text { Wolfgat } \\
\text { Nature } \\
\text { Reserves }\end{array}$ & $\begin{array}{l}\text { H. Mananga, } \\
\text { personal } \\
\text { communication }\end{array}$ \\
\hline
\end{tabular}




\begin{tabular}{|c|c|c|c|c|c|c|c|c|c|}
\hline ASPARAGACEAE & $\begin{array}{l}\text { Asparagus suaveolens } \\
\text { (Burch.) Oberm. }\end{array}$ & $\begin{array}{c}\text { Wild asparagus / } \\
\text { Katbossie }\end{array}$ & 1 Rhizome & Medicine & Hand & $\begin{array}{c}\text { Least } \\
\text { Concern }\end{array}$ & $\begin{array}{c}\text { Cape } \\
\text { indigenous }\end{array}$ & $\begin{array}{l}\text { Cape Town - } \\
\text { general }\end{array}$ & Nzue (2009) \\
\hline PROTEACEAE & $\begin{array}{l}\text { Aulax cancellata }(\mathbf{L} .) \\
\text { Druce }\end{array}$ & & $\begin{array}{c}\text { Flowers / } \\
\text { foliage }\end{array}$ & $\begin{array}{l}\text { Flowers / } \\
\text { foliage }\end{array}$ & Hand & $\begin{array}{l}\text { Least } \\
\text { Concern }\end{array}$ & $\begin{array}{l}\text { Locally } \\
\text { indigenous }\end{array}$ & $\begin{array}{c}\text { Table } \\
\text { Mountain } \\
\text { National } \\
\text { Park }\end{array}$ & Rebelo (1996) \\
\hline BRUNIACEAE & $\begin{array}{l}\text { Berzelia abrotanoides } \\
\text { (L.) Brongn. }\end{array}$ & Rooibeentjies & $\begin{array}{c}\text { Flowers / } \\
\text { foliage }\end{array}$ & $\begin{array}{l}\text { Flowers / } \\
\text { foliage }\end{array}$ & Hand & Not listed & $\begin{array}{l}\text { Locally } \\
\text { indigenous }\end{array}$ & $\begin{array}{c}\text { Atlantis } \\
\text { Conservation } \\
\text { Area }\end{array}$ & $\begin{array}{c}\text { T. Abrahams } \\
\text { and C. McKie, } \\
\text { personal } \\
\text { communication }\end{array}$ \\
\hline BOLETACEAE & Boletus edulis Bull. & $\begin{array}{l}\text { Porcini } \\
\text { mushroom }\end{array}$ & $1 \begin{array}{c}\text { Whole } \\
\text { organism }\end{array}$ & $\begin{array}{l}\text { Food } \\
\text { source }\end{array}$ & Hand & Not listed & $\begin{array}{l}\text { Locally } \\
\text { indigenous }\end{array}$ & $\begin{array}{c}\text { Table } \\
\text { Mountain } \\
\text { National } \\
\text { Park } \\
\end{array}$ & $\begin{array}{c}\text { Harvester } \\
\text { informants, } \\
\text { personal } \\
\text { communication }\end{array}$ \\
\hline AMARYLLIDACEAE & $\begin{array}{l}\text { Boophone disticha (L.f.) } \\
\text { Herb. }\end{array}$ & $\begin{array}{l}\text { Cape poison } \\
\text { bulb / } \\
\text { Kopseerblom }\end{array}$ & Bulb & Medicine & Hand & Declining & $\begin{array}{c}\text { Locally } \\
\text { indigenous }\end{array}$ & $\begin{array}{c}\text { Harmony } \\
\text { Flats Nature } \\
\text { Reserve }\end{array}$ & $\begin{array}{c}\text { S. Lindane, } \\
\text { personal } \\
\text { communication }\end{array}$ \\
\hline LILIACEAE & $\begin{array}{l}\text { Bowiea volubilis } \\
\text { Harv.ex Hook.f. }\end{array}$ & $\begin{array}{l}\text { Climbing potato } \\
\text { / Knolklimop }\end{array}$ & Bulb & Medicine & Hand & $\begin{array}{l}\text { Least } \\
\text { Concern }\end{array}$ & $\begin{array}{l}\text { South Africa } \\
\text { indigenous }\end{array}$ & $\begin{array}{c}\text { Table } \\
\text { Mountain } \\
\text { National } \\
\text { Park } \\
\end{array}$ & $\begin{array}{c}\text { Harvester } \\
\text { informants, } \\
\text { personal } \\
\text { communication }\end{array}$ \\
\hline BUDDLEJACEAE & Buddleja saligna Willd. & $\begin{array}{l}\text { Mountain sage / } \\
\text { Salie }\end{array}$ & $\begin{array}{l}\text { Leaves / } \\
\text { stems }\end{array}$ & Medicine & Hand & $\begin{array}{l}\text { Least } \\
\text { Concern }\end{array}$ & $\begin{array}{l}\text { Locally } \\
\text { indigenous }\end{array}$ & $\begin{array}{c}\text { Table } \\
\text { Mountain } \\
\text { National } \\
\text { Park } \\
\end{array}$ & $\begin{array}{c}\text { Harvester } \\
\text { informants, } \\
\text { personal } \\
\text { communication }\end{array}$ \\
\hline ASPHODELACEAE & $\begin{array}{l}\text { Bulbine abyssinica } \mathbf{A} . \\
\text { Rich }\end{array}$ & & 1 Whole plant & Medicine & Hand & $\begin{array}{l}\text { Least } \\
\text { Concern }\end{array}$ & $\begin{array}{l}\text { Locally } \\
\text { indigenous }\end{array}$ & $\begin{array}{c}\text { Table } \\
\text { Mountain } \\
\text { National } \\
\text { Park }\end{array}$ & $\begin{array}{c}\text { Harvester } \\
\text { informants, } \\
\text { personal } \\
\text { communication }\end{array}$ \\
\hline ASPHODELACEAE & $\begin{array}{l}\text { Bulbine frutescens }(\mathbf{L} .) \\
\text { Willd }\end{array}$ & $\begin{array}{c}\text { Cat's tail / } \\
\text { Katstert }\end{array}$ & Leaves & Medicine & Hand & $\begin{array}{l}\text { Least } \\
\text { Concern }\end{array}$ & $\begin{array}{l}\text { Locally } \\
\text { indigenous }\end{array}$ & $\begin{array}{c}\text { Table } \\
\text { Mountain } \\
\text { National } \\
\text { Park } \\
\end{array}$ & $\begin{array}{c}\text { Harvester } \\
\text { informants, } \\
\text { personal } \\
\text { communication }\end{array}$ \\
\hline ASPHODELACEAE & $\begin{array}{l}\text { Bulbinella triquetra } \\
\text { (L.f.) Kunth }\end{array}$ & & $\begin{array}{c}1 \text { Flowers / } \\
\text { fruits }\end{array}$ & Medicine & Hand & Not listed & $\begin{array}{l}\text { Locally } \\
\text { indigenous }\end{array}$ & $\begin{array}{c}\text { Atlantis } \\
\text { Conservation } \\
\text { Area }\end{array}$ & $\begin{array}{c}\text { T. Abrahams } \\
\text { and C. McKie, } \\
\text { personal } \\
\text { communication }\end{array}$ \\
\hline RESTIONACEAE & $\begin{array}{l}\text { Calopsis paniculata } \\
\text { (Rottb.) Desv. }\end{array}$ & & Leaves & $\begin{array}{c}\text { Flowers / } \\
\text { foliage / } \\
\text { Fiber }\end{array}$ & Hand & $\begin{array}{c}\text { Least } \\
\text { Concern }\end{array}$ & $\begin{array}{l}\text { Locally } \\
\text { indigenous }\end{array}$ & $\begin{array}{l}\text { Cape Town - } \\
\text { general }\end{array}$ & $\begin{array}{c}\text { Harvester } \\
\text { informants, } \\
\text { personal } \\
\text { communication }\end{array}$ \\
\hline CANNABACEAE & Cannabis sativa $\mathbf{L}$. & $\begin{array}{c}\text { Marijuana / } \\
\text { Dagga }\end{array}$ & $\begin{array}{c}1 \text { Leaves / } \\
\text { stems }\end{array}$ & Medicine & Hand & Not listed & $\begin{array}{c}\text { Alien to South } \\
\text { Africa } \\
\end{array}$ & $\begin{array}{c}\text { Cape Town - } \\
\text { general }\end{array}$ & Nzue (2009) \\
\hline RESTIONACEAE & $\begin{array}{l}\text { Cannomois virgata } \\
\text { (Rottb.) Steud }\end{array}$ & & Leaves & $\begin{array}{c}\text { Flowers / } \\
\text { foliage / } \\
\text { Fiber }\end{array}$ & Hand & $\begin{array}{c}\text { Least } \\
\text { Concern }\end{array}$ & $\begin{array}{l}\text { Locally } \\
\text { indigenous }\end{array}$ & $\begin{array}{l}\text { Cape Town - } \\
\text { general }\end{array}$ & $\begin{array}{c}\text { Harvester } \\
\text { informants, } \\
\text { personal } \\
\text { communication }\end{array}$ \\
\hline MESEMBRYANTHEMACEA & $\begin{array}{l}\text { Carpobrotus } \\
\text { acinaciformis (L.) L. } \\
\text { Bolus }\end{array}$ & $\begin{array}{c}\text { Sour fig / } \\
\text { Elandsvy, } \\
\text { goenavy, suurvy }\end{array}$ & 1 Fruit / leaves & $\begin{array}{c}\text { Food } \\
\text { source / } \\
\text { Medicine }\end{array}$ & Hand & $\begin{array}{l}\text { Least } \\
\text { Concern }\end{array}$ & $\begin{array}{l}\text { Locally } \\
\text { indigenous }\end{array}$ & $\begin{array}{c}\text { Macassar / } \\
\text { Wolfgat } \\
\text { Nature } \\
\text { Reserves }\end{array}$ & $\begin{array}{c}\text { SANBI (2005), } \\
\text { H. Mananga, } \\
\text { personal } \\
\text { communication }\end{array}$ \\
\hline MESEMBRYANTHEMACEA & $\begin{array}{l}\text { Earpobrotus edulis (L.) } \\
\text { L. Bolus subsp. Edulis }\end{array}$ & $\begin{array}{l}\text { Cape fig, Sour } \\
\text { fig / Elandsvy, } \\
\text { goenavy, suurvy }\end{array}$ & 1 Fruit / leaves & $\begin{array}{c}\text { Food } \\
\text { source / } \\
\text { Medicine }\end{array}$ & Hand & $\begin{array}{l}\text { Least } \\
\text { Concern }\end{array}$ & $\begin{array}{l}\text { Locally } \\
\text { indigenous }\end{array}$ & $\begin{array}{c}\text { Atlantis } \\
\text { Conservation } \\
\text { Area, } \\
\text { Macassar / } \\
\text { Wolfgat } \\
\text { Nature } \\
\text { Reserves } \\
\end{array}$ & $\begin{array}{l}\text { Loundou (2008) } \\
\text { H. Mananga / T. } \\
\text { Abrahams } \\
\text { personal } \\
\text { communication }\end{array}$ \\
\hline MACKINLAYACEAE & $\begin{array}{l}\text { Centella asiatica } \mathbf{L} \text {. } \\
\text { (urban) }\end{array}$ & & Leaves & Medicine & Hand & Not listed & $\begin{array}{c}\text { Locally } \\
\text { indigenous }\end{array}$ & $\begin{array}{l}\text { Cape Town - } \\
\text { general }\end{array}$ & Loundou (2008) \\
\hline IRIDACEAE & $\begin{array}{l}\text { Chasmanthe aethiopica } \\
\text { (L.) N.E.Br }\end{array}$ & Suurkanol & 1 Flowers/bulb & $\begin{array}{l}\text { Flowers / } \\
\text { medicine }\end{array}$ & Hand & $\begin{array}{l}\text { Least } \\
\text { Concern }\end{array}$ & $\begin{array}{c}\text { Locally } \\
\text { indigenous }\end{array}$ & $\begin{array}{l}\text { Cape Town - } \\
\text { general }\end{array}$ & $\begin{array}{c}\text { D. Gibbs, } \\
\text { personal } \\
\text { communication }\end{array}$ \\
\hline IRIDACEAE & $\begin{array}{l}\text { Chasmanthe floribunda } \\
\text { (Salisb.) N.E.Br. }\end{array}$ & Suurkanol & 1 Flowers/bulb & $\begin{array}{l}\text { Flowers / } \\
\text { medicine }\end{array}$ & Hand & $\begin{array}{l}\text { Least } \\
\text { Concern }\end{array}$ & $\begin{array}{l}\text { Locally } \\
\text { indigenous }\end{array}$ & $\begin{array}{l}\text { Cape Town - } \\
\text { general }\end{array}$ & $\begin{array}{c}\text { D. Gibbs, } \\
\text { personal } \\
\text { communication }\end{array}$ \\
\hline GENTIANACEAE & Chironia baccifera $\mathbf{L}$. & $\begin{array}{c}\text { Christmas berry / } \\
\text { Bitterbossie }\end{array}$ & $\begin{array}{c}1 \text { Flowers / } \\
\text { fruits }\end{array}$ & Medicine & Hand & $\begin{array}{l}\text { Least } \\
\text { Concern }\end{array}$ & $\begin{array}{l}\text { Locally } \\
\text { indigenous }\end{array}$ & $\begin{array}{l}\text { Macassar / } \\
\text { Wolfgat } \\
\text { Nature } \\
\text { Reserves }\end{array}$ & $\begin{array}{l}\text { H. Mananga, } \\
\text { personal } \\
\text { communication }\end{array}$ \\
\hline
\end{tabular}




\begin{tabular}{|c|c|c|c|c|c|c|c|c|c|c|}
\hline RESTIONACEAE & $\begin{array}{l}\text { Chondropetalum } \\
\text { tectorum (L.f.) Raf. }\end{array}$ & Thatch & 1 & Stems & Fiber & Hand & Not listed & $\begin{array}{l}\text { Locally } \\
\text { indigenous }\end{array}$ & $\begin{array}{l}\text { Macassar / } \\
\text { Wolfgat } \\
\text { Nature } \\
\text { Reserves } \\
\end{array}$ & $\begin{array}{l}\text { H. Mananga, } \\
\text { personal } \\
\text { communication }\end{array}$ \\
\hline LAURACEAE & $\begin{array}{l}\text { Cinnamomum camphora } \\
\text { Nees and Eberm }\end{array}$ & $\begin{array}{l}\text { Camphor laurel / } \\
\text { Kamferboom }\end{array}$ & & Bark & Medicine & $\begin{array}{l}\text { Axe / } \\
\text { saw }\end{array}$ & Not listed & $\begin{array}{c}\text { Alien to South } \\
\text { Africa }\end{array}$ & $\begin{array}{l}\text { Cape Town - } \\
\text { general }\end{array}$ & $\begin{array}{c}\text { Harvester } \\
\text { informants, } \\
\text { personal } \\
\text { communication }\end{array}$ \\
\hline MENISPERMACEAE & $\begin{array}{l}\text { Cissampelos capensis } \\
\text { L.f. }\end{array}$ & $\begin{array}{c}\text { David root / } \\
\text { Dawidjiewortel }\end{array}$ & 1 & Rhizome & Medicine & Hand & $\begin{array}{c}\text { Least } \\
\text { Concern }\end{array}$ & $\begin{array}{l}\text { Locally } \\
\text { indigenous }\end{array}$ & $\begin{array}{l}\text { Macassar / } \\
\text { Wolfgat } \\
\text { Nature } \\
\text { Reserves } \\
\end{array}$ & $\begin{array}{l}\text { H. Mananga, } \\
\text { personal } \\
\text { communication }\end{array}$ \\
\hline RUTACEAE & $\begin{array}{l}\text { Clausena anisata } \\
\text { (Willd.) Hook f. ex } \\
\text { Benth var. anisata }\end{array}$ & & 1 & Leaves & Medicine & Hand & $\begin{array}{c}\text { Least } \\
\text { Concern }\end{array}$ & $\begin{array}{l}\text { South Africa } \\
\text { indigenous }\end{array}$ & $\begin{array}{l}\text { Cape Town - } \\
\text { general }\end{array}$ & $\begin{array}{c}\text { Harvester } \\
\text { informants, } \\
\text { personal } \\
\text { communication }\end{array}$ \\
\hline ROSACEAE & Cliffortia odorata L.f. & $\begin{array}{l}\text { Wild grape / } \\
\text { Wilde wingerd }\end{array}$ & 1 & Leaves & Medicine & Hand & $\begin{array}{c}\text { Least } \\
\text { Concern }\end{array}$ & $\begin{array}{l}\text { Locally } \\
\text { indigenous }\end{array}$ & $\begin{array}{c}\text { Table } \\
\text { Mountain } \\
\text { National } \\
\text { Park } \\
\end{array}$ & $\begin{array}{c}\text { Harvester } \\
\text { informants, } \\
\text { personal } \\
\text { communication }\end{array}$ \\
\hline COMMELINACEAE & $\begin{array}{l}\text { Commelina africana } \mathbf{L} . \\
\text { var. Africana }\end{array}$ & & 1 & Rhizome & Medicine & Hand & $\begin{array}{c}\text { Least } \\
\text { Concern }\end{array}$ & $\begin{array}{c}\text { Locally } \\
\text { indigenous }\end{array}$ & $\begin{array}{l}\text { Cape Town - } \\
\text { general }\end{array}$ & $\begin{array}{c}\text { Lewu and } \\
\text { Afolayan (2009 }\end{array}$ \\
\hline CRASSULACEAE & $\begin{array}{l}\text { Cotyledon orbiculata } \\
\text { var. orbiculata } \mathbf{L} \text {. }\end{array}$ & $\begin{array}{l}\text { Pig's ear / } \\
\text { Koutrei }\end{array}$ & 1 & Leaves & Medicine & Hand & $\begin{array}{c}\text { Least } \\
\text { Concern }\end{array}$ & $\begin{array}{l}\text { Locally } \\
\text { indigenous }\end{array}$ & $\begin{array}{l}\text { Cape Town - } \\
\text { general }\end{array}$ & $\begin{array}{c}\text { Harvester } \\
\text { informants, } \\
\text { personal } \\
\text { communication }\end{array}$ \\
\hline CRASSULACEAE & Crassula dejecta Jacq. & & 1 & $\begin{array}{c}\text { Leaves / } \\
\text { stems }\end{array}$ & Medicine & Hand & $\begin{array}{c}\text { Least } \\
\text { Concern }\end{array}$ & $\begin{array}{l}\text { Locally } \\
\text { indigenous }\end{array}$ & $\begin{array}{l}\text { Tygerberg } \\
\text { Nature } \\
\text { Reserve }\end{array}$ & $\begin{array}{c}\text { Harvester } \\
\text { informants, } \\
\text { personal } \\
\text { communication }\end{array}$ \\
\hline EUPHORBIACEAE & $\begin{array}{l}\text { Croton rivularis Mull. } \\
\text { Arg }\end{array}$ & Leventelbos & 1 & Seeds & Medicine & Hand & $\begin{array}{c}\text { Least } \\
\text { Concern }\end{array}$ & $\begin{array}{c}\text { South Africa } \\
\text { indigenous }\end{array}$ & $\begin{array}{l}\text { Cape Town - } \\
\text { general }\end{array}$ & $\begin{array}{c}\text { Harvester } \\
\text { informants, } \\
\text { personal } \\
\text { communication }\end{array}$ \\
\hline CORNACEAE & $\begin{array}{l}\text { Curtisia dentata } \\
\text { (Burm.f.) }\end{array}$ & $\begin{array}{l}\text { Assegaaiwood / } \\
\text { Assegaaihout }\end{array}$ & 1 & Bark & Medicine & $\begin{array}{l}\text { Axe / } \\
\text { saw }\end{array}$ & $\begin{array}{c}\text { Near } \\
\text { Threatened }\end{array}$ & $\begin{array}{l}\text { Locally } \\
\text { indigenous }\end{array}$ & $\begin{array}{c}\text { Table } \\
\text { Mountain } \\
\text { National } \\
\text { Park } \\
\end{array}$ & $\begin{array}{l}\text { Nzue (2009); } \\
\text { Loundou (2008) }\end{array}$ \\
\hline CYATHEACEAE & $\begin{array}{l}\text { Cyathea capensis }(\mathbf{L} . \mathbf{f}) \\
\text { Sm. var. capensis }\end{array}$ & & 1 & Whole plant & Nursery & Hand & Declining & $\begin{array}{c}\text { Locally } \\
\text { indigenous }\end{array}$ & $\begin{array}{c}\text { Cape Town - } \\
\text { general }\end{array}$ & $\begin{array}{c}\text { Raimondo et al. } \\
\text { (2009) }\end{array}$ \\
\hline FABACEAE & $\begin{array}{l}\text { Cyclopia buxifolia } \\
\text { (Burm.f.) Kies }\end{array}$ & Honeybush tea & 1 & $\begin{array}{l}\text { Leaves / } \\
\text { stems }\end{array}$ & Medicine & Hand & $\begin{array}{l}\text { Least } \\
\text { Concern }\end{array}$ & $\begin{array}{c}\text { Locally } \\
\text { indigenous }\end{array}$ & $\begin{array}{l}\text { Cape Town - } \\
\text { general }\end{array}$ & $\begin{array}{c}\text { Harvester } \\
\text { informants, } \\
\text { personal } \\
\text { communication }\end{array}$ \\
\hline FABACEAE & $\begin{array}{l}\text { Cyclopia genistoides } \\
\text { (L.) R.Br. }\end{array}$ & Honeybush tea & 1 & $\begin{array}{l}\text { Leaves / } \\
\text { stems }\end{array}$ & Medicine & Hand & $\begin{array}{l}\text { Least } \\
\text { Concern }\end{array}$ & $\begin{array}{l}\text { Locally } \\
\text { indigenous }\end{array}$ & $\begin{array}{c}\text { Atlantis } \\
\text { Conservation } \\
\text { Area }\end{array}$ & $\begin{array}{c}\text { T. Abrahams } \\
\text { and C. McKie, } \\
\text { personal } \\
\text { communication }\end{array}$ \\
\hline CYPERACEAE & Cyperus textilis Thunb. & Tall star sedge & 1 & $\begin{array}{l}\text { Flowers / } \\
\text { stems }\end{array}$ & Fiber & Hand & $\begin{array}{l}\text { Least } \\
\text { Concern }\end{array}$ & $\begin{array}{c}\text { Locally } \\
\text { indigenous }\end{array}$ & $\begin{array}{c}\text { False Bay } \\
\text { Ecology } \\
\text { Park area }\end{array}$ & $\begin{array}{c}\text { D. Gibbs, } \\
\text { personal } \\
\text { communication }\end{array}$ \\
\hline AMARYLLIDACEAE & $\begin{array}{l}\text { Cyrtanthus breviflorus } \\
\text { Harv. }\end{array}$ & $\begin{array}{l}\text { Wild crocus / } \\
\text { Vuurlelie }\end{array}$ & 1 & Bulb & Medicine & Hand & $\begin{array}{l}\text { Least } \\
\text { Concern }\end{array}$ & $\begin{array}{c}\text { South Africa } \\
\text { indigenous }\end{array}$ & $\begin{array}{c}\text { Table } \\
\text { Mountain } \\
\text { National } \\
\text { Park } \\
\end{array}$ & $\begin{array}{c}\text { Harvester } \\
\text { informants, } \\
\text { personal } \\
\text { communication }\end{array}$ \\
\hline AMARYLLIDACEAE & $\begin{array}{l}\text { Cyrtanthus carneus } \\
\text { Lindl. }\end{array}$ & Wild crocus & 1 & Bulb & Medicine & Hand & Vulnerable & $\begin{array}{l}\text { Locally } \\
\text { indigenous }\end{array}$ & $\begin{array}{c}\text { Table } \\
\text { Mountain } \\
\text { National } \\
\text { Park } \\
\end{array}$ & $\begin{array}{c}\text { Harvester } \\
\text { informants, } \\
\text { personal } \\
\text { communication }\end{array}$ \\
\hline FUMARIACEAE & $\begin{array}{l}\text { Cysticapnos vessicaria } \\
\text { (L.) Fedde }\end{array}$ & $\begin{array}{l}\text { African fumitory } \\
\text { / Klapperbos }\end{array}$ & & Stems & Medicine & Hand & Not listed & $\begin{array}{l}\text { Locally } \\
\text { indigenous }\end{array}$ & $\begin{array}{c}\text { Atlantis } \\
\text { Conservation } \\
\text { Area }\end{array}$ & $\begin{array}{l}\text { T. Abrahams } \\
\text { and C. McKie, } \\
\text { personal } \\
\text { communication }\end{array}$ \\
\hline SOLANACEAE & Datura stramonium $\mathbf{L}$. & & 1 & $\begin{array}{c}\text { Leaves / } \\
\text { fruits }\end{array}$ & Medicine & Hand & Not listed & $\begin{array}{c}\text { Alien to South } \\
\text { Africa }\end{array}$ & $\begin{array}{l}\text { Cape Town - } \\
\text { general }\end{array}$ & $\begin{array}{c}\text { Lewu and } \\
\text { Afolayan (2009 }\end{array}$ \\
\hline PROTEACEAE & $\begin{array}{l}\text { Diastella thymelaeoides } \\
\text { (PJ Bergius) Rourke } \\
\text { subsp. meridiana } \\
\text { Rourke }\end{array}$ & $\begin{array}{l}\text { Hangklip } \\
\text { Silkypuff }\end{array}$ & 1 & $\begin{array}{l}\text { Flowers / } \\
\text { foliage }\end{array}$ & $\begin{array}{l}\text { Flowers / } \\
\text { foliage }\end{array}$ & Hand & Vulnerable & $\begin{array}{l}\text { Locally } \\
\text { indigenous }\end{array}$ & $\begin{array}{c}\text { Table } \\
\text { Mountain } \\
\text { National } \\
\text { Park }\end{array}$ & Rebelo (1996) \\
\hline
\end{tabular}




\begin{tabular}{|c|c|c|c|c|c|c|c|c|c|c|}
\hline ORCHIDACEAE & Disa longicornu L.f. & & 1 & Whole plant & $\begin{array}{l}\text { Nursery / } \\
\text { Fiber }\end{array}$ & Hand & Vulnerable & $\begin{array}{l}\text { Locally } \\
\text { indigenous }\end{array}$ & $\begin{array}{c}\text { Table } \\
\text { Mountain } \\
\text { National } \\
\text { Park }\end{array}$ & $\begin{array}{l}\text { Raimondo et al. } \\
\text { (2009) }\end{array}$ \\
\hline SAPINDACEAE & $\begin{array}{l}\text { Dodonaea angustifolia } \\
\text { L.f. }\end{array}$ & $\begin{array}{c}\text { Sand olive / } \\
\text { Ysterhouttoppe }\end{array}$ & 1 & $\begin{array}{c}\text { Leaves / } \\
\text { stems }\end{array}$ & Medicine & Hand & Not listed & $\begin{array}{l}\text { Locally } \\
\text { indigenous }\end{array}$ & $\begin{array}{c}\text { Table } \\
\text { Mountain } \\
\text { National } \\
\text { Park }\end{array}$ & Nzue (2009) \\
\hline HYACINTHACEAE & $\begin{array}{l}\text { Drimia capensis Burm. } \\
\text { f. Wijnands }\end{array}$ & Brandui & 1 & Bulb & Medicine & Hand & $\begin{array}{c}\text { Least } \\
\text { Concern }\end{array}$ & $\begin{array}{l}\text { Locally } \\
\text { indigenous }\end{array}$ & $\begin{array}{c}\text { Tygerberg } \\
\text { Nature } \\
\text { Reserve }\end{array}$ & $\begin{array}{c}\text { Harvester } \\
\text { informants, } \\
\text { personal } \\
\text { communication }\end{array}$ \\
\hline HYACINTHACEAE & $\begin{array}{l}\text { Drimia elata Jacq. ex } \\
\text { Willd. }\end{array}$ & Brandui & 1 & Bulb & Medicine & Hand & Not listed & $\begin{array}{l}\text { Locally } \\
\text { indigenous }\end{array}$ & $\begin{array}{c}\text { Tygerberg } \\
\text { Nature } \\
\text { Reserve }\end{array}$ & $\begin{array}{c}\text { Harvester } \\
\text { informants, } \\
\text { personal } \\
\text { communication }\end{array}$ \\
\hline PONTEDERIACEAE & $\begin{array}{l}\text { Eichornia crassipes } \\
\text { Kunth. }\end{array}$ & Water hyacinth & 1 & Whole plant & Medicine & Hand & Not listed & $\begin{array}{c}\text { Alien to South } \\
\text { Africa }\end{array}$ & $\begin{array}{c}\text { Edith } \\
\text { Stephens } \\
\text { Nature } \\
\text { Reserve } \\
\end{array}$ & $\begin{array}{c}\text { L. Isaacs, } \\
\text { personal } \\
\text { communication }\end{array}$ \\
\hline RESTIONACEAE & $\begin{array}{l}\text { Elegia capensis (Burm. } \\
\text { f) Schelpe }\end{array}$ & & 1 & Leaves & $\begin{array}{c}\text { Flowers / } \\
\text { foliage / } \\
\text { Fiber }\end{array}$ & Hand & $\begin{array}{c}\text { Least } \\
\text { Concern }\end{array}$ & $\begin{array}{l}\text { Locally } \\
\text { indigenous }\end{array}$ & $\begin{array}{l}\text { Cape Town - } \\
\text { general }\end{array}$ & $\begin{array}{c}\text { Harvester } \\
\text { informants, } \\
\text { personal } \\
\text { communication }\end{array}$ \\
\hline RESTIONACEAE & $\begin{array}{l}\text { Elegia tectorum (L.f.) } \\
\text { Moline and H.P.Linder }\end{array}$ & Dekriet & 1 & Leaves & Fiber & Hand & Not listed & $\begin{array}{l}\text { Locally } \\
\text { indigenous }\end{array}$ & $\begin{array}{c}\text { False Bay } \\
\text { Ecology } \\
\text { Park area } \\
\end{array}$ & $\begin{array}{c}\text { D. Gibbs, } \\
\text { personal } \\
\text { communication }\end{array}$ \\
\hline ASTERACEAE & $\begin{array}{l}\text { Elytropappus } \\
\text { rhinocerotis L.f. }\end{array}$ & $\begin{array}{c}\text { Rhenoster bush / } \\
\text { Renosterbos }\end{array}$ & 1 & $\begin{array}{c}\text { Leaves / } \\
\text { stems }\end{array}$ & Medicine & Hand & Not listed & $\begin{array}{l}\text { Locally } \\
\text { indigenous }\end{array}$ & $\begin{array}{c}\text { Table } \\
\text { Mountain } \\
\text { National } \\
\text { Park }\end{array}$ & $\begin{array}{c}\text { Harvester } \\
\text { informants, } \\
\text { personal } \\
\text { communication }\end{array}$ \\
\hline ERICACEAE & Erica curviflora $\mathbf{L}$. & Water heath & 1 & Flowers & $\begin{array}{l}\text { Flowers / } \\
\text { foliage }\end{array}$ & Hand & Not listed & $\begin{array}{l}\text { Locally } \\
\text { indigenous }\end{array}$ & $\begin{array}{l}\text { Cape Town - } \\
\text { general }\end{array}$ & $\begin{array}{c}\text { Harvester } \\
\text { informants, } \\
\text { personal } \\
\text { communication }\end{array}$ \\
\hline ERICACEAE & $\begin{array}{l}\text { Erica plukenetii }(\mathbf{L} .) \\
\text { subsp. plukenetii }\end{array}$ & Klipheide & 1 & $\begin{array}{c}\text { Flowers / } \\
\text { foliage }\end{array}$ & $\begin{array}{c}\text { Flowers / } \\
\text { foliage }\end{array}$ & Hand & $\begin{array}{c}\text { Least } \\
\text { Concern }\end{array}$ & $\begin{array}{c}\text { Locally } \\
\text { indigenous }\end{array}$ & $\begin{array}{c}\text { Atlantis } \\
\text { Conservation } \\
\text { Area } \\
\end{array}$ & $\begin{array}{c}\text { C. Dorse, } \\
\text { personal } \\
\text { communication }\end{array}$ \\
\hline ERICACEAE & Erica plumosa Thunb. & & 1 & $\begin{array}{l}\text { Flowers / } \\
\text { foliage }\end{array}$ & $\begin{array}{l}\text { Flowers / } \\
\text { foliage }\end{array}$ & Hand & $\begin{array}{c}\text { Least } \\
\text { Concern }\end{array}$ & $\begin{array}{c}\text { Locally } \\
\text { indigenous }\end{array}$ & $\begin{array}{c}\text { Atlantis } \\
\text { Conservation } \\
\text { Area }\end{array}$ & $\begin{array}{c}\text { T. Abrahams } \\
\text { and C. McKie, } \\
\text { personal } \\
\text { communication }\end{array}$ \\
\hline ASTERACEAE & $\begin{array}{l}\text { Eriocephalus africanus } \\
\text { (L.) var. africanus }\end{array}$ & $\begin{array}{l}\text { Wild rosemary / } \\
\text { Wilde roosmaryn }\end{array}$ & 1 & Leaves & Medicine & Hand & $\begin{array}{c}\text { Least } \\
\text { Concern }\end{array}$ & $\begin{array}{c}\text { Locally } \\
\text { indigenous }\end{array}$ & $\begin{array}{c}\text { Atlantis } \\
\text { Conservation } \\
\text { Area }\end{array}$ & $\begin{array}{c}\text { H. Mananga, } \\
\text { personal } \\
\text { communication, } \\
\text { Abrahams and } \\
\text { McKie (2011) }\end{array}$ \\
\hline RUSCACEAE & $\begin{array}{l}\text { Eriospermum } \\
\text { lanceifolium Jacq. }\end{array}$ & & 1 & $\begin{array}{c}\text { Flowers / } \\
\text { fruits }\end{array}$ & Medicine & Hand & $\begin{array}{c}\text { Least } \\
\text { Concern }\end{array}$ & $\begin{array}{l}\text { Locally } \\
\text { indigenous }\end{array}$ & $\begin{array}{l}\text { Cape Town - } \\
\text { general }\end{array}$ & $\begin{array}{c}\text { Harvester } \\
\text { informants, } \\
\text { personal } \\
\text { communication }\end{array}$ \\
\hline MYRTACEAE & $\begin{array}{l}\text { Eucalyptus globulus } \\
\text { Labill }\end{array}$ & $\begin{array}{c}\text { Bluegum / } \\
\text { Bloekom }\end{array}$ & 1 & Leaves & Medicine & Hand & Not listed & $\begin{array}{c}\text { Alien to South } \\
\text { Africa }\end{array}$ & $\begin{array}{l}\text { Cape Town - } \\
\text { general }\end{array}$ & $\begin{array}{c}\text { Harvester } \\
\text { informants, } \\
\text { personal } \\
\text { communication }\end{array}$ \\
\hline MYRTACEAE & $\begin{array}{l}\text { Eucalyptus lehmannii } \\
\text { (Schauer) Benth }\end{array}$ & $\begin{array}{l}\text { Bluegum / } \\
\text { Bloekom }\end{array}$ & 1 & Leaves & Medicine & $\begin{array}{l}\text { Axe / } \\
\text { saw }\end{array}$ & Not listed & $\begin{array}{c}\text { Alien to South } \\
\text { Africa }\end{array}$ & $\begin{array}{l}\text { Cape Town - } \\
\text { general }\end{array}$ & $\begin{array}{c}\text { Harvester } \\
\text { informants, } \\
\text { personal } \\
\text { communication }\end{array}$ \\
\hline EBENACEAE & $\begin{array}{l}\text { Euclea racemosa } \\
\text { Murray subsp. } \\
\text { racemosa Murray }\end{array}$ & $\begin{array}{l}\text { Sea guarri / } \\
\text { Seeghwarri }\end{array}$ & 1 & Bark & Medicine & $\begin{array}{l}\text { Axe / } \\
\text { saw }\end{array}$ & $\begin{array}{c}\text { Least } \\
\text { Concern }\end{array}$ & $\begin{array}{c}\text { Locally } \\
\text { indigenous }\end{array}$ & $\begin{array}{c}\text { False Bay } \\
\text { Ecology } \\
\text { Park area }\end{array}$ & $\begin{array}{c}\text { D. Gibbs, } \\
\text { personal } \\
\text { communication }\end{array}$ \\
\hline ORCHIDACEAE & $\begin{array}{l}\text { Eulophia speciosa } \\
\text { (R.Br. Ex Lindl) Bolus }\end{array}$ & & 1 & $\begin{array}{c}\text { Flowers / } \\
\text { fruits }\end{array}$ & Medicine & Hand & $\begin{array}{c}\text { Least } \\
\text { Concern } \\
\end{array}$ & $\begin{array}{c}\text { South Africa } \\
\text { indigenous }\end{array}$ & $\begin{array}{c}\text { Cape Town - } \\
\text { general }\end{array}$ & $\begin{array}{c}\text { Raimondo et al. } \\
\text { (2009) }\end{array}$ \\
\hline APIACEAE & $\begin{array}{l}\text { Foeniculum vulgare } \\
\text { Mill. }\end{array}$ & Fennel & 1 & Whole plant & $\begin{array}{c}\text { Food } \\
\text { source }\end{array}$ & Hand & Not listed & $\begin{array}{c}\text { Alien to South } \\
\text { Africa }\end{array}$ & $\begin{array}{c}\text { Edith } \\
\text { Stephens } \\
\text { Nature } \\
\text { Reserve } \\
\end{array}$ & $\begin{array}{c}\text { L. Isaacs, } \\
\text { personal } \\
\text { communication }\end{array}$ \\
\hline ASTERACEAE & $\begin{array}{l}\text { Gazania pectinata } \\
\text { Gaertn. }\end{array}$ & & 1 & Whole plant & $\begin{array}{l}\text { Medicine } \\
\text { / Nursery }\end{array}$ & Hand & $\begin{array}{c}\text { Least } \\
\text { Concern }\end{array}$ & $\begin{array}{c}\text { Locally } \\
\text { indigenous }\end{array}$ & $\begin{array}{c}\text { Table } \\
\text { Mountain } \\
\text { National }\end{array}$ & $\begin{array}{c}\text { SANBI (2005), } \\
\text { Harvester } \\
\text { informants, }\end{array}$ \\
\hline
\end{tabular}




\begin{tabular}{|c|c|c|c|c|c|c|c|c|c|}
\hline & & & & & & & & Park & $\begin{array}{c}\text { personal } \\
\text { communication }\end{array}$ \\
\hline GERANIACEAE & $\begin{array}{l}\text { Geranium incanum var. } \\
\text { incanum Burm. f. }\end{array}$ & $\begin{array}{l}\text { Carpet geranium } \\
\text { / Bergtee }\end{array}$ & $2 \begin{array}{c}\text { Flowers / } \\
\text { leaves / roots }\end{array}$ & Medicine & Hand & $\begin{array}{l}\text { Least } \\
\text { Concern }\end{array}$ & $\begin{array}{l}\text { Locally } \\
\text { indigenous }\end{array}$ & $\begin{array}{l}\text { Cape Town - } \\
\text { general }\end{array}$ & $\begin{array}{c}\text { Harvester } \\
\text { informants, } \\
\text { personal } \\
\text { communication }\end{array}$ \\
\hline IRIDACEAE & Gladiolus alatus $\mathbf{L}$. & Turkey chick & 1 Flowers/bulb & $\begin{array}{l}\text { Flowers / } \\
\text { foliage }\end{array}$ & Hand & Endangered & $\begin{array}{l}\text { Locally } \\
\text { indigenous }\end{array}$ & $\begin{array}{c}\text { Atlantis } \\
\text { Conservation } \\
\text { Area }\end{array}$ & $\begin{array}{l}\text { T. Abrahams } \\
\text { and C. McKie, } \\
\text { personal } \\
\text { communication }\end{array}$ \\
\hline IRIDACEAE & Gladiolus angustus $\mathbf{L}$. & $\begin{array}{l}\text { Painted lady / } \\
\text { Pypie }\end{array}$ & 1 Flowers/bulb & $\begin{array}{l}\text { Flowers / } \\
\text { foliage }\end{array}$ & Hand & $\begin{array}{l}\text { Least } \\
\text { Concern }\end{array}$ & $\begin{array}{l}\text { Locally } \\
\text { indigenous }\end{array}$ & $\begin{array}{c}\text { False Bay } \\
\text { Ecology } \\
\text { Park area } \\
\end{array}$ & $\begin{array}{c}\text { D. Gibbs, } \\
\text { personal } \\
\text { communication }\end{array}$ \\
\hline IRIDACEAE & $\begin{array}{l}\text { Gladiolus carinatus } \\
\text { Aiton }\end{array}$ & Blou afrikaaner & 1 Flowers/bulb & $\begin{array}{l}\text { Flowers / } \\
\text { foliage }\end{array}$ & Hand & $\begin{array}{l}\text { Least } \\
\text { Concern }\end{array}$ & $\begin{array}{l}\text { Locally } \\
\text { indigenous }\end{array}$ & $\begin{array}{c}\text { False Bay } \\
\text { Ecology } \\
\text { Park area }\end{array}$ & $\begin{array}{c}\text { D. Gibbs, } \\
\text { personal } \\
\text { communication }\end{array}$ \\
\hline IRIDACEAE & $\begin{array}{l}\text { Gladiolus carneus } \mathbf{D} . \\
\text { Delaroche }\end{array}$ & & 1 Flowers/bulb & $\begin{array}{l}\text { Flowers / } \\
\text { foliage }\end{array}$ & Hand & Not listed & $\begin{array}{l}\text { Locally } \\
\text { indigenous }\end{array}$ & $\begin{array}{c}\text { False Bay } \\
\text { Ecology } \\
\text { Park area }\end{array}$ & $\begin{array}{c}\text { D. Gibbs, } \\
\text { personal } \\
\text { communication }\end{array}$ \\
\hline IRIDACEAE & $\begin{array}{l}\text { Gladiolus cunonius }(\mathbf{L} .) \\
\text { Gaertn. }\end{array}$ & & 1 Flowers/bulb & $\begin{array}{l}\text { Flowers / } \\
\text { foliage }\end{array}$ & Hand & $\begin{array}{l}\text { Least } \\
\text { Concern }\end{array}$ & $\begin{array}{l}\text { Locally } \\
\text { indigenous }\end{array}$ & $\begin{array}{c}\text { False Bay } \\
\text { Ecology } \\
\text { Park area } \\
\end{array}$ & $\begin{array}{c}\text { D. Gibbs, } \\
\text { personal } \\
\text { communication }\end{array}$ \\
\hline IRIDACEAE & Gladiolus ornatus Klatt & & 1 Flowers/bulb & $\begin{array}{l}\text { Flowers / } \\
\text { foliage }\end{array}$ & Hand & Not listed & $\begin{array}{l}\text { Locally } \\
\text { indigenous }\end{array}$ & $\begin{array}{c}\text { False Bay } \\
\text { Ecology } \\
\text { Park area }\end{array}$ & $\begin{array}{c}\text { D. Gibbs, } \\
\text { personal } \\
\text { communication }\end{array}$ \\
\hline GUNNERACEAE & Gunnera perpensa $\mathbf{L}$. & $\begin{array}{l}\text { River pumpkin / } \\
\text { Wilde-ramenas }\end{array}$ & 1 Rhizome & Medicine & Hand & Declining & $\begin{array}{c}\text { South Africa } \\
\text { indigenous }\end{array}$ & $\begin{array}{c}\text { Table } \\
\text { Mountain } \\
\text { National } \\
\text { Park } \\
\end{array}$ & $\begin{array}{c}\text { Harvester } \\
\text { informants, } \\
\text { personal } \\
\text { communication }\end{array}$ \\
\hline GUNNERACEAE & $\begin{array}{l}\text { Haemanthus albiflos } \\
\text { Jacq. }\end{array}$ & $\begin{array}{l}\text { Paintbrush / } \\
\text { Poeierkwas }\end{array}$ & 1 Bulb / flower & Medicine & Hand & $\begin{array}{c}\text { Least } \\
\text { Concern }\end{array}$ & $\begin{array}{c}\text { South Africa } \\
\text { indigenous }\end{array}$ & $\begin{array}{l}\text { Cape Town - } \\
\text { general }\end{array}$ & $\begin{array}{c}\text { Harvester } \\
\text { informants, } \\
\text { personal } \\
\text { communication }\end{array}$ \\
\hline AMARYLLIDACEAE & $\begin{array}{l}\text { Haemanthus coccineus } \\
\text { L. }\end{array}$ & $\begin{array}{c}\text { March flower, } \\
\text { paintbrush lily, / } \\
\text { Bergajuin, } \\
\text { rooikwas }\end{array}$ & 1 Bulb, flower & $\begin{array}{l}\text { Flowers / } \\
\text { foliage / } \\
\text { Medicine }\end{array}$ & Hand & $\begin{array}{c}\text { Least } \\
\text { Concern }\end{array}$ & $\begin{array}{l}\text { Locally } \\
\text { indigenous }\end{array}$ & $\begin{array}{l}\text { Cape Town - } \\
\text { general }\end{array}$ & $\begin{array}{c}\text { SANBI (2005), } \\
\text { P. Glanville, } \\
\text { personal } \\
\text { communication }\end{array}$ \\
\hline AMARYLLIDACEAE & $\begin{array}{l}\text { Haemanthus pubescens } \\
\text { (L.) f. subsp. pubescens }\end{array}$ & $\begin{array}{l}\text { March flower, } \\
\text { paintbrush lily, / } \\
\text { Bergajuin, } \\
\text { rooikwas }\end{array}$ & 1 Bulb, flower & $\begin{array}{l}\text { Flowers / } \\
\text { foliage / } \\
\text { Medicine }\end{array}$ & Hand & $\begin{array}{c}\text { Least } \\
\text { Concern }\end{array}$ & $\begin{array}{l}\text { Locally } \\
\text { indigenous }\end{array}$ & $\begin{array}{c}\text { False Bay } \\
\text { Ecology } \\
\text { Park area }\end{array}$ & $\begin{array}{c}\text { D. Gibbs, } \\
\text { personal } \\
\text { communication }\end{array}$ \\
\hline AMARYLLIDACEAE & $\begin{array}{l}\text { Haemanthus sanguineus } \\
\text { Jacq. }\end{array}$ & & Bulb & Medicine & Hand & $\begin{array}{l}\text { Least } \\
\text { Concern }\end{array}$ & $\begin{array}{l}\text { Locally } \\
\text { indigenous }\end{array}$ & $\begin{array}{c}\text { Macassar / } \\
\text { Wolfgat } \\
\text { Nature } \\
\text { Reserves } \\
\end{array}$ & $\begin{array}{l}\text { H. Mananga, } \\
\text { personal } \\
\text { communication }\end{array}$ \\
\hline ASTERACEAE & $\begin{array}{l}\text { Helichrysum cymosum } \\
\text { Sch.Bip. subsp. } \\
\text { cymosum }\end{array}$ & $\begin{array}{l}\text { Everlasting / } \\
\text { Kooigoed }\end{array}$ & $\begin{array}{c}1 \text { Flowers / } \\
\text { stems }\end{array}$ & Medicine & Hand & $\begin{array}{c}\text { Least } \\
\text { Concern }\end{array}$ & $\begin{array}{l}\text { Locally } \\
\text { indigenous }\end{array}$ & $\begin{array}{l}\text { Macassar / } \\
\text { Wolfgat } \\
\text { Nature } \\
\text { Reserves } \\
\end{array}$ & $\begin{array}{l}\text { H. Mananga, } \\
\text { personal } \\
\text { communication }\end{array}$ \\
\hline ASTERACEAE & $\begin{array}{l}\text { Helichrysum } \\
\text { odoratissimum (L) Less. }\end{array}$ & Everlasting & $\begin{array}{c}1 \text { Flowers / } \\
\text { stems }\end{array}$ & Medicine & Hand & $\begin{array}{l}\text { Least } \\
\text { Concern }\end{array}$ & $\begin{array}{l}\text { Locally } \\
\text { indigenous }\end{array}$ & $\begin{array}{c}\text { Tygerberg } \\
\text { Nature } \\
\text { Reserve } \\
\end{array}$ & $\begin{array}{c}\text { P. Glanville, } \\
\text { personal } \\
\text { communication }\end{array}$ \\
\hline ASTERACEAE & Helichrysum spp. & Everlasting & $\begin{array}{c}5 \text { Flowers / } \\
\text { stems }\end{array}$ & Medicine & Hand & Not listed & $\begin{array}{l}\text { Locally } \\
\text { indigenous }\end{array}$ & $\begin{array}{l}\text { Cape Town - } \\
\text { general }\end{array}$ & $\begin{array}{c}\text { Harvester } \\
\text { informants } \\
(2010) \\
\end{array}$ \\
\hline MALVACEAE & Hermannia spp. & & $\begin{array}{c}\text { Flowers / } \\
\text { leaves }\end{array}$ & Medicine & Hand & Not listed & $\begin{array}{c}\text { Locally } \\
\text { indigenous }\end{array}$ & $\begin{array}{l}\text { Macassar / } \\
\text { Wolfgat } \\
\text { Nature } \\
\text { Reserves }\end{array}$ & $\begin{array}{c}\text { H. Mananga, } \\
\text { personal } \\
\text { communication }\end{array}$ \\
\hline POACEAE & $\begin{array}{l}\text { Hyparrhenia anamesa } \\
\text { Clayton }\end{array}$ & & Leaves & $\begin{array}{c}\text { Flowers / } \\
\text { foliage / } \\
\text { Fiber }\end{array}$ & Hand & $\begin{array}{c}\text { Least } \\
\text { Concern }\end{array}$ & $\begin{array}{l}\text { Locally } \\
\text { indigenous }\end{array}$ & $\begin{array}{l}\text { Cape Town - } \\
\text { general }\end{array}$ & $\begin{array}{c}\text { Harvester } \\
\text { informants, } \\
\text { personal } \\
\text { communication }\end{array}$ \\
\hline POACEAE & $\begin{array}{l}\text { Hyparrhenia dregeana } \\
\text { (Nees) Stapf ex Stent }\end{array}$ & Rooigrass & Leaves & $\begin{array}{c}\text { Flowers / } \\
\text { foliage / } \\
\text { Fiber }\end{array}$ & Hand & $\begin{array}{c}\text { Least } \\
\text { Concern }\end{array}$ & $\begin{array}{c}\text { South Africa } \\
\text { indigenous }\end{array}$ & $\begin{array}{l}\text { Cape Town - } \\
\text { general }\end{array}$ & $\begin{array}{c}\text { Harvester } \\
\text { informants, } \\
\text { personal } \\
\text { communication }\end{array}$ \\
\hline POACEAE & $\begin{array}{l}\text { Hyparrhenia filipendula } \\
\text { (Hochst) Stapf. var } \\
\text { filipendula }\end{array}$ & & Leaves & $\begin{array}{c}\text { Flowers / } \\
\text { foliage / } \\
\text { Fiber }\end{array}$ & Hand & $\begin{array}{c}\text { Least } \\
\text { Concern }\end{array}$ & $\begin{array}{c}\text { South Africa } \\
\text { indigenous }\end{array}$ & $\begin{array}{l}\text { Cape Town - } \\
\text { general }\end{array}$ & $\begin{array}{c}\text { Harvester } \\
\text { informants, } \\
\text { personal }\end{array}$ \\
\hline
\end{tabular}




\begin{tabular}{|c|c|c|c|c|c|c|c|c|c|c|}
\hline & & & & & & & & & & communication \\
\hline POACEAE & $\begin{array}{l}\text { Hyparrhenia filipendula } \\
\text { (Hochst) Stapf. var } \\
\text { pilosa } \text { Hochst (Stapf.) }\end{array}$ & & 1 & Leaves & $\begin{array}{c}\text { Flowers / } \\
\text { foliage / } \\
\text { Fiber }\end{array}$ & Hand & $\begin{array}{c}\text { Least } \\
\text { Concern }\end{array}$ & $\begin{array}{c}\text { South Africa } \\
\text { indigenous }\end{array}$ & $\begin{array}{l}\text { Cape Town - } \\
\text { general }\end{array}$ & $\begin{array}{c}\text { Harvester } \\
\text { informants, } \\
\text { personal } \\
\text { communication }\end{array}$ \\
\hline POACEAE & $\begin{array}{l}\text { Hyparrhenia hirta (L.) } \\
\text { Stapf. }\end{array}$ & & 1 & Leaves & $\begin{array}{c}\text { Flowers / } \\
\text { foliage / } \\
\text { Fiber }\end{array}$ & Hand & $\begin{array}{c}\text { Least } \\
\text { Concern }\end{array}$ & $\begin{array}{l}\text { Locally } \\
\text { indigenous }\end{array}$ & $\begin{array}{l}\text { Cape Town - } \\
\text { general }\end{array}$ & $\begin{array}{c}\text { Harvester } \\
\text { informants, } \\
\text { personal } \\
\text { communication }\end{array}$ \\
\hline POACEAE & $\begin{array}{l}\text { Imperata cylindrica }(\mathbf{L}) \\
\text { Raeusch. }\end{array}$ & River grass & 1 & Leaves & $\begin{array}{c}\text { Flowers / } \\
\text { foliage / } \\
\text { Fiber }\end{array}$ & Hand & $\begin{array}{l}\text { Least } \\
\text { Concern }\end{array}$ & $\begin{array}{l}\text { Locally } \\
\text { indigenous }\end{array}$ & $\begin{array}{l}\text { Cape Town - } \\
\text { general }\end{array}$ & $\begin{array}{c}\text { Harvester } \\
\text { informants, } \\
\text { personal } \\
\text { communication }\end{array}$ \\
\hline CUCURBITACEAE & Kedrostis nana (Lam) & & 1 & Tuber & Medicine & Hand & Not listed & $\begin{array}{l}\text { Locally } \\
\text { indigenous }\end{array}$ & $\begin{array}{l}\text { Wolfgat } \\
\text { Nature } \\
\text { Reserve } \\
\end{array}$ & $\begin{array}{c}\text { H. Mananga, } \\
\text { personal } \\
\text { communication }\end{array}$ \\
\hline RANUNCULACEAE & $\begin{array}{l}\text { Knowltonia bracteata } \\
\text { Harv ex. J Zahlbr. }\end{array}$ & Katjiedrie Blaar & 1 & Whole plant & Medicine & Hand & Vulnerable & $\begin{array}{c}\text { South Africa } \\
\text { indigenous }\end{array}$ & $\begin{array}{c}\text { Table } \\
\text { Mountain } \\
\text { National } \\
\text { Park } \\
\end{array}$ & $\begin{array}{c}\text { Harvester } \\
\text { informants, } \\
\text { personal } \\
\text { communication }\end{array}$ \\
\hline RANUNCULACEAE & $\begin{array}{l}\text { Knowltonia vesicatoria } \\
\text { (L.f.) Sims. subsp. } \\
\text { vesicatoria }\end{array}$ & $\begin{array}{c}\text { Blisterleaf / } \\
\text { Brandblaar, } \\
\text { katjiedrieblaar } \\
\end{array}$ & 1 & Rhizome & Medicine & Hand & $\begin{array}{c}\text { Least } \\
\text { Concern }\end{array}$ & $\begin{array}{l}\text { Locally } \\
\text { indigenous }\end{array}$ & $\begin{array}{c}\text { False Bay } \\
\text { Ecology } \\
\text { Park area } \\
\end{array}$ & $\begin{array}{c}\text { D. Gibbs, } \\
\text { personal } \\
\text { communication } \\
\end{array}$ \\
\hline HYACINTHACEAE & $\begin{array}{l}\text { Lachenalia bulbifera } \\
\text { (Cirillo) Engl. }\end{array}$ & Rooinaeltjie & & $\begin{array}{l}\text { Reproductive } \\
\text { structures / } \\
\text { systems } \\
\end{array}$ & $\begin{array}{l}\text { Flowers / } \\
\text { foliage }\end{array}$ & Hand & $\begin{array}{c}\text { Least } \\
\text { Concern }\end{array}$ & $\begin{array}{c}\text { Locally } \\
\text { indigenous }\end{array}$ & $\begin{array}{c}\text { False Bay } \\
\text { Ecology } \\
\text { Park area } \\
\end{array}$ & $\begin{array}{c}\text { D. Gibbs, } \\
\text { personal } \\
\text { communication } \\
\end{array}$ \\
\hline RUSSULACEAE & $\begin{array}{l}\text { Lactarius deliciosus (L. } \\
\text { ex Fr.) S.F.Gray }\end{array}$ & Pine rings & 1 & $\begin{array}{c}\text { Whole } \\
\text { organism }\end{array}$ & $\begin{array}{c}\text { Food } \\
\text { source }\end{array}$ & Hand & Not listed & $\begin{array}{l}\text { Locally } \\
\text { indigenous }\end{array}$ & $\begin{array}{c}\text { Table } \\
\text { Mountain } \\
\text { National } \\
\text { Park } \\
\end{array}$ & $\begin{array}{c}\text { Harvester } \\
\text { informants, } \\
\text { personal } \\
\text { communication }\end{array}$ \\
\hline POLYPORACEAE & Laetiporus sp. & $\begin{array}{c}\text { Hen and chicken } \\
\text { mushroom }\end{array}$ & & $\begin{array}{l}\text { Whole } \\
\text { organism }\end{array}$ & $\begin{array}{l}\text { Food } \\
\text { source }\end{array}$ & Hand & Not listed & $\begin{array}{c}\text { Locally } \\
\text { indigenous }\end{array}$ & $\begin{array}{c}\text { Table } \\
\text { Mountain } \\
\text { National } \\
\text { Park } \\
\end{array}$ & $\begin{array}{c}\text { Harvester } \\
\text { informants, } \\
\text { personal } \\
\text { communication }\end{array}$ \\
\hline LAMIACEAE & Lavandula sp. & Lavender & & $\begin{array}{l}\text { Reproductive } \\
\text { structures / } \\
\text { systems }\end{array}$ & Medicine & Hand & Not listed & $\begin{array}{l}\text { Alien to South } \\
\text { Africa }\end{array}$ & $\begin{array}{l}\text { Macassar / } \\
\text { Wolfgat } \\
\text { Nature } \\
\text { Reserves } \\
\end{array}$ & $\begin{array}{l}\text { H. Mananga, } \\
\text { personal } \\
\text { communication }\end{array}$ \\
\hline LAMIACEAE & Leonotis leonurus $\mathbf{R} . \mathbf{B r}$ & Wild dagga & 1 & Leaves & Medicine & Hand & $\begin{array}{c}\text { Least } \\
\text { Concern }\end{array}$ & $\begin{array}{l}\text { Locally } \\
\text { indigenous }\end{array}$ & $\begin{array}{c}\text { Macassar / } \\
\text { Wolfgat } \\
\text { Nature } \\
\text { Reserves } \\
\end{array}$ & $\begin{array}{c}\text { H. Mananga, } \\
\text { personal } \\
\text { communication }\end{array}$ \\
\hline FABACEAE & $\begin{array}{l}\text { Lessertia frutescens }(\mathbf{L} .) \\
\text { Goldblatt and J. C. } \\
\text { Manning. }\end{array}$ & $\begin{array}{l}\text { Cancer bush / } \\
\text { Kankerbossie }\end{array}$ & 1 & $\begin{array}{c}\text { Leaves / } \\
\text { stems }\end{array}$ & Medicine & Hand & $\begin{array}{c}\text { Least } \\
\text { Concern }\end{array}$ & $\begin{array}{c}\text { South Africa } \\
\text { indigenous }\end{array}$ & $\begin{array}{c}\text { Macassar / } \\
\text { Wolfgat } \\
\text { Nature } \\
\text { Reserves } \\
\end{array}$ & $\begin{array}{l}\text { H. Mananga, } \\
\text { personal } \\
\text { communication }\end{array}$ \\
\hline PROTEACEAE & $\begin{array}{l}\text { Leucadendron album } \\
\text { (Thunb) Fourc. }\end{array}$ & Peach conebush & 1 & $\begin{array}{c}\text { Flowers / } \\
\text { foliage }\end{array}$ & $\begin{array}{c}\text { Flowers / } \\
\text { foliage }\end{array}$ & Hand & $\begin{array}{c}\text { Least } \\
\text { Concern }\end{array}$ & $\begin{array}{l}\text { Locally } \\
\text { indigenous }\end{array}$ & $\begin{array}{c}\text { Table } \\
\text { Mountain } \\
\text { National } \\
\text { Park } \\
\end{array}$ & Rebelo (1996) \\
\hline PROTEACEAE & $\begin{array}{l}\text { Leucadendron } \\
\text { argenteum }(\mathbf{L} .) \text { R. Br. }\end{array}$ & Silver tree & 1 & $\begin{array}{c}\text { Flowers / } \\
\text { foliage }\end{array}$ & $\begin{array}{c}\text { Flowers / } \\
\text { foliage }\end{array}$ & Hand & Endangered & $\begin{array}{l}\text { Locally } \\
\text { indigenous }\end{array}$ & $\begin{array}{c}\text { Table } \\
\text { Mountain } \\
\text { National } \\
\text { Park } \\
\end{array}$ & Rebelo (1996) \\
\hline PROTEACEAE & $\begin{array}{l}\text { Leucadendron } \\
\text { corymbosum P.J. } \\
\text { Bergius }\end{array}$ & $\begin{array}{l}\text { Swartveld } \\
\text { conebush }\end{array}$ & 1 & $\begin{array}{l}\text { Flowers / } \\
\text { foliage }\end{array}$ & $\begin{array}{c}\text { Flowers / } \\
\text { foliage }\end{array}$ & Hand & Vulnerable & $\begin{array}{c}\text { Locally } \\
\text { indigenous }\end{array}$ & $\begin{array}{c}\text { Table } \\
\text { Mountain } \\
\text { National } \\
\text { Park }\end{array}$ & Rebelo (1996) \\
\hline PROTEACEAE & $\begin{array}{l}\text { Leucadendron } \\
\text { daphnoides (Thunb.) } \\
\text { Meisn. }\end{array}$ & Giant pompom & 1 & $\begin{array}{c}\text { Flowers / } \\
\text { foliage }\end{array}$ & $\begin{array}{c}\text { Flowers / } \\
\text { foliage }\end{array}$ & Hand & Endangered & $\begin{array}{l}\text { Locally } \\
\text { indigenous }\end{array}$ & $\begin{array}{c}\text { Table } \\
\text { Mountain } \\
\text { National } \\
\text { Park } \\
\end{array}$ & Rebelo (1996) \\
\hline PROTEACEAE & $\begin{array}{l}\text { Leucadendron discolor } \\
\text { E. Phillips and Hutch }\end{array}$ & Flame goldtips & 1 & $\begin{array}{c}\text { Flowers / } \\
\text { foliage }\end{array}$ & $\begin{array}{c}\text { Flowers / } \\
\text { foliage }\end{array}$ & Hand & Endangered & $\begin{array}{l}\text { Locally } \\
\text { indigenous }\end{array}$ & $\begin{array}{c}\text { Table } \\
\text { Mountain } \\
\text { National } \\
\text { Park } \\
\end{array}$ & Rebelo (1996) \\
\hline PROTEACEAE & $\begin{array}{l}\text { Leucadendron floridum } \\
\text { R. Br. }\end{array}$ & $\begin{array}{c}\text { Flats conebush / } \\
\text { Tolbos }\end{array}$ & & $\begin{array}{l}\text { Flowers / } \\
\text { foliage }\end{array}$ & $\begin{array}{c}\text { Flowers / } \\
\text { foliage }\end{array}$ & Hand & $\begin{array}{c}\text { Critically } \\
\text { Endangered }\end{array}$ & $\begin{array}{c}\text { Locally } \\
\text { indigenous }\end{array}$ & $\begin{array}{c}\text { Table } \\
\text { Mountain } \\
\text { National } \\
\text { Park }\end{array}$ & $\begin{array}{c}\text { Raimondo et al. } \\
\text { (2009) }\end{array}$ \\
\hline
\end{tabular}




\begin{tabular}{|c|c|c|c|c|c|c|c|c|c|c|}
\hline PROTEACEAE & $\begin{array}{l}\text { Leucadendron galpinii } \\
\text { E. Phillips and Hutch }\end{array}$ & $\begin{array}{l}\text { Silver cone } \\
\text { conebush }\end{array}$ & 1 & $\begin{array}{l}\text { Flowers / } \\
\text { foliage }\end{array}$ & $\begin{array}{l}\text { Flowers / } \\
\text { foliage }\end{array}$ & Hand & Vulnerable & $\begin{array}{l}\text { Locally } \\
\text { indigenous }\end{array}$ & $\begin{array}{c}\text { Table } \\
\text { Mountain } \\
\text { National } \\
\text { Park } \\
\end{array}$ & Rebelo (1996) \\
\hline PROTEACEAE & $\begin{array}{l}\text { Leucadendron gydoense } \\
\text { I. Williams }\end{array}$ & Gydo conebush & 1 & $\begin{array}{l}\text { Flowers / } \\
\text { foliage }\end{array}$ & $\begin{array}{l}\text { Flowers / } \\
\text { foliage }\end{array}$ & Hand & Endangered & $\begin{array}{c}\text { Cape } \\
\text { indigenous }\end{array}$ & $\begin{array}{c}\text { Table } \\
\text { Mountain } \\
\text { National } \\
\text { Park }\end{array}$ & Rebelo (1996) \\
\hline PROTEACEAE & $\begin{array}{l}\text { Leucadendron laxum } \mathbf{I} \text {. } \\
\text { Williams }\end{array}$ & $\begin{array}{l}\text { Bredasdorp } \\
\text { conebush }\end{array}$ & 1 & $\begin{array}{l}\text { Flowers / } \\
\text { foliage }\end{array}$ & $\begin{array}{l}\text { Flowers / } \\
\text { foliage }\end{array}$ & Hand & Endangered & $\begin{array}{c}\text { Cape } \\
\text { indigenous }\end{array}$ & $\begin{array}{c}\text { Table } \\
\text { Mountain } \\
\text { National } \\
\text { Park }\end{array}$ & Rebelo (1996) \\
\hline PROTEACEAE & $\begin{array}{l}\text { Leucadendron levisanus } \\
\text { (L.) P.J. Bergius }\end{array}$ & $\begin{array}{l}\text { Cape flats } \\
\text { conebush }\end{array}$ & 1 & $\begin{array}{l}\text { Flowers / } \\
\text { foliage }\end{array}$ & $\begin{array}{l}\text { Flowers / } \\
\text { foliage }\end{array}$ & Hand & $\begin{array}{c}\text { Critically } \\
\text { Endangered }\end{array}$ & $\begin{array}{l}\text { Locally } \\
\text { indigenous }\end{array}$ & $\begin{array}{c}\text { Table } \\
\text { Mountain } \\
\text { National } \\
\text { Park } \\
\end{array}$ & Rebelo (1996) \\
\hline PROTEACEAE & $\begin{array}{l}\text { Leucadendron linifolium } \\
\text { (Jacq.) R. Br. }\end{array}$ & $\begin{array}{l}\text { Line leaf } \\
\text { conebush }\end{array}$ & 1 & $\begin{array}{l}\text { Flowers / } \\
\text { foliage }\end{array}$ & $\begin{array}{l}\text { Flowers / } \\
\text { foliage }\end{array}$ & Hand & Vulnerable & $\begin{array}{l}\text { Locally } \\
\text { indigenous }\end{array}$ & $\begin{array}{c}\text { Table } \\
\text { Mountain } \\
\text { National } \\
\text { Park }\end{array}$ & $\begin{array}{c}\text { Raimondo et al. } \\
\text { (2009), } \\
\text { Harvester } \\
\text { informants, } \\
\text { personal } \\
\text { communication }\end{array}$ \\
\hline PROTEACEAE & $\begin{array}{l}\text { Leucadendron } \\
\text { platyspermum } \mathbf{R} . \mathbf{B r}\end{array}$ & $\begin{array}{l}\text { Flat seed } \\
\text { conebush }\end{array}$ & 1 & $\begin{array}{l}\text { Flowers / } \\
\text { foliage }\end{array}$ & $\begin{array}{l}\text { Flowers / } \\
\text { foliage }\end{array}$ & Hand & Vulnerable & $\begin{array}{l}\text { Locally } \\
\text { indigenous }\end{array}$ & $\begin{array}{c}\text { Table } \\
\text { Mountain } \\
\text { National } \\
\text { Park } \\
\end{array}$ & Rebelo (1996) \\
\hline PROTEACEAE & $\begin{array}{l}\text { Leucadendron rubrum } \\
\text { Burm. F }\end{array}$ & Tolbos & 1 & $\begin{array}{l}\text { Flowers / } \\
\text { foliage }\end{array}$ & $\begin{array}{l}\text { Flowers / } \\
\text { foliage }\end{array}$ & Hand & $\begin{array}{c}\text { Least } \\
\text { Concern }\end{array}$ & $\begin{array}{c}\text { Locally } \\
\text { indigenous }\end{array}$ & $\begin{array}{c}\text { Table } \\
\text { Mountain } \\
\text { National } \\
\text { Park }\end{array}$ & Rebelo (1996) \\
\hline PROTEACEAE & $\begin{array}{l}\text { Leucadendron } \\
\text { spissifolium (Salisb. Ex } \\
\text { Knight) I. Williams } \\
\text { subsp. spissifolium } \\
\end{array}$ & & 1 & $\begin{array}{l}\text { Flowers / } \\
\text { foliage }\end{array}$ & $\begin{array}{l}\text { Flowers / } \\
\text { foliage }\end{array}$ & Hand & $\begin{array}{c}\text { Least } \\
\text { Concern }\end{array}$ & $\begin{array}{l}\text { Locally } \\
\text { indigenous }\end{array}$ & $\begin{array}{c}\text { Table } \\
\text { Mountain } \\
\text { National } \\
\text { Park } \\
\end{array}$ & Rebelo (1996) \\
\hline PROTEACEAE & $\begin{array}{l}\text { Leucadendron } \\
\text { spissifolium (Salisb. Ex } \\
\text { Knight) I. Williams } \\
\text { subsp. phillipsii (Hutch) } \\
\text { I. Williams }\end{array}$ & $\begin{array}{c}\text { Spear-leaf } \\
\text { Conebush / } \\
\text { Kareedouwvlakte }\end{array}$ & 1 & $\begin{array}{l}\text { Flowers / } \\
\text { foliage }\end{array}$ & $\begin{array}{l}\text { Flowers / } \\
\text { foliage }\end{array}$ & Hand & $\begin{array}{c}\text { Least } \\
\text { Concern }\end{array}$ & $\begin{array}{l}\text { Locally } \\
\text { indigenous }\end{array}$ & $\begin{array}{c}\text { Table } \\
\text { Mountain } \\
\text { National } \\
\text { Park }\end{array}$ & Rebelo (1996) \\
\hline PROTEACEAE & $\begin{array}{l}\text { Leucadendron } \\
\text { strobilinum }(\mathbf{L} .) \text { Druce }\end{array}$ & $\begin{array}{l}\text { Peninsula } \\
\text { conebush }\end{array}$ & 1 & $\begin{array}{l}\text { Flowers / } \\
\text { foliage }\end{array}$ & $\begin{array}{l}\text { Flowers / } \\
\text { foliage }\end{array}$ & Hand & $\begin{array}{l}\text { Near } \\
\text { Threatened }\end{array}$ & $\begin{array}{l}\text { Locally } \\
\text { indigenous }\end{array}$ & $\begin{array}{c}\text { Table } \\
\text { Mountain } \\
\text { National } \\
\text { Park }\end{array}$ & Rebelo (1996) \\
\hline PROTEACEAE & $\begin{array}{l}\text { Leucadendron } \\
\text { xanthoconus (Kuntze) } \\
\text { K. Schum. }\end{array}$ & $\begin{array}{l}\text { Glossy leaf } \\
\text { conebush }\end{array}$ & 1 & $\begin{array}{l}\text { Flowers / } \\
\text { foliage }\end{array}$ & $\begin{array}{l}\text { Flowers / } \\
\text { foliage }\end{array}$ & Hand & $\begin{array}{c}\text { Least } \\
\text { Concern }\end{array}$ & $\begin{array}{l}\text { Locally } \\
\text { indigenous }\end{array}$ & $\begin{array}{c}\text { Table } \\
\text { Mountain } \\
\text { National } \\
\text { Park } \\
\end{array}$ & Rebelo (1996) \\
\hline PROTEACEAE & $\begin{array}{l}\text { Leucospermum } \\
\text { conocarpodendron (L.) } \\
\text { H. Buek subsp. } \\
\text { conocarpodendron } \\
\end{array}$ & $\begin{array}{l}\text { Grey tree } \\
\text { pincushion }\end{array}$ & 1 & $\begin{array}{l}\text { Flowers / } \\
\text { foliage }\end{array}$ & $\begin{array}{l}\text { Flowers / } \\
\text { foliage }\end{array}$ & Hand & Endangered & $\begin{array}{c}\text { Locally } \\
\text { indigenous }\end{array}$ & $\begin{array}{c}\text { Table } \\
\text { Mountain } \\
\text { National } \\
\text { Park } \\
\end{array}$ & Rebelo (1996) \\
\hline PROTEACEAE & $\begin{array}{l}\text { Leucospermum } \\
\text { conocarpodendron (L.) } \\
\text { H. Buek subsp. viridum } \\
\text { Rourke }\end{array}$ & Pincushion & 1 & $\begin{array}{c}\text { Flowers / } \\
\text { foliage }\end{array}$ & $\begin{array}{l}\text { Flowers / } \\
\text { foliage }\end{array}$ & Hand & $\begin{array}{c}\text { Near } \\
\text { Threatened }\end{array}$ & $\begin{array}{c}\text { Locally } \\
\text { indigenous }\end{array}$ & $\begin{array}{c}\text { Table } \\
\text { Mountain } \\
\text { National } \\
\text { Park } \\
\end{array}$ & Rebelo (1996) \\
\hline PROTEACEAE & $\begin{array}{l}\text { Leucospermum } \\
\text { grandiflorum (Salisb.) } \\
\text { R. Br. }\end{array}$ & $\begin{array}{l}\text { Rainbow } \\
\text { pincushion }\end{array}$ & 1 & $\begin{array}{l}\text { Flowers / } \\
\text { foliage }\end{array}$ & $\begin{array}{l}\text { Flowers / } \\
\text { foliage }\end{array}$ & Hand & Endangered & $\begin{array}{c}\text { Locally } \\
\text { indigenous }\end{array}$ & $\begin{array}{c}\text { Table } \\
\text { Mountain } \\
\text { National } \\
\text { Park } \\
\end{array}$ & Rebelo (1996) \\
\hline PROTEACEAE & $\begin{array}{l}\text { Leucospermum } \\
\text { heterophyllum (Thunb.) } \\
\text { Rourke }\end{array}$ & Snakebush & 1 & $\begin{array}{c}\text { Flowers / } \\
\text { foliage }\end{array}$ & $\begin{array}{l}\text { Flowers / } \\
\text { foliage }\end{array}$ & Hand & Endangered & $\begin{array}{c}\text { Locally } \\
\text { indigenous }\end{array}$ & $\begin{array}{c}\text { Table } \\
\text { Mountain } \\
\text { National } \\
\text { Park } \\
\end{array}$ & Rebelo (1996) \\
\hline PROTEACEAE & $\begin{array}{l}\text { Leucospermum } \\
\text { hypophyllocarpodendron } \\
\text { (L.) Druce subsp. } \\
\text { hypophyllocarpodendron }\end{array}$ & & 1 & $\begin{array}{l}\text { Flowers / } \\
\text { foliage }\end{array}$ & $\begin{array}{l}\text { Flowers / } \\
\text { foliage }\end{array}$ & Hand & Vulnerable & $\begin{array}{c}\text { Locally } \\
\text { indigenous }\end{array}$ & $\begin{array}{c}\text { Table } \\
\text { Mountain } \\
\text { National } \\
\text { Park } \\
\end{array}$ & $\begin{array}{l}\text { Raimondo et al. } \\
\text { (2009) }\end{array}$ \\
\hline PROTEACEAE & $\begin{array}{l}\text { Leucospermum } \\
\text { oleifolium (P.J. Bergius) } \\
\text { R. Br. }\end{array}$ & $\begin{array}{c}\text { Flame } \\
\text { pincushion }\end{array}$ & 1 & $\begin{array}{c}\text { Flowers / } \\
\text { foliage }\end{array}$ & $\begin{array}{l}\text { Flowers / } \\
\text { foliage }\end{array}$ & Hand & $\begin{array}{c}\text { Least } \\
\text { Concern }\end{array}$ & $\begin{array}{c}\text { Locally } \\
\text { indigenous }\end{array}$ & $\begin{array}{c}\text { Table } \\
\text { Mountain } \\
\text { National } \\
\text { Park }\end{array}$ & Rebelo (1996) \\
\hline
\end{tabular}




\begin{tabular}{|c|c|c|c|c|c|c|c|c|c|c|}
\hline PROTEACEAE & $\begin{array}{l}\text { Leucospermum reflexum } \\
\text { H. Buek ex Meisn var. } \\
\text { reflexum }\end{array}$ & Perdekoppe & 1 & $\begin{array}{l}\text { Flowers / } \\
\text { foliage }\end{array}$ & $\begin{array}{l}\text { Flowers / } \\
\text { foliage }\end{array}$ & Hand & $\begin{array}{c}\text { Near } \\
\text { Threatened }\end{array}$ & $\begin{array}{c}\text { Locally } \\
\text { indigenous }\end{array}$ & $\begin{array}{c}\text { Table } \\
\text { Mountain } \\
\text { National } \\
\text { Park }\end{array}$ & Rebelo (1996) \\
\hline PROTEACEAE & $\begin{array}{l}\text { Leucospermum vestitum } \\
\text { (Lam.) Rourke }\end{array}$ & $\begin{array}{l}\text { Silky hair } \\
\text { pincushion }\end{array}$ & 1 & $\begin{array}{l}\text { Flowers / } \\
\text { foliage }\end{array}$ & $\begin{array}{l}\text { Flowers / } \\
\text { foliage }\end{array}$ & Hand & $\begin{array}{c}\text { Near } \\
\text { Threatened }\end{array}$ & $\begin{array}{l}\text { Locally } \\
\text { indigenous }\end{array}$ & $\begin{array}{c}\text { Table } \\
\text { Mountain } \\
\text { National } \\
\text { Park }\end{array}$ & Rebelo (1996) \\
\hline BORAGINACEAE & $\begin{array}{l}\text { Lobostemon fruticosus } \\
\text { (L.) H. Buek. English }\end{array}$ & $\begin{array}{c}\text { Eight-day } \\
\text { healing bush / } \\
\text { Agdaegeneesbos }\end{array}$ & 4 & $\begin{array}{c}\text { Leaves / } \\
\text { stems }\end{array}$ & Medicine & Hand & $\begin{array}{c}\text { Least } \\
\text { Concern }\end{array}$ & $\begin{array}{l}\text { Locally } \\
\text { indigenous }\end{array}$ & $\begin{array}{c}\text { Table } \\
\text { Mountain } \\
\text { National } \\
\text { Park }\end{array}$ & $\begin{array}{c}\text { Nzue (2009), } \\
\text { Harvester } \\
\text { informants, } \\
\text { personal } \\
\text { communication }\end{array}$ \\
\hline SOLANACEAE & $\begin{array}{l}\text { Lycium ferocissimum } \\
\text { Miers }\end{array}$ & Slangbossie & 1 & Leaves & Medicine & Hand & $\begin{array}{c}\text { Least } \\
\text { Concern }\end{array}$ & $\begin{array}{c}\text { Locally } \\
\text { indigenous }\end{array}$ & $\begin{array}{l}\text { Macassar / } \\
\text { Wolfgat } \\
\text { Nature } \\
\text { Reserves }\end{array}$ & $\begin{array}{l}\text { H. Mananga, } \\
\text { personal } \\
\text { communication }\end{array}$ \\
\hline MELIANTHACEAE & Melianthus major $\mathbf{L}$. & $\begin{array}{l}\text { Honey flower / } \\
\text { Kruidjie- } \\
\text { roer-my- nie }\end{array}$ & 1 & Leaves & Medicine & Hand & $\begin{array}{c}\text { Least } \\
\text { Concern }\end{array}$ & $\begin{array}{c}\text { Locally } \\
\text { indigenous }\end{array}$ & $\begin{array}{c}\text { Table } \\
\text { Mountain } \\
\text { National } \\
\text { Park }\end{array}$ & $\begin{array}{c}\text { Nzue (2009), } \\
\text { Harvester } \\
\text { informants, } \\
\text { personal } \\
\text { communication }\end{array}$ \\
\hline LAMIACEAE & $\begin{array}{l}\text { Mentha longifolia }(\mathbf{L} .) \\
\text { Huds. subsp. capensis } \\
\text { (Thunb). }\end{array}$ & $\begin{array}{l}\text { Wild mint / } \\
\text { Kruisement }\end{array}$ & 1 & $\begin{array}{l}\text { Leaves / } \\
\text { stems }\end{array}$ & Medicine & Hand & $\begin{array}{c}\text { Least } \\
\text { Concern }\end{array}$ & $\begin{array}{c}\text { Locally } \\
\text { indigenous }\end{array}$ & $\begin{array}{c}\text { Table } \\
\text { Mountain } \\
\text { National } \\
\text { Park } \\
\end{array}$ & $\begin{array}{c}\text { Harvester } \\
\text { informants, } \\
\text { personal } \\
\text { communication }\end{array}$ \\
\hline MYRICACEAE & Metalasia $\mathrm{sp}$ & Blombos & 3 & $\begin{array}{c}\text { Flowers / } \\
\text { stems }\end{array}$ & Medicine & Hand & Not listed & $\begin{array}{c}\text { Locally } \\
\text { indigenous }\end{array}$ & $\begin{array}{l}\text { Cape Town - } \\
\text { general }\end{array}$ & $\begin{array}{c}\text { Harvester } \\
\text { informants, } \\
\text { personal } \\
\text { communication }\end{array}$ \\
\hline SCROPHULARIACEAE & $\begin{array}{l}\text { Microdon capitatus } \\
\text { (Levyns) }\end{array}$ & $\begin{array}{l}\text { Knopbos / } \\
\text { Levyns }\end{array}$ & 1 & $\begin{array}{l}\text { Flowers / } \\
\text { foliage }\end{array}$ & $\begin{array}{l}\text { Flowers / } \\
\text { foliage }\end{array}$ & Hand & Not listed & $\begin{array}{c}\text { Locally } \\
\text { indigenous }\end{array}$ & $\begin{array}{c}\text { Atlantis } \\
\text { Conservation } \\
\text { Area }\end{array}$ & $\begin{array}{l}\text { T. Abrahams } \\
\text { and C. McKie, } \\
\text { personal } \\
\text { communication }\end{array}$ \\
\hline PROTEACEAE & $\begin{array}{l}\text { Mimetes hirtus (L.) } \\
\text { Salisb. Ex Knight }\end{array}$ & Pineapple bush & 1 & $\begin{array}{c}\text { Flowers / } \\
\text { foliage }\end{array}$ & $\begin{array}{c}\text { Flowers / } \\
\text { foliage }\end{array}$ & Hand & Vulnerable & $\begin{array}{l}\text { Locally } \\
\text { indigenous }\end{array}$ & $\begin{array}{c}\text { Table } \\
\text { Mountain } \\
\text { National } \\
\text { Park } \\
\end{array}$ & Rebelo (1996) \\
\hline IRIDACEAE & $\begin{array}{l}\text { Moraea fugax (Jacq.) } \\
\text { subsp. fugax }\end{array}$ & Bobiaanuintjie & & Flowers/bulb & $\begin{array}{c}\text { Flowers / } \\
\text { foliage }\end{array}$ & Hand & $\begin{array}{c}\text { Least } \\
\text { Concern }\end{array}$ & $\begin{array}{c}\text { Locally } \\
\text { indigenous }\end{array}$ & $\begin{array}{l}\text { Cape Town - } \\
\text { general }\end{array}$ & $\begin{array}{c}\text { D. Gibbs, } \\
\text { personal } \\
\text { communication }\end{array}$ \\
\hline IRIDACEAE & $\begin{array}{l}\text { Moraea villosa (Ker } \\
\text { Gawl.) Ker Gaw }\end{array}$ & Peacock moraea & 1 & Bulb & Medicine & Hand & $\begin{array}{c}\text { Near } \\
\text { Threatened }\end{array}$ & $\begin{array}{c}\text { Locally } \\
\text { indigenous }\end{array}$ & $\begin{array}{c}\text { Atlantis } \\
\text { Conservation } \\
\text { Area }\end{array}$ & $\begin{array}{l}\text { T. Abrahams } \\
\text { and C. McKie, } \\
\text { personal } \\
\text { communication }\end{array}$ \\
\hline MYRICACEAE & $\begin{array}{l}\text { Morella cordifolia }(\mathbf{L} .) \\
\text { Killick }\end{array}$ & & 1 & Fruit & $\begin{array}{l}\text { Food } \\
\text { source }\end{array}$ & Hand & $\begin{array}{c}\text { Least } \\
\text { Concern }\end{array}$ & $\begin{array}{l}\text { Locally } \\
\text { indigenous }\end{array}$ & $\begin{array}{l}\text { Macassar / } \\
\text { Wolfgat } \\
\text { Nature } \\
\text { Reserves }\end{array}$ & $\begin{array}{c}\text { Nzue (2009), } \\
\text { Harvester } \\
\text { informants, } \\
\text { personal } \\
\text { communication }\end{array}$ \\
\hline LAMIACEAE & Ocimum spp. & Thyme / Timie & 1 & Leaves & Medicine & Hand & $\begin{array}{c}\text { Least } \\
\text { Concern }\end{array}$ & $\begin{array}{c}\text { Locally } \\
\text { indigenous }\end{array}$ & $\begin{array}{c}\text { Table } \\
\text { Mountain } \\
\text { National } \\
\text { Park }\end{array}$ & $\begin{array}{c}\text { Nzue (2009), } \\
\text { Harvester } \\
\text { informants, } \\
\text { personal } \\
\text { communication }\end{array}$ \\
\hline LAURACEAE & $\begin{array}{l}\text { Ocotea bullata (Burch.) } \\
\text { Baill. }\end{array}$ & $\begin{array}{l}\text { Black stinkwood } \\
\text { / Stinkhout }\end{array}$ & 1 & Bark & Medicine & $\begin{array}{c}\text { Axe / } \\
\text { saw }\end{array}$ & Endangered & $\begin{array}{l}\text { Locally } \\
\text { indigenous }\end{array}$ & $\begin{array}{l}\text { Macassar / } \\
\text { Wolfgat } \\
\text { Nature } \\
\text { Reserves }\end{array}$ & $\begin{array}{l}\text { H. Mananga, } \\
\text { personal } \\
\text { communication }\end{array}$ \\
\hline OLEACEAE & $\begin{array}{l}\text { Olea europaea L. subsp. } \\
\text { africana (Mill) P.S. } \\
\text { Green }\end{array}$ & $\begin{array}{l}\text { Wild olive / } \\
\text { Olienhout }\end{array}$ & 1 & Leaves & Medicine & Hand & $\begin{array}{c}\text { Least } \\
\text { Concern }\end{array}$ & $\begin{array}{c}\text { Locally } \\
\text { indigenous }\end{array}$ & $\begin{array}{c}\text { Macassar / } \\
\text { Wolfgat } \\
\text { Nature } \\
\text { Reserves } \\
\end{array}$ & $\begin{array}{l}\text { H. Mananga, } \\
\text { personal } \\
\text { communication }\end{array}$ \\
\hline ASTERACEAE & $\begin{array}{l}\text { Oncosiphon } \\
\text { suffruticosum }(\mathbf{L} .) \\
\text { Kallersjo }\end{array}$ & & 1 & Leaves & Medicine & Hand & $\begin{array}{c}\text { Least } \\
\text { Concern }\end{array}$ & $\begin{array}{c}\text { Locally } \\
\text { indigenous }\end{array}$ & $\begin{array}{l}\text { Macassar / } \\
\text { Wolfgat } \\
\text { Nature } \\
\text { Reserves } \\
\end{array}$ & $\begin{array}{c}\text { H. Mananga, } \\
\text { personal } \\
\text { communication }\end{array}$ \\
\hline LILIACEAE & $\begin{array}{l}\text { Ornithogalum thyrsoides } \\
\text { Jacq. }\end{array}$ & $\begin{array}{l}\text { Wonder-flower, } \\
\text { star-of- } \\
\text { Bethlehem, } \\
\text { chincherinchee; }\end{array}$ & 1 & $\begin{array}{l}\text { Flowers / } \\
\text { foliage }\end{array}$ & $\begin{array}{l}\text { Flowers / } \\
\text { foliage }\end{array}$ & Hand & Not listed & $\begin{array}{c}\text { Locally } \\
\text { indigenous }\end{array}$ & $\begin{array}{c}\text { Atlantis } \\
\text { Conservation } \\
\text { Area }\end{array}$ & $\begin{array}{c}\text { T. Abrahams } \\
\text { and C. McKie, } \\
\text { personal } \\
\text { communication }\end{array}$ \\
\hline
\end{tabular}




\begin{tabular}{|c|c|c|c|c|c|c|c|c|c|c|}
\hline OXALIDACEAE & $\begin{array}{l}\text { Oxalis pes-caprae } \mathbf{L} \text {. var } \\
\text { pes-caprae }\end{array}$ & Wood sorrel & 1 & Bulbs & $\begin{array}{l}\text { Food } \\
\text { source }\end{array}$ & Hand & $\begin{array}{c}\text { Least } \\
\text { Concern }\end{array}$ & $\begin{array}{l}\text { Locally } \\
\text { indigenous }\end{array}$ & $\begin{array}{l}\text { False Bay } \\
\text { Ecology } \\
\text { Park area }\end{array}$ & $\begin{array}{c}\text { D. Gibbs, } \\
\text { personal } \\
\text { communication }\end{array}$ \\
\hline PROTEACEAE & $\begin{array}{l}\text { Paranomus reflexus } \\
\text { (E.Phillips and Hutch.) } \\
\text { Fourc. }\end{array}$ & Green scepter & 1 & $\begin{array}{l}\text { Flowers / } \\
\text { foliage }\end{array}$ & $\begin{array}{l}\text { Flowers / } \\
\text { foliage }\end{array}$ & Hand & Endangered & $\begin{array}{l}\text { Locally } \\
\text { indigenous }\end{array}$ & $\begin{array}{c}\text { Table } \\
\text { Mountain } \\
\text { National } \\
\text { Park } \\
\end{array}$ & Rebelo (1996) \\
\hline GERANIACEAE & $\begin{array}{l}\text { Pelargonium ellaphieae } \\
\text { E.M. Marais }\end{array}$ & & 1 & Whole plant & Nursery & Hand & Endangered & $\begin{array}{c}\text { Locally } \\
\text { indigenous }\end{array}$ & $\begin{array}{l}\text { Cape Town - } \\
\text { general }\end{array}$ & $\begin{array}{c}\text { Raimondo et al. } \\
\text { (2009) }\end{array}$ \\
\hline GERANIACEAE & $\begin{array}{l}\text { Pelargonium leptum } \mathbf{L} \text {. } \\
\text { Bolus }\end{array}$ & & 1 & Whole plant & Medicine & Hand & Vulnerable & $\begin{array}{c}\text { Locally } \\
\text { indigenous }\end{array}$ & $\begin{array}{l}\text { Cape Town - } \\
\text { general }\end{array}$ & $\begin{array}{c}\text { Raimondo et al. } \\
\text { (2009) }\end{array}$ \\
\hline GERANIACEAE & $\begin{array}{l}\text { Pelargonium lobatum } \\
\text { (Burm. F.) L'Her' }\end{array}$ & $\begin{array}{l}\text { Malva / elephant } \\
\text { foot }\end{array}$ & 1 & Tuber & Medicine & Hand & $\begin{array}{l}\text { Least } \\
\text { Concern }\end{array}$ & $\begin{array}{l}\text { Locally } \\
\text { indigenous }\end{array}$ & $\begin{array}{c}\text { Table } \\
\text { Mountain } \\
\text { National } \\
\text { Park }\end{array}$ & $\begin{array}{c}\text { Nzue (2009), } \\
\text { Harvester } \\
\text { informants, } \\
\text { personal } \\
\text { communication }\end{array}$ \\
\hline GERANIACEAE & $\begin{array}{l}\text { Pelargonium triste }(\mathbf{L} .) \\
\text { L'Hér. }\end{array}$ & $\begin{array}{c}\text { Sand geranium / } \\
\text { Kaneelbol }\end{array}$ & 1 & Tuber & Medicine & Hand & $\begin{array}{c}\text { Least } \\
\text { Concern }\end{array}$ & $\begin{array}{c}\text { Locally } \\
\text { indigenous }\end{array}$ & $\begin{array}{c}\text { False Bay } \\
\text { Ecology } \\
\text { Park area }\end{array}$ & $\begin{array}{l}\text { Raimondo et al. } \\
\text { (2009), D. } \\
\text { Gibbs, personal } \\
\text { communication }\end{array}$ \\
\hline POACEAE & $\begin{array}{l}\text { Pennisetum } \\
\text { clandestinum (Hocst ex } \\
\text { Chiov) }\end{array}$ & Kikuyu & 1 & $\begin{array}{l}\text { Harvest of } \\
\text { reproductive } \\
\text { structures / } \\
\text { systems }\end{array}$ & $\begin{array}{l}\text { Flowers / } \\
\text { foliage / } \\
\text { Nursery }\end{array}$ & Hand & Not listed & $\begin{array}{c}\text { Alien to South } \\
\text { Africa }\end{array}$ & $\begin{array}{l}\text { Cape Town - } \\
\text { general }\end{array}$ & $\begin{array}{c}\text { Nzue (2009), } \\
\text { Harvester } \\
\text { informants, } \\
\text { personal } \\
\text { communication }\end{array}$ \\
\hline APIACEAE & $\begin{array}{l}\text { Peucedanum galbanum } \\
\text { (L.) Drude }\end{array}$ & $\begin{array}{l}\text { Blister bush / } \\
\text { Bergseldery }\end{array}$ & 1 & $\begin{array}{l}\text { Leaves / } \\
\text { stems }\end{array}$ & Medicine & Hand & $\begin{array}{c}\text { Least } \\
\text { Concern }\end{array}$ & $\begin{array}{c}\text { Locally } \\
\text { indigenous }\end{array}$ & $\begin{array}{c}\text { Table } \\
\text { Mountain } \\
\text { National } \\
\text { Park }\end{array}$ & $\begin{array}{c}\text { Dold and Cocks } \\
\text { (2001), } \\
\text { Harvester } \\
\text { informants, } \\
\text { personal } \\
\text { communication }\end{array}$ \\
\hline POACEAE & $\begin{array}{l}\text { Phragmites australis } \\
\text { (Cav.) Steud. }\end{array}$ & Common reed & 1 & Leaves & Fiber & Hand & $\begin{array}{c}\text { Least } \\
\text { Concern }\end{array}$ & $\begin{array}{l}\text { Locally } \\
\text { indigenous }\end{array}$ & $\begin{array}{l}\text { Cape Town - } \\
\text { general }\end{array}$ & $\begin{array}{c}\text { Harvester } \\
\text { informants, } \\
\text { personal } \\
\text { communication }\end{array}$ \\
\hline ERICACEAE & Phylica ericoides $\mathbf{L}$. & Heath phylica & 1 & Flowers & $\begin{array}{l}\text { Flowers / } \\
\text { foliage }\end{array}$ & Hand & Not listed & $\begin{array}{l}\text { Locally } \\
\text { indigenous }\end{array}$ & $\begin{array}{l}\text { Cape Town - } \\
\text { general }\end{array}$ & $\begin{array}{c}\text { Harvester } \\
\text { informants, } \\
\text { personal } \\
\text { communication }\end{array}$ \\
\hline PINACEAE & Pinus elliotii Engelm. & Slash pine & 1 & Bark & Nursery & $\begin{array}{l}\text { Axe / } \\
\text { saw }\end{array}$ & Not listed & $\begin{array}{c}\text { Alien to South } \\
\text { Africa }\end{array}$ & $\begin{array}{l}\text { Cape Town - } \\
\text { general }\end{array}$ & $\begin{array}{c}\text { D. Gibbs, } \\
\text { personal } \\
\text { communication }\end{array}$ \\
\hline ASTERACEAE & $\begin{array}{l}\text { Plecostachys } \\
\text { serpyllifolia }(\mathbf{P} . J . \\
\text { Bergius) Hilliard and } \\
\text { B.L. Burtt } \\
\end{array}$ & Koeigoed & 1 & Leaves & Medicine & Hand & Not listed & $\begin{array}{l}\text { Locally } \\
\text { indigenous }\end{array}$ & $\begin{array}{c}\text { False Bay } \\
\text { Ecology } \\
\text { Park area }\end{array}$ & $\begin{array}{c}\text { D. Gibbs, } \\
\text { personal } \\
\text { communication }\end{array}$ \\
\hline PODOCARPACEAE & $\begin{array}{l}\text { Podocarpus latifolius } \\
\text { (Thunb.) R Br. Ex } \\
\text { Mirb. }\end{array}$ & & 1 & Leaves & Medicine & Hand & $\begin{array}{c}\text { Least } \\
\text { Concern }\end{array}$ & $\begin{array}{l}\text { Locally } \\
\text { indigenous }\end{array}$ & $\begin{array}{c}\text { Table } \\
\text { Mountain } \\
\text { National } \\
\text { Park } \\
\end{array}$ & $\begin{array}{c}\text { Harvester } \\
\text { informants, } \\
\text { personal } \\
\text { communication }\end{array}$ \\
\hline POLYGALACEAE & $\begin{array}{l}\text { Polygala fruticosa P.J. } \\
\text { Berguis }\end{array}$ & Slangwortel & 1 & $\begin{array}{c}\text { Leaves / } \\
\text { stems }\end{array}$ & $\begin{array}{l}\text { Medicine } \\
\text { / Nursery }\end{array}$ & Hand & $\begin{array}{c}\text { Least } \\
\text { Concern }\end{array}$ & $\begin{array}{l}\text { Locally } \\
\text { indigenous }\end{array}$ & $\begin{array}{l}\text { Cape Town - } \\
\text { general }\end{array}$ & $\begin{array}{c}\text { Dold and Cocks } \\
\text { (2002), } \\
\text { Harvester } \\
\text { informants, } \\
\text { personal } \\
\text { communication }\end{array}$ \\
\hline POLYGALACEAE & $\begin{array}{l}\text { Polygala serpentaria } \\
\text { Eckl. and Zeyh. }\end{array}$ & Slangwortel & 1 & Rhizome & Medicine & Hand & Not listed & $\begin{array}{c}\text { South Africa } \\
\text { indigenous }\end{array}$ & & $\begin{array}{c}\text { Raimondo et al } \\
(2009)\end{array}$ \\
\hline PROTEACEAE & $\begin{array}{l}\text { Protea acaulos }(\mathbf{L} .) \\
\text { Reichard. }\end{array}$ & $\begin{array}{c}\text { Common ground } \\
\text { sugarbush }\end{array}$ & & $\begin{array}{c}\text { Flowers / } \\
\text { foliage }\end{array}$ & $\begin{array}{l}\text { Flowers / } \\
\text { foliage }\end{array}$ & Hand & $\begin{array}{c}\text { Least } \\
\text { Concern }\end{array}$ & $\begin{array}{l}\text { Locally } \\
\text { indigenous }\end{array}$ & $\begin{array}{c}\text { Table } \\
\text { Mountain } \\
\text { National } \\
\text { Park } \\
\end{array}$ & Rebelo (1996) \\
\hline PROTEACEAE & $\begin{array}{l}\text { Protea aurea (Burm. f) } \\
\text { subsp. aurea }\end{array}$ & $\begin{array}{c}\text { Christmas candle } \\
\text { protea }\end{array}$ & & $\begin{array}{l}\text { Flowers / } \\
\text { foliage }\end{array}$ & $\begin{array}{l}\text { Flowers / } \\
\text { foliage }\end{array}$ & Hand & $\begin{array}{c}\text { Least } \\
\text { Concern }\end{array}$ & $\begin{array}{l}\text { Locally } \\
\text { indigenous }\end{array}$ & $\begin{array}{c}\text { Table } \\
\text { Mountain } \\
\text { National } \\
\text { Park }\end{array}$ & Rebelo (1996) \\
\hline PROTEACEAE & $\begin{array}{l}\text { Protea burchelli Stapf, } \\
\text { (L). }\end{array}$ & Burchells protea & & $\begin{array}{l}\text { Flowers / } \\
\text { foliage }\end{array}$ & $\begin{array}{l}\text { Flowers / } \\
\text { foliage }\end{array}$ & Hand & Not listed & $\begin{array}{l}\text { Locally } \\
\text { indigenous }\end{array}$ & $\begin{array}{c}\text { Atlantis } \\
\text { Conservation } \\
\text { Area }\end{array}$ & $\begin{array}{c}\text { T. Abrahams } \\
\text { and C. McKie, } \\
\text { personal } \\
\text { communication }\end{array}$ \\
\hline
\end{tabular}




\begin{tabular}{|c|c|c|c|c|c|c|c|c|c|c|}
\hline PROTEACEAE & Protea compacta $\mathbf{R}$. Br. & Pink protea & 1 & $\begin{array}{l}\text { Flowers / } \\
\text { foliage }\end{array}$ & $\begin{array}{l}\text { Flowers / } \\
\text { foliage }\end{array}$ & Hand & Not listed & $\begin{array}{l}\text { Locally } \\
\text { indigenous }\end{array}$ & $\begin{array}{c}\text { Table } \\
\text { Mountain } \\
\text { National } \\
\text { Park } \\
\end{array}$ & Rebelo (1996) \\
\hline PROTEACEAE & Protea coronata Lam. & Green sugarbush & 1 & $\begin{array}{l}\text { Flowers / } \\
\text { foliage }\end{array}$ & $\begin{array}{l}\text { Flowers / } \\
\text { foliage }\end{array}$ & Hand & Not listed & $\begin{array}{l}\text { Locally } \\
\text { indigenous }\end{array}$ & $\begin{array}{c}\text { Table } \\
\text { Mountain } \\
\text { National } \\
\text { Park }\end{array}$ & Rebelo (1996) \\
\hline PROTEACEAE & Protea cynaroides $(\mathbf{L})$. & King protea & 1 & $\begin{array}{l}\text { Flowers / } \\
\text { foliage }\end{array}$ & $\begin{array}{l}\text { Flowers / } \\
\text { foliage }\end{array}$ & Hand & $\begin{array}{c}\text { Least } \\
\text { Concern }\end{array}$ & $\begin{array}{l}\text { Locally } \\
\text { indigenous }\end{array}$ & $\begin{array}{c}\text { Table } \\
\text { Mountain } \\
\text { National } \\
\text { Park } \\
\end{array}$ & Rebelo (1996) \\
\hline PROTEACEAE & $\begin{array}{l}\text { Protea effusa } \mathbf{E} \text {. Mey. ex } \\
\text { Meisn. }\end{array}$ & $\begin{array}{l}\text { Marloth's } \\
\text { sugarbush }\end{array}$ & 1 & $\begin{array}{l}\text { Flowers / } \\
\text { foliage }\end{array}$ & $\begin{array}{l}\text { Flowers / } \\
\text { foliage }\end{array}$ & Hand & $\begin{array}{c}\text { Near } \\
\text { Threatened }\end{array}$ & $\begin{array}{c}\text { Locally } \\
\text { indigenous }\end{array}$ & $\begin{array}{c}\text { Table } \\
\text { Mountain } \\
\text { National } \\
\text { Park } \\
\end{array}$ & Rebelo (1996) \\
\hline PROTEACEAE & $\begin{array}{l}\text { Protea grandiceps } \\
\text { Tratt. }\end{array}$ & $\begin{array}{c}\text { Coral coloured } \\
\text { protea }\end{array}$ & 1 & $\begin{array}{l}\text { Flowers / } \\
\text { foliage }\end{array}$ & $\begin{array}{l}\text { Flowers / } \\
\text { foliage }\end{array}$ & Hand & $\begin{array}{c}\text { Near } \\
\text { Threatened }\end{array}$ & $\begin{array}{c}\text { Locally } \\
\text { indigenous }\end{array}$ & $\begin{array}{c}\text { Cape Town - } \\
\text { general }\end{array}$ & $\begin{array}{c}\text { Raimondo et al. } \\
\text { (2009) }\end{array}$ \\
\hline PROTEACEAE & Protea lacticolor Salisb. & $\begin{array}{l}\text { Hottentott } \\
\text { sugarbush }\end{array}$ & 1 & $\begin{array}{l}\text { Flowers / } \\
\text { foliage }\end{array}$ & $\begin{array}{l}\text { Flowers / } \\
\text { foliage }\end{array}$ & Hand & Endangered & $\begin{array}{l}\text { Locally } \\
\text { indigenous }\end{array}$ & $\begin{array}{c}\text { Table } \\
\text { Mountain } \\
\text { National } \\
\text { Park } \\
\end{array}$ & Rebelo (1996) \\
\hline PROTEACEAE & $\begin{array}{l}\text { Protea laurifolia } \\
\text { Thunb. }\end{array}$ & Pastel protea & 1 & $\begin{array}{l}\text { Flowers / } \\
\text { foliage }\end{array}$ & $\begin{array}{l}\text { Flowers / } \\
\text { foliage }\end{array}$ & Hand & $\begin{array}{c}\text { Least } \\
\text { Concern }\end{array}$ & $\begin{array}{c}\text { Locally } \\
\text { indigenous }\end{array}$ & $\begin{array}{c}\text { Table } \\
\text { Mountain } \\
\text { National } \\
\text { Park } \\
\end{array}$ & Rebelo (1996) \\
\hline PROTEACEAE & Protea magnifica Link & Queen protea & 1 & $\begin{array}{l}\text { Flowers / } \\
\text { foliage }\end{array}$ & $\begin{array}{l}\text { Flowers / } \\
\text { foliage }\end{array}$ & Hand & $\begin{array}{c}\text { Least } \\
\text { Concern }\end{array}$ & $\begin{array}{l}\text { Locally } \\
\text { indigenous }\end{array}$ & $\begin{array}{c}\text { Table } \\
\text { Mountain } \\
\text { National } \\
\text { Park }\end{array}$ & Rebelo (1996) \\
\hline PROTEACEAE & Protea neriifolia $\mathbf{R} . \mathbf{B r}$. & $\begin{array}{l}\text { Blackbeard } \\
\text { sugarbush }\end{array}$ & 1 & $\begin{array}{l}\text { Flowers / } \\
\text { foliage }\end{array}$ & $\begin{array}{l}\text { Flowers / } \\
\text { foliage }\end{array}$ & Hand & $\begin{array}{l}\text { Least } \\
\text { Concern }\end{array}$ & $\begin{array}{l}\text { Locally } \\
\text { indigenous }\end{array}$ & $\begin{array}{c}\text { Table } \\
\text { Mountain } \\
\text { National } \\
\text { Park } \\
\end{array}$ & Rebelo (1996) \\
\hline PROTEACEAE & Protea nitida Mill. & $\begin{array}{l}\text { Cape wagon tree } \\
\text { / Waboom }\end{array}$ & 1 & $\begin{array}{l}\text { Flowers / } \\
\text { foliage }\end{array}$ & $\begin{array}{l}\text { Flowers / } \\
\text { foliage }\end{array}$ & Hand & $\begin{array}{c}\text { Least } \\
\text { Concern }\end{array}$ & $\begin{array}{l}\text { Locally } \\
\text { indigenous }\end{array}$ & $\begin{array}{c}\text { Table } \\
\text { Mountain } \\
\text { National } \\
\text { Park } \\
\end{array}$ & Rebelo (1996) \\
\hline PROTEACEAE & Protea pudens Rourke & Creeping protea & 1 & $\begin{array}{l}\text { Flowers / } \\
\text { foliage }\end{array}$ & $\begin{array}{l}\text { Flowers / } \\
\text { foliage }\end{array}$ & Hand & Endangered & $\begin{array}{c}\text { Cape } \\
\text { indigenous }\end{array}$ & $\begin{array}{c}\text { Table } \\
\text { Mountain } \\
\text { National } \\
\text { Park } \\
\end{array}$ & Rebelo (1996) \\
\hline PROTEACEAE & Protea punctata Meisn. & Water sugarbush & 1 & $\begin{array}{l}\text { Flowers / } \\
\text { foliage }\end{array}$ & $\begin{array}{l}\text { Flowers / } \\
\text { foliage }\end{array}$ & Hand & $\begin{array}{c}\text { Least } \\
\text { Concern }\end{array}$ & $\begin{array}{c}\text { Locally } \\
\text { indigenous }\end{array}$ & $\begin{array}{c}\text { Table } \\
\text { Mountain } \\
\text { National } \\
\text { Park } \\
\end{array}$ & Rebelo (1996) \\
\hline PROTEACEAE & Protea repens $\mathbf{L}$. & Cape sugarbush & 1 & $\begin{array}{l}\text { Flowers / } \\
\text { foliage }\end{array}$ & $\begin{array}{l}\text { Flowers / } \\
\text { foliage }\end{array}$ & Hand & $\begin{array}{c}\text { Least } \\
\text { Concern }\end{array}$ & $\begin{array}{c}\text { Locally } \\
\text { indigenous }\end{array}$ & $\begin{array}{c}\text { Table } \\
\text { Mountain } \\
\text { National } \\
\text { Park } \\
\end{array}$ & Rebelo (1996) \\
\hline PROTEACEAE & $\begin{array}{l}\text { Protea scolymocephala } \\
\text { (L.) Reichard }\end{array}$ & $\begin{array}{c}\text { Thistle protea, } \\
\text { thistle sugarbush } \\
\text { / Skollie }\end{array}$ & 1 & Flowers & $\begin{array}{l}\text { Flowers / } \\
\text { foliage }\end{array}$ & Hand & Not listed & $\begin{array}{c}\text { Locally } \\
\text { indigenous }\end{array}$ & $\begin{array}{c}\text { Atlantis } \\
\text { Conservation } \\
\text { Area }\end{array}$ & $\begin{array}{c}\text { T. Abrahams } \\
\text { and C. McKie, } \\
\text { personal } \\
\text { communication }\end{array}$ \\
\hline PROTEACEAE & $\begin{array}{l}\text { Protea subvestita N. E. } \\
\text { Br. }\end{array}$ & & 1 & $\begin{array}{l}\text { Flowers / } \\
\text { foliage }\end{array}$ & $\begin{array}{l}\text { Flowers / } \\
\text { foliage }\end{array}$ & Hand & Vulnerable & $\begin{array}{c}\text { Cape } \\
\text { indigenous }\end{array}$ & $\begin{array}{c}\text { Table } \\
\text { Mountain } \\
\text { National } \\
\text { Park } \\
\end{array}$ & Rebelo (1996) \\
\hline CELASTRACEAE & $\begin{array}{l}\text { Pterocelastrus rostratus } \\
\text { (Thunb.) Walp. }\end{array}$ & & 1 & Bark & Medicine & $\begin{array}{c}\text { Axe / } \\
\text { saw }\end{array}$ & Declining & $\begin{array}{c}\text { Locally } \\
\text { indigenous }\end{array}$ & $\begin{array}{c}\text { Cape Town - } \\
\text { general }\end{array}$ & Nzue (2009) \\
\hline RANUNCULACEAE & $\begin{array}{l}\text { Ranunculus multifidus } \\
\text { Forssk. }\end{array}$ & Brandblare & 1 & Rhizome & Medicine & Hand & $\begin{array}{c}\text { Least } \\
\text { Concern }\end{array}$ & $\begin{array}{l}\text { Locally } \\
\text { indigenous }\end{array}$ & $\begin{array}{c}\text { Table } \\
\text { Mountain } \\
\text { National } \\
\text { Park }\end{array}$ & $\begin{array}{c}\text { Nzue (2009), } \\
\text { Harvester } \\
\text { informants, } \\
\text { personal } \\
\text { communication }\end{array}$ \\
\hline MYRSINACEAE & $\begin{array}{l}\text { Rapanea melanophloeos } \\
\text { (L.) Mez. }\end{array}$ & $\begin{array}{l}\text { Cape beech / } \\
\text { Kaapse } \\
\text { boekenhout }\end{array}$ & 1 & Bark & Medicine & $\begin{array}{c}\text { Axe / } \\
\text { saw }\end{array}$ & Declining & $\begin{array}{c}\text { Locally } \\
\text { indigenous }\end{array}$ & $\begin{array}{c}\text { Table } \\
\text { Mountain } \\
\text { National } \\
\text { Park }\end{array}$ & $\begin{array}{c}\text { Dold and Cocks } \\
\text { (2002), } \\
\text { Harvester } \\
\text { informants, } \\
\text { personal } \\
\text { communication }\end{array}$ \\
\hline
\end{tabular}




\begin{tabular}{|c|c|c|c|c|c|c|c|c|c|c|}
\hline VITACEAE & $\begin{array}{l}\text { Rhoicissus tomentosa } \\
\text { Lam. Wild and } \\
\text { Drummond }\end{array}$ & $\begin{array}{l}\text { Wild forest grape } \\
\text { / Bobbejaantou }\end{array}$ & & Tuber & Medicine & Hand & $\begin{array}{l}\text { Least } \\
\text { Concern }\end{array}$ & $\begin{array}{c}\text { South Africa } \\
\text { indigenous }\end{array}$ & $\begin{array}{l}\text { Cape Town - } \\
\text { general }\end{array}$ & $\begin{array}{c}\text { Harvester } \\
\text { informants, } \\
\text { personal } \\
\text { communication }\end{array}$ \\
\hline LAMIACEAE & $\begin{array}{l}\text { Rosmarinus officinalis } \\
\text { L. }\end{array}$ & Rosmaryn & 1 & $\begin{array}{l}\text { Flowers / } \\
\text { leaves }\end{array}$ & Medicine & Hand & Not listed & $\begin{array}{c}\text { Alien to South } \\
\text { Africa }\end{array}$ & $\begin{array}{l}\text { Cape Town - } \\
\text { general }\end{array}$ & $\begin{array}{l}\text { Dold and Cocks } \\
\text { (2002), } \\
\text { Harvester } \\
\text { informants, } \\
\text { personal } \\
\text { communication }\end{array}$ \\
\hline POLYGONACEAE & $\begin{array}{l}\text { Rumex steudelii Hochst. } \\
\text { Ex. A. Rich. }\end{array}$ & Beestongblaar & 1 & Rhizome & Medicine & Hand & $\begin{array}{c}\text { Least } \\
\text { Concern }\end{array}$ & $\begin{array}{c}\text { South Africa } \\
\text { indigenous }\end{array}$ & $\begin{array}{l}\text { Macassar / } \\
\text { Wolfgat } \\
\text { Nature } \\
\text { Reserves } \\
\end{array}$ & $\begin{array}{l}\text { H. Mananga, } \\
\text { personal } \\
\text { communication }\end{array}$ \\
\hline LAMIACEAE & $\begin{array}{l}\text { Salvia africana-caerulea } \\
\text { L. }\end{array}$ & $\begin{array}{l}\text { Wild sage / } \\
\text { Wildesalie }\end{array}$ & 2 & $\begin{array}{l}\text { Flowers / } \\
\text { foliage }\end{array}$ & Medicinal & Hand & $\begin{array}{c}\text { Least } \\
\text { Concern }\end{array}$ & $\begin{array}{l}\text { Locally } \\
\text { indigenous }\end{array}$ & $\begin{array}{c}\text { Edith } \\
\text { Stephens } \\
\text { Nature } \\
\text { Reserve }\end{array}$ & $\begin{array}{c}\text { L. Isaacs, } \\
\text { personal } \\
\text { communication }\end{array}$ \\
\hline LAMIACEAE & Salvia africana-lutea $\mathbf{L}$. & $\begin{array}{c}\text { Brown salvia / } \\
\text { Bruinsalie }\end{array}$ & 2 & $\begin{array}{l}\text { Flowers / } \\
\text { foliage }\end{array}$ & Medicinal & Hand & $\begin{array}{l}\text { Least } \\
\text { Concern }\end{array}$ & $\begin{array}{l}\text { Locally } \\
\text { indigenous }\end{array}$ & $\begin{array}{c}\text { Edith } \\
\text { Stephens } \\
\text { Nature } \\
\text { Reserve }\end{array}$ & $\begin{array}{c}\text { L. Isaacs, } \\
\text { personal } \\
\text { communication }\end{array}$ \\
\hline LAMIACEAE & Salvia lanceolata Lam. & Sage & 1 & $\begin{array}{l}\text { Flowers / } \\
\text { foliage }\end{array}$ & Medicinal & Hand & $\begin{array}{c}\text { Least } \\
\text { Concern }\end{array}$ & $\begin{array}{l}\text { Locally } \\
\text { indigenous }\end{array}$ & $\begin{array}{c}\text { Edith } \\
\text { Stephens } \\
\text { Nature } \\
\text { Reserve } \\
\end{array}$ & $\begin{array}{c}\text { L. Isaacs, } \\
\text { personal } \\
\text { communication }\end{array}$ \\
\hline DRACAENACEAE & $\begin{array}{l}\text { Sanseviera aethopica } \\
\text { Thunb. }\end{array}$ & Bitter patat & 1 & Tuber & Medicine & Hand & $\begin{array}{c}\text { Least } \\
\text { Concern }\end{array}$ & $\begin{array}{c}\text { South Africa } \\
\text { indigenous }\end{array}$ & $\begin{array}{l}\text { Cape Town - } \\
\text { general }\end{array}$ & $\begin{array}{c}\text { Dold and Cocks } \\
\text { (2002), } \\
\text { Harvester } \\
\text { informants, } \\
\text { personal } \\
\text { communication }\end{array}$ \\
\hline BALANOPHORACEAE & $\begin{array}{l}\text { Sarcophyte sanguinea } \\
\text { Sparrm. subsp. } \\
\text { sanguinea }\end{array}$ & Wolwekos & 1 & Tuber & Medicine & Hand & $\begin{array}{l}\text { Least } \\
\text { Concern }\end{array}$ & $\begin{array}{c}\text { South Africa } \\
\text { indigenous }\end{array}$ & $\begin{array}{l}\text { Macassar / } \\
\text { Wolfgat } \\
\text { Nature } \\
\text { Reserves } \\
\end{array}$ & $\begin{array}{l}\text { H. Mananga, } \\
\text { personal } \\
\text { communication }\end{array}$ \\
\hline ORCHIDACEAE & $\begin{array}{l}\text { Satyrium carneum } \\
\text { (Dryand.) Sims }\end{array}$ & Rooikappie & 1 & Whole plant & Nursery & Hand & $\begin{array}{c}\text { Near } \\
\text { Threatened }\end{array}$ & $\begin{array}{l}\text { Locally } \\
\text { indigenous }\end{array}$ & $\begin{array}{l}\text { Cape Town - } \\
\text { general }\end{array}$ & $\begin{array}{c}\text { Raimondo et al. } \\
\text { (2009), } \\
\text { Harvester } \\
\text { informants, } \\
\text { personal } \\
\text { communication }\end{array}$ \\
\hline ORCHIDACEAE & Satyrium foliosum $\mathbf{S w}$. & & 1 & Whole plant & Nursery & Hand & $\begin{array}{c}\text { Near } \\
\text { Threatened }\end{array}$ & $\begin{array}{c}\text { Locally } \\
\text { indigenous }\end{array}$ & $\begin{array}{l}\text { Cape Town - } \\
\text { general }\end{array}$ & $\begin{array}{c}\text { Raimondo et al. } \\
\text { (2009), } \\
\text { Harvester } \\
\text { informants, } \\
\text { personal } \\
\text { communication }\end{array}$ \\
\hline ORCHIDACEAE & $\begin{array}{l}\text { Satyrium striatum } \\
\text { Thunb. }\end{array}$ & & 1 & Whole plant & Nursery & Hand & Not listed & $\begin{array}{c}\text { Locally } \\
\text { indigenous }\end{array}$ & $\begin{array}{l}\text { Cape Town - } \\
\text { general }\end{array}$ & $\begin{array}{c}\text { Raimondo et al. } \\
\text { (2009), } \\
\text { Harvester } \\
\text { informants, } \\
\text { personal } \\
\text { communication }\end{array}$ \\
\hline DIPSACACEAE & Scabiosa columbaria $\mathbf{L}$. & & 1 & Rhizome & Medicine & Hand & $\begin{array}{c}\text { Least } \\
\text { Concern }\end{array}$ & $\begin{array}{c}\text { Locally } \\
\text { indigenous }\end{array}$ & $\begin{array}{c}\text { Table } \\
\text { Mountain } \\
\text { National } \\
\text { Park }\end{array}$ & $\begin{array}{c}\text { Nzue (2009), } \\
\text { Harvester } \\
\text { informants, } \\
\text { personal } \\
\text { communication }\end{array}$ \\
\hline CYPERACEAE & $\begin{array}{l}\text { Schoenoplectus } \\
\text { scirpoides (Schrad.) } \\
\text { Browning }\end{array}$ & Steekbesie & 1 & $\begin{array}{c}\text { Leaves / } \\
\text { stems }\end{array}$ & Fiber & Hand & $\begin{array}{l}\text { Least } \\
\text { Concern }\end{array}$ & $\begin{array}{l}\text { Locally } \\
\text { indigenous }\end{array}$ & $\begin{array}{c}\text { False Bay } \\
\text { Ecology } \\
\text { Park area }\end{array}$ & $\begin{array}{c}\text { D. Gibbs, } \\
\text { personal } \\
\text { communication }\end{array}$ \\
\hline ANACARDIACEAE & $\begin{array}{l}\text { Searsia lucida (L.) F.A. } \\
\text { Barkley forma lucida }\end{array}$ & Rhus & 1 & $\begin{array}{l}\text { Flowers / } \\
\text { foliage }\end{array}$ & $\begin{array}{l}\text { Flowers / } \\
\text { foliage }\end{array}$ & Hand & $\begin{array}{c}\text { Least } \\
\text { Concern }\end{array}$ & $\begin{array}{c}\text { Locally } \\
\text { indigenous }\end{array}$ & $\begin{array}{l}\text { Cape Town - } \\
\text { general }\end{array}$ & $\begin{array}{c}\text { C. Dorse, } \\
\text { personal } \\
\text { communication }\end{array}$ \\
\hline SCROPHULARIACEAE & Selago spp. & & 6 & Rhizome & Medicine & Hand & $\begin{array}{c}\text { Least } \\
\text { Concern }\end{array}$ & $\begin{array}{l}\text { Locally } \\
\text { indigenous }\end{array}$ & $\begin{array}{l}\text { Cape Town - } \\
\text { general }\end{array}$ & $\begin{array}{c}\text { Harvester } \\
\text { informants, } \\
\text { personal } \\
\text { communication }\end{array}$ \\
\hline PROTEACEAE & $\begin{array}{l}\text { Serruria acrocarpa } \mathbf{R} . \\
\mathbf{B r} .\end{array}$ & Spinnekopbossie & & $\begin{array}{c}\text { Flowers / } \\
\text { foliage }\end{array}$ & $\begin{array}{c}\text { Flowers / } \\
\text { foliage }\end{array}$ & Hand & $\begin{array}{c}\text { Least } \\
\text { Concern }\end{array}$ & $\begin{array}{c}\text { Locally } \\
\text { indigenous }\end{array}$ & $\begin{array}{c}\text { Table } \\
\text { Mountain }\end{array}$ & Rebelo (1996) \\
\hline
\end{tabular}




\begin{tabular}{|c|c|c|c|c|c|c|c|c|c|c|}
\hline & & & & & & & & & $\begin{array}{l}\text { National } \\
\text { Park }\end{array}$ & \\
\hline PROTEACEAE & $\begin{array}{l}\text { Serruria adscendens } \\
\text { (Lam.) R.Br. }\end{array}$ & $\begin{array}{l}\text { Kleinmond } \\
\text { spiderhead }\end{array}$ & 1 & $\begin{array}{l}\text { Flowers / } \\
\text { foliage }\end{array}$ & $\begin{array}{c}\text { Flowers / } \\
\text { foliage }\end{array}$ & Hand & $\begin{array}{c}\text { Near } \\
\text { Threatened }\end{array}$ & $\begin{array}{c}\text { Locally } \\
\text { indigenous }\end{array}$ & $\begin{array}{c}\text { Table } \\
\text { Mountain } \\
\text { National } \\
\text { Park }\end{array}$ & Rebelo (1996) \\
\hline PROTEACEAE & $\begin{array}{l}\text { Serruria fasciflora } \\
\text { Salisb. ex Knight }\end{array}$ & $\begin{array}{c}\text { Common pin } \\
\text { spiderhead }\end{array}$ & 1 & $\begin{array}{l}\text { Flowers / } \\
\text { foliage }\end{array}$ & $\begin{array}{c}\text { Flowers / } \\
\text { foliage }\end{array}$ & Hand & $\begin{array}{c}\text { Near } \\
\text { Threatened }\end{array}$ & $\begin{array}{c}\text { Locally } \\
\text { indigenous }\end{array}$ & $\begin{array}{c}\text { Table } \\
\text { Mountain } \\
\text { National } \\
\text { Park }\end{array}$ & Rebelo (1996) \\
\hline PROTEACEAE & $\begin{array}{l}\text { Serruria florida } \\
\text { (Thunb.) Salisb. ex } \\
\text { Knight }\end{array}$ & Blushing bride & 1 & $\begin{array}{l}\text { Flowers / } \\
\text { foliage }\end{array}$ & $\begin{array}{c}\text { Flowers / } \\
\text { foliage }\end{array}$ & Hand & $\begin{array}{c}\text { Critically } \\
\text { Endangered }\end{array}$ & $\begin{array}{l}\text { Locally } \\
\text { indigenous }\end{array}$ & $\begin{array}{c}\text { Table } \\
\text { Mountain } \\
\text { National } \\
\text { Park }\end{array}$ & Rebelo (1996) \\
\hline PROTEACEAE & Serruria nervosa Meisn. & Blushing bride & 1 & $\begin{array}{l}\text { Flowers / } \\
\text { foliage }\end{array}$ & $\begin{array}{c}\text { Flowers / } \\
\text { foliage }\end{array}$ & Hand & $\begin{array}{c}\text { Near } \\
\text { Threatened }\end{array}$ & $\begin{array}{l}\text { Locally } \\
\text { indigenous }\end{array}$ & $\begin{array}{c}\text { Table } \\
\text { Mountain } \\
\text { National } \\
\text { Park }\end{array}$ & Rebelo (1996) \\
\hline SOLANACEAE & $\begin{array}{l}\text { Solanum aculeastrum } \\
\text { Dun. subsp. aculeastrum }\end{array}$ & $\begin{array}{l}\text { Goat apple / } \\
\text { Bitterappel }\end{array}$ & 1 & $\begin{array}{c}\text { Flowers / } \\
\text { fruits }\end{array}$ & Medicine & Hand & $\begin{array}{c}\text { Least } \\
\text { Concern }\end{array}$ & $\begin{array}{c}\text { South Africa } \\
\text { indigenous }\end{array}$ & $\begin{array}{c}\text { Table } \\
\text { Mountain } \\
\text { National } \\
\text { Park }\end{array}$ & $\begin{array}{c}\text { Dold and Cocks } \\
\text { (2002), } \\
\text { Harvester } \\
\text { informants, } \\
\text { personal } \\
\text { communication }\end{array}$ \\
\hline SOLANACEAE & $\begin{array}{l}\text { Solanum linnaeanum } \\
\text { Hepper and Jaeger }\end{array}$ & $\begin{array}{c}\text { Bitter apple / } \\
\text { Gifappel }\end{array}$ & & Fruit / leaves & Medicine & Hand & $\begin{array}{c}\text { Least } \\
\text { Concern }\end{array}$ & $\begin{array}{c}\text { South Africa } \\
\text { indigenous }\end{array}$ & $\begin{array}{c}\text { Table } \\
\text { Mountain } \\
\text { National } \\
\text { Park } \\
\end{array}$ & $\begin{array}{c}\text { Harvester } \\
\text { informants, } \\
\text { personal } \\
\text { communication }\end{array}$ \\
\hline SOLANACEAE & $\begin{array}{l}\text { Solanum sodomaeodes } \\
\text { Kuntze }\end{array}$ & & 1 & $\begin{array}{l}\text { Flowers / } \\
\text { fruits }\end{array}$ & Medicine & Hand & $\begin{array}{c}\text { Least } \\
\text { Concern }\end{array}$ & $\begin{array}{c}\text { South Africa } \\
\text { indigenous }\end{array}$ & $\begin{array}{l}\text { Cape Town - } \\
\text { general }\end{array}$ & $\begin{array}{c}\text { Harvester } \\
\text { informants, } \\
\text { personal } \\
\text { communication }\end{array}$ \\
\hline BRUNIACEAE & $\begin{array}{l}\text { Staavia radiata }(\mathbf{L} .) \\
\text { Dahl }\end{array}$ & Altydbossie & 1 & $\begin{array}{l}\text { Flowers / } \\
\text { foliage }\end{array}$ & $\begin{array}{c}\text { Flowers / } \\
\text { foliage }\end{array}$ & Hand & $\begin{array}{c}\text { Least } \\
\text { Concern }\end{array}$ & $\begin{array}{c}\text { Locally } \\
\text { indigenous }\end{array}$ & $\begin{array}{c}\text { Atlantis } \\
\text { Conservation } \\
\text { Area } \\
\end{array}$ & $\begin{array}{c}\text { C. Dorse, } \\
\text { personal } \\
\text { communication }\end{array}$ \\
\hline POACEAE & $\begin{array}{l}\text { Stenotaphrum } \\
\text { secundatum (Walt.) } \\
\text { Kuntze }\end{array}$ & $\begin{array}{c}\text { Buffalo grass / } \\
\text { Cape Kweek } \\
\text { grass } \\
\end{array}$ & 1 & Whole plant & Nursery & Hand & Not listed & $\begin{array}{l}\text { Locally } \\
\text { indigenous }\end{array}$ & $\begin{array}{c}\text { False Bay } \\
\text { Ecology } \\
\text { Park area } \\
\end{array}$ & $\begin{array}{c}\text { C. Dorse, } \\
\text { personal } \\
\text { communication } \\
\end{array}$ \\
\hline THYMELAEACEAE & $\begin{array}{l}\text { Struthiola leptantha } \\
\text { Bolus }\end{array}$ & & 1 & Bark & Medicine & Hand & Not listed & $\begin{array}{c}\text { Locally } \\
\text { indigenous }\end{array}$ & $\begin{array}{c}\text { Atlantis } \\
\text { Conservation } \\
\text { Area }\end{array}$ & $\begin{array}{c}\text { T. Abrahams } \\
\text { and C. McKie, } \\
\text { personal } \\
\text { communication }\end{array}$ \\
\hline ASTERACEAE & $\begin{array}{l}\text { Syncarpha vestita (L.) } \\
\text { B.Nord. }\end{array}$ & $\begin{array}{l}\text { Cape snow / } \\
\text { Sewejaartjie }\end{array}$ & 1 & $\begin{array}{c}\text { Flowers / } \\
\text { foliage }\end{array}$ & $\begin{array}{c}\text { Flowers / } \\
\text { foliage }\end{array}$ & Hand & $\begin{array}{c}\text { Least } \\
\text { Concern }\end{array}$ & $\begin{array}{l}\text { Locally } \\
\text { indigenous }\end{array}$ & $\begin{array}{c}\text { Table } \\
\text { Mountain } \\
\text { National } \\
\text { Park }\end{array}$ & $\begin{array}{c}\text { Raimondo et al } \\
\text { (2009), } \\
\text { Harvester } \\
\text { informants, } \\
\text { personal } \\
\text { communication }\end{array}$ \\
\hline RESTIONACEAE & $\begin{array}{l}\text { Thamnochortus erectus } \\
\text { (Thunb.) Mast. }\end{array}$ & $\begin{array}{c}\text { Dekriet/ } \\
\text { Jakkalstert }\end{array}$ & 1 & Leaves & $\begin{array}{c}\text { Flowers / } \\
\text { foliage / } \\
\text { Fiber }\end{array}$ & Hand & $\begin{array}{c}\text { Least } \\
\text { Concern }\end{array}$ & $\begin{array}{c}\text { Locally } \\
\text { indigenous }\end{array}$ & $\begin{array}{l}\text { Cape Town - } \\
\text { general }\end{array}$ & $\begin{array}{c}\text { Campbell } \\
\text { (2006), } \\
\text { Harvester } \\
\text { informants, } \\
\text { personal } \\
\text { communication }\end{array}$ \\
\hline RESTIONACEAE & $\begin{array}{l}\text { Thamnochortus } \\
\text { fruticosus } \mathbf{P} . J . \text { Berguis }\end{array}$ & Besemriet & 1 & Leaves & $\begin{array}{c}\text { Flowers / } \\
\text { foliage / } \\
\text { Fiber } \\
\end{array}$ & Hand & $\begin{array}{c}\text { Least } \\
\text { Concern }\end{array}$ & $\begin{array}{l}\text { Locally } \\
\text { indigenous }\end{array}$ & $\begin{array}{l}\text { Cape Town - } \\
\text { general }\end{array}$ & $\begin{array}{c}\text { S. Lindane, } \\
\text { personal } \\
\text { communication }\end{array}$ \\
\hline RESTIONACEAE & $\begin{array}{l}\text { Thamnochortus insignis } \\
\text { Mast. }\end{array}$ & Dekriet & 1 & Leaves & $\begin{array}{c}\text { Flowers / } \\
\text { foliage / } \\
\text { Fiber }\end{array}$ & Hand & $\begin{array}{c}\text { Least } \\
\text { Concern }\end{array}$ & $\begin{array}{c}\text { Locally } \\
\text { indigenous }\end{array}$ & $\begin{array}{l}\text { Cape Town - } \\
\text { general }\end{array}$ & $\begin{array}{c}\text { Campbell } \\
\text { (2006), } \\
\text { Harvester } \\
\text { informants, } \\
\text { personal } \\
\text { communication }\end{array}$ \\
\hline RESTIONACEAE & $\begin{array}{l}\text { Thamnochortus } \\
\text { spicigerus (Thunb.) } \\
\text { Spreng. }\end{array}$ & Dekriet & 1 & Leaves & $\begin{array}{c}\text { Flowers / } \\
\text { foliage / } \\
\text { Fiber }\end{array}$ & Hand & $\begin{array}{c}\text { Least } \\
\text { Concern }\end{array}$ & $\begin{array}{l}\text { Locally } \\
\text { indigenous }\end{array}$ & $\begin{array}{c}\text { Atlantis } \\
\text { Conservation } \\
\text { Area }\end{array}$ & $\begin{array}{c}\text { T. Abrahams } \\
\text { and C. McKie, } \\
\text { personal } \\
\text { communication }\end{array}$ \\
\hline IRIDACEAE & Tritonia sp. & Bergkatjietee & 1 & Bulb & Medicine & Hand & $\begin{array}{c}\text { Least } \\
\text { Concern }\end{array}$ & $\begin{array}{l}\text { Locally } \\
\text { indigenous }\end{array}$ & $\begin{array}{l}\text { Tygerberg } \\
\text { Nature } \\
\text { Reserve }\end{array}$ & $\begin{array}{l}\text { P. Glanville, } \\
\text { personal } \\
\text { communication }\end{array}$ \\
\hline
\end{tabular}




\begin{tabular}{|c|c|c|c|c|c|c|c|c|c|c|}
\hline ALLIACEAE & Tulbaghia capensis $\mathbf{L}$. & $\begin{array}{l}\text { Wild garlic / } \\
\text { Wilde Knoffel }\end{array}$ & 1 & Rhizome & Medicine & Hand & $\begin{array}{c}\text { Least } \\
\text { Concern }\end{array}$ & $\begin{array}{l}\text { Locally } \\
\text { indigenous }\end{array}$ & $\begin{array}{c}\text { Tygerberg } \\
\text { Nature } \\
\text { Reserve }\end{array}$ & $\begin{array}{c}\text { P. Glanville, } \\
\text { personal } \\
\text { communication }\end{array}$ \\
\hline UNIDENTIFIED & Unidentified & Bitterpatat & 1 & Tuber & Medicine & Hand & Not listed & $\begin{array}{l}\text { Locally } \\
\text { indigenous }\end{array}$ & $\begin{array}{l}\text { Cape Town - } \\
\text { general }\end{array}$ & $\begin{array}{c}\text { Nzue (2009), } \\
\text { Harvester } \\
\text { informants, } \\
\text { personal } \\
\text { communication }\end{array}$ \\
\hline VISCACEAE & Viscum capense $\mathbf{L}$. f. & $\begin{array}{c}\text { Cape mistletoe / } \\
\text { Voëlent }\end{array}$ & 1 & Stems & Medicine & Hand & $\begin{array}{l}\text { Least } \\
\text { Concern }\end{array}$ & $\begin{array}{l}\text { Locally } \\
\text { indigenous }\end{array}$ & $\begin{array}{c}\text { Table } \\
\text { Mountain } \\
\text { National } \\
\text { Park }\end{array}$ & $\begin{array}{c}\text { Nzue } \\
\text { (2009),Harvester } \\
\text { informants, } \\
\text { personal } \\
\text { communication }\end{array}$ \\
\hline IRIDACEAE & $\begin{array}{l}\text { Watsonia meriana }(\mathbf{L} .) \\
\text { Mill. Var. meriana }\end{array}$ & Pypie & & Flowers/bulb & $\begin{array}{l}\text { Flowers / } \\
\text { foliage }\end{array}$ & Hand & $\begin{array}{c}\text { Least } \\
\text { Concern }\end{array}$ & $\begin{array}{l}\text { Locally } \\
\text { indigenous }\end{array}$ & $\begin{array}{c}\text { False Bay } \\
\text { Ecology } \\
\text { Park area }\end{array}$ & $\begin{array}{c}\text { D. Gibbs, } \\
\text { personal } \\
\text { communication }\end{array}$ \\
\hline IRIDACEAE & Watsonia spp. & & 3 & Rhizome & Medicine & Hand & $\begin{array}{c}\text { Least } \\
\text { Concern }\end{array}$ & $\begin{array}{l}\text { Locally } \\
\text { indigenous }\end{array}$ & $\begin{array}{l}\text { Cape Town } \\
\text { general }\end{array}$ & $\begin{array}{c}\text { Harvester } \\
\text { informants, } \\
\text { personal } \\
\text { communication }\end{array}$ \\
\hline ARACEAE & $\begin{array}{l}\text { Zantedeschia aethiopica } \\
\text { L. }\end{array}$ & $\begin{array}{c}\text { White or } \\
\text { common arum } \\
\text { lily / Wit varkoor }\end{array}$ & 1 & $\begin{array}{l}\text { Flowers / } \\
\text { foliage }\end{array}$ & $\begin{array}{l}\text { Flowers / } \\
\text { foliage }\end{array}$ & Hand & $\begin{array}{c}\text { Least } \\
\text { Concern }\end{array}$ & $\begin{array}{c}\text { Locally } \\
\text { indigenous }\end{array}$ & $\begin{array}{c}\text { Atlantis } \\
\text { Conservation } \\
\text { Area }\end{array}$ & $\begin{array}{l}\text { T. Abrahams } \\
\text { and C. McKie, } \\
\text { personal } \\
\text { communication }\end{array}$ \\
\hline
\end{tabular}


Apppendix 2. The totality of locally collected fauna species from within the City of Cape Town and related information.

\begin{tabular}{|c|c|c|c|c|c|c|c|c|c|}
\hline Class & Scientific Name & $\begin{array}{l}\text { Common } \\
\text { Names } \\
\text { (English / } \\
\text { Afrikaans) }\end{array}$ & $\begin{array}{c}\text { N Harvest } \\
\text { target }\end{array}$ & $\begin{array}{l}\text { Common } \\
\text { usage }\end{array}$ & & $\begin{array}{c}\text { Red List } \\
\text { status }\end{array}$ & Indigenous-ness & Source & References \\
\hline Aves & $\begin{array}{c}\text { Alpochen } \\
\text { aegyptiaca }\end{array}$ & $\begin{array}{l}\text { Egyptian } \\
\text { goose }\end{array}$ & 1 Animal & $\begin{array}{l}\text { Food } \\
\text { source }\end{array}$ & $\begin{array}{l}\text { Trap / } \\
\text { snare }\end{array}$ & $\begin{array}{c}\text { Least } \\
\text { Concern }\end{array}$ & $\begin{array}{c}\text { Locally } \\
\text { indigenous }\end{array}$ & $\begin{array}{c}\text { Cape Town } \\
\text { general }\end{array}$ & $\begin{array}{c}\text { L. Isaacs, } \\
\text { personal } \\
\text { communication }\end{array}$ \\
\hline Reptilia & $\begin{array}{c}\text { Amplorhinus } \\
\text { multimaculatus }\end{array}$ & $\begin{array}{l}\text { Many spotted } \\
\text { snake }\end{array}$ & 1 Animal & Medicine & Hand & Not listed & $\begin{array}{c}\text { Locally } \\
\text { indigenous }\end{array}$ & $\begin{array}{c}\text { Cape Town } \\
\text { general }\end{array}$ & $\begin{array}{c}\text { Harvester } \\
\text { informants, } \\
\text { personal } \\
\text { communication }\end{array}$ \\
\hline Aves & Anas capensis & Cape teal & 1 Animal & $\begin{array}{l}\text { Food } \\
\text { source }\end{array}$ & $\begin{array}{l}\text { Trap / } \\
\text { snare }\end{array}$ & $\begin{array}{c}\text { Least } \\
\text { Concern }\end{array}$ & $\begin{array}{c}\text { Locally } \\
\text { indigenous }\end{array}$ & $\begin{array}{c}\text { All } \\
\text { waterways }\end{array}$ & $\begin{array}{c}\text { L. Isaacs, } \\
\text { personal } \\
\text { communication }\end{array}$ \\
\hline Aves & $\begin{array}{c}\text { Anas } \\
\text { erythrorhyncha }\end{array}$ & $\begin{array}{l}\text { Red-billed } \\
\text { teal }\end{array}$ & 1 Animal & $\begin{array}{l}\text { Food } \\
\text { source }\end{array}$ & $\begin{array}{l}\text { Trap / } \\
\text { snare }\end{array}$ & $\begin{array}{c}\text { Least } \\
\text { Concern }\end{array}$ & $\begin{array}{c}\text { Locally } \\
\text { indigenous }\end{array}$ & $\begin{array}{c}\text { All } \\
\text { waterways }\end{array}$ & $\begin{array}{c}\text { L. Isaacs, } \\
\text { personal } \\
\text { communication } \\
\end{array}$ \\
\hline Aves & $\begin{array}{c}\text { Anas } \\
\text { platyrhynchos }\end{array}$ & Mallard & 1 Animal & $\begin{array}{l}\text { Food } \\
\text { source }\end{array}$ & $\begin{array}{l}\text { Trap / } \\
\text { snare }\end{array}$ & $\begin{array}{c}\text { Least } \\
\text { Concern }\end{array}$ & $\begin{array}{c}\text { Locally } \\
\text { indigenous }\end{array}$ & $\begin{array}{c}\text { All } \\
\text { waterways }\end{array}$ & $\begin{array}{c}\text { L. Isaacs, } \\
\text { personal } \\
\text { communication }\end{array}$ \\
\hline Aves & Anas smithii & $\begin{array}{c}\text { Cape } \\
\text { shoveller }\end{array}$ & 1 Animal & $\begin{array}{l}\text { Food } \\
\text { source }\end{array}$ & $\begin{array}{l}\text { Trap / } \\
\text { snare }\end{array}$ & $\begin{array}{c}\text { Least } \\
\text { Concern }\end{array}$ & $\begin{array}{l}\text { Locally } \\
\text { indigenous }\end{array}$ & $\begin{array}{c}\text { All } \\
\text { waterways }\end{array}$ & $\begin{array}{c}\text { L. Isaacs, } \\
\text { personal } \\
\text { communication }\end{array}$ \\
\hline Aves & Anas sparsa & $\begin{array}{c}\text { African black } \\
\text { duck }\end{array}$ & 1 Animal & $\begin{array}{l}\text { Food } \\
\text { source }\end{array}$ & $\begin{array}{l}\text { Trap / } \\
\text { snare }\end{array}$ & $\begin{array}{c}\text { Least } \\
\text { Concern }\end{array}$ & $\begin{array}{c}\text { Locally } \\
\text { indigenous }\end{array}$ & $\begin{array}{c}\text { All } \\
\text { waterways }\end{array}$ & $\begin{array}{c}\text { L. Isaacs, } \\
\text { personal } \\
\text { communication }\end{array}$ \\
\hline Aves & Anas undulata & $\begin{array}{c}\text { Yellow-billed } \\
\text { duck }\end{array}$ & 1 Animal & $\begin{array}{l}\text { Food } \\
\text { source }\end{array}$ & $\begin{array}{l}\text { Trap / } \\
\text { snare }\end{array}$ & $\begin{array}{c}\text { Least } \\
\text { Concern }\end{array}$ & $\begin{array}{c}\text { Locally } \\
\text { indigenous }\end{array}$ & $\begin{array}{c}\text { All } \\
\text { waterways }\end{array}$ & $\begin{array}{c}\text { L. Isaacs, } \\
\text { personal } \\
\text { communication } \\
\end{array}$ \\
\hline Mammalia & $\begin{array}{c}\text { Arctocephalus } \\
\text { pusillus }\end{array}$ & Cape fur seal & 1 Animal & Medicine & Hand & $\begin{array}{c}\text { Least } \\
\text { Concern }\end{array}$ & $\begin{array}{c}\text { Locally } \\
\text { indigenous }\end{array}$ & $\begin{array}{c}\text { Macassar / } \\
\text { Wolfgat } \\
\text { Nature } \\
\text { Reserve }\end{array}$ & $\begin{array}{c}\text { H. Mananga, } \\
\text { personal } \\
\text { communication }\end{array}$ \\
\hline Polychaeta & Arenicola loveni & Bloodworm & 1 Animal & Bait & Pump & Not listed & $\begin{array}{c}\text { Locally } \\
\text { indigenous }\end{array}$ & $\begin{array}{c}\text { Muizenberg } \\
\text { shoreline }\end{array}$ & $\begin{array}{c}\text { Harvester } \\
\text { informants, } \\
\text { personal } \\
\text { communication } \\
\end{array}$ \\
\hline Osteichthyes & Argyrosomus spp. & Kob & 1 Animal & $\begin{array}{l}\text { Food } \\
\text { source }\end{array}$ & Boat & Not listed & $\begin{array}{l}\text { Locally } \\
\text { indigenous }\end{array}$ & $\begin{array}{l}\text { False Bay } \\
\text { Coastline } \\
(\mathrm{TMNP})\end{array}$ & $\begin{array}{c}\text { Harvester } \\
\text { informants, } \\
\text { personal } \\
\text { communication }\end{array}$ \\
\hline Mammalia & Bathyergus suillus & $\begin{array}{c}\text { Cape dune } \\
\text { molerat }\end{array}$ & 1 Animal & $\begin{array}{c}\text { Food } \\
\text { source }\end{array}$ & $\begin{array}{c}\text { Trap / } \\
\text { snare / } \\
\text { dog }\end{array}$ & $\begin{array}{c}\text { Least } \\
\text { Concern }\end{array}$ & $\begin{array}{c}\text { Locally } \\
\text { indigenous }\end{array}$ & $\begin{array}{c}\text { Cape Town } \\
\text { general }\end{array}$ & $\begin{array}{c}\text { Harvester } \\
\text { informants, } \\
\text { personal } \\
\text { communication }\end{array}$ \\
\hline Reptilia & Bitis arietans & Puff adder & 1 Animal & Medicine & Hand & Not listed & $\begin{array}{c}\text { Locally } \\
\text { indigenous }\end{array}$ & $\begin{array}{c}\text { Cape Town } \\
\text { general }\end{array}$ & $\begin{array}{c}\text { Harvester } \\
\text { informants, } \\
\text { personal } \\
\text { communication } \\
\end{array}$ \\
\hline Reptilia & Bitis atropos & Berg adder & 1 Animal & Medicine & Hand & $\begin{array}{c}\text { Least } \\
\text { Concern }\end{array}$ & $\begin{array}{c}\text { Locally } \\
\text { indigenous }\end{array}$ & $\begin{array}{c}\text { Cape Town } \\
\text { general }\end{array}$ & $\begin{array}{c}\text { Harvester } \\
\text { informants, } \\
\text { personal } \\
\text { communication }\end{array}$ \\
\hline
\end{tabular}




\begin{tabular}{|c|c|c|c|c|c|c|c|c|c|}
\hline Reptilia & $\begin{array}{l}\text { Bradypodion } \\
\text { pumilum }\end{array}$ & $\begin{array}{l}\text { Cape dwarf } \\
\text { chameleon }\end{array}$ & 1 Animal & $\begin{array}{l}\text { Medicine } \\
\text { / } \\
\text { Gambling } \\
\text { / Sport / } \\
\text { Pet trade }\end{array}$ & Hand & Not listed & $\begin{array}{c}\text { Locally } \\
\text { indigenous }\end{array}$ & $\begin{array}{c}\text { Cape Town } \\
\text { general }\end{array}$ & $\begin{array}{c}\text { C. Dorse, } \\
\text { personal } \\
\text { communication }\end{array}$ \\
\hline Gastropoda & Bullia spp. & Plough shells & 5 Animal & $\begin{array}{c}\text { Food } \\
\text { source / } \\
\text { Bait }\end{array}$ & Hand & Not listed & $\begin{array}{l}\text { Locally } \\
\text { indigenous }\end{array}$ & $\begin{array}{l}\text { False Bay } \\
\text { Coastline } \\
\text { (TMNP) }\end{array}$ & $\begin{array}{c}\text { Harvester } \\
\text { informants, } \\
\text { personal } \\
\text { communication }\end{array}$ \\
\hline Insecta & Butterflies & all species & 5 Animal & $\begin{array}{l}\text { Pet trade / } \\
\text { collectors }\end{array}$ & Net & Listed & $\begin{array}{l}\text { Locally } \\
\text { indigenous }\end{array}$ & $\begin{array}{c}\text { Table } \\
\text { Mountain } \\
\text { National } \\
\text { Park } \\
\end{array}$ & $\begin{array}{c}\text { Harvester } \\
\text { informants, } \\
\text { personal } \\
\text { communication }\end{array}$ \\
\hline Insecta & Butterflies & all species & 29 Animal & $\begin{array}{l}\text { Pet trade / } \\
\text { collectors }\end{array}$ & Net & Not listed & $\begin{array}{l}\text { Locally } \\
\text { indigenous }\end{array}$ & $\begin{array}{c}\text { Table } \\
\text { Mountain } \\
\text { National } \\
\text { Park }\end{array}$ & $\begin{array}{c}\text { CoCT / } \\
\text { Geertsema } \\
(2004)\end{array}$ \\
\hline Crustacea & $\begin{array}{c}\text { Callianassa } \\
\text { kraussi }\end{array}$ & $\begin{array}{l}\text { Estuarine } \\
\text { mudprawn } \\
\text { /African } \\
\text { sandprawn }\end{array}$ & 1 Animal & Bait & Pump & Not listed & $\begin{array}{c}\text { Locally } \\
\text { indigenous }\end{array}$ & $\begin{array}{l}\text { Zandvlei } \\
\text { Estuary }\end{array}$ & $\begin{array}{c}\text { Harvester } \\
\text { informants, } \\
\text { personal } \\
\text { communication }\end{array}$ \\
\hline Reptilia & $\begin{array}{l}\text { Chersina } \\
\text { angulata }\end{array}$ & $\begin{array}{l}\text { Angulate } \\
\text { tortoise }\end{array}$ & 1 Animal & $\begin{array}{l}\text { Medicine } \\
\text { / Pet trade } \\
\text { / } \\
\text { Collectors }\end{array}$ & Hand & Not listed & $\begin{array}{c}\text { Locally } \\
\text { indigenous }\end{array}$ & $\begin{array}{c}\text { Macassar / } \\
\text { Wolfgat } \\
\text { Nature } \\
\text { Reserve } \\
\end{array}$ & $\begin{array}{c}\text { H. Mananga, } \\
\text { personal } \\
\text { communication }\end{array}$ \\
\hline Pteriomorphia & Choromytilus spp. & Black mussel & 5 Animal & $\begin{array}{c}\text { Food } \\
\text { source / } \\
\text { Bait }\end{array}$ & Hand & Not listed & $\begin{array}{l}\text { Locally } \\
\text { indigenous }\end{array}$ & $\begin{array}{l}\text { False Bay } \\
\text { Coastline } \\
\text { (TMNP) }\end{array}$ & $\begin{array}{c}\text { Marine and } \\
\text { Coastal } \\
\text { Management } \\
\text { (2008), } \\
\text { Harvester } \\
\text { informants, } \\
\text { personal } \\
\text { communication }\end{array}$ \\
\hline Osteichthyes & $\begin{array}{c}\text { Chrysoblephus } \\
\text { cristiceps }\end{array}$ & Dageraad & 1 Animal & $\begin{array}{c}\text { Food } \\
\text { source }\end{array}$ & Net & Not & $\begin{array}{c}\text { Locally } \\
\text { indigenous }\end{array}$ & $\begin{array}{l}\text { False Bay } \\
\text { Coastline } \\
\text { (TMNP) }\end{array}$ & $\begin{array}{c}\text { Harvester } \\
\text { informants, } \\
\text { personal } \\
\text { communication }\end{array}$ \\
\hline Osteichthyes & $\begin{array}{l}\text { Chrysoblephus } \\
\text { gibbiceps }\end{array}$ & $\begin{array}{c}\text { Red } \\
\text { stumpnose / } \\
\text { Miss Lucy }\end{array}$ & 1 Animal & $\begin{array}{c}\text { Food } \\
\text { source }\end{array}$ & Net & Not listed & $\begin{array}{l}\text { Locally } \\
\text { indigenous }\end{array}$ & $\begin{array}{l}\text { False Bay } \\
\text { Coastline } \\
\text { (TMNP) }\end{array}$ & $\begin{array}{c}\text { Harvester } \\
\text { informants, } \\
\text { personal } \\
\text { communication }\end{array}$ \\
\hline Insecta & Colophon beetles & all species & 2 Animal & $\begin{array}{l}\text { Pet trade / } \\
\text { collectors }\end{array}$ & Hand & Endangered & $\begin{array}{l}\text { Locally } \\
\text { indigenous }\end{array}$ & $\begin{array}{c}\text { Table } \\
\text { Mountain } \\
\text { National } \\
\text { Park }\end{array}$ & $\begin{array}{c}\text { C. Dorse, } \\
\text { personal } \\
\text { communication }\end{array}$ \\
\hline Reptilia & $\begin{array}{c}\text { Crotaphopeltis } \\
\text { hotamboeia }\end{array}$ & Herald snake & 1 Anima & $\begin{array}{l}\text { Medicine } \\
\text { / Pet trade } \\
\text { / } \\
\text { Collectors }\end{array}$ & Hand & Not listed & $\begin{array}{l}\text { Locally } \\
\text { indigenous }\end{array}$ & $\begin{array}{c}\text { Cape Town } \\
\text { general }\end{array}$ & $\begin{array}{c}\text { Harvester } \\
\text { informants, } \\
\text { personal } \\
\text { communication }\end{array}$ \\
\hline Osteichthyes & Cyprinus carpio & Common carp & 1 Animal & $\begin{array}{c}\text { Food } \\
\text { source }\end{array}$ & Hand & Vulnerable & $\begin{array}{c}\text { Alien to South } \\
\text { Africa }\end{array}$ & $\begin{array}{c}\text { All } \\
\text { waterways }\end{array}$ & $\begin{array}{c}\text { D. Gibbs, } \\
\text { personal } \\
\text { communication }\end{array}$ \\
\hline Reptilia & Dasypeltis scabra & $\begin{array}{l}\text { Rhombic egg } \\
\text { eater }\end{array}$ & 1 Anim & $\begin{array}{l}\text { Medicine } \\
\text { / Pet trade } \\
\text { / } \\
\text { Collectors }\end{array}$ & Hand & $\begin{array}{l}\text { Least } \\
\text { Concern }\end{array}$ & $\begin{array}{c}\text { Locally } \\
\text { indigenous }\end{array}$ & $\begin{array}{l}\text { Cape Town } \\
\text { general }\end{array}$ & $\begin{array}{c}\text { Harvester } \\
\text { informants, } \\
\text { personal } \\
\text { communication }\end{array}$ \\
\hline
\end{tabular}




\begin{tabular}{|c|c|c|c|c|c|c|c|c|c|}
\hline Osteichthyes & $\begin{array}{c}\text { Dichistius } \\
\text { capensis }\end{array}$ & Galjoen & 1 Animal & $\begin{array}{c}\text { Food } \\
\text { source }\end{array}$ & Net & Not listed & $\begin{array}{c}\text { Locally } \\
\text { indigenous }\end{array}$ & $\begin{array}{l}\text { False Bay } \\
\text { Coastline } \\
(\mathrm{TMNP})\end{array}$ & $\begin{array}{c}\text { Harvester } \\
\text { informants, } \\
\text { personal } \\
\text { communication }\end{array}$ \\
\hline Polyplacophora & Dinoplax gigas & $\begin{array}{c}\text { Larger chiton, } \\
\text { Giant chiton } \\
\text { or Armadillo }\end{array}$ & , 11 Animal & $\begin{array}{c}\text { Food } \\
\text { source / } \\
\text { Bait }\end{array}$ & Hand & Not listed & $\begin{array}{c}\text { Locally } \\
\text { indigenous }\end{array}$ & $\begin{array}{l}\text { False Bay } \\
\text { Coastline } \\
(\mathrm{TMNP})\end{array}$ & $\begin{array}{c}\text { Harvester } \\
\text { informants, } \\
\text { personal } \\
\text { communication }\end{array}$ \\
\hline Reptilia & Dispholidus typus & s Boomslang & 1 Animal & Medicine & Hand & Not listed & $\begin{array}{c}\text { Locally } \\
\text { indigenous }\end{array}$ & $\begin{array}{l}\text { Cape Town } \\
\text { general }\end{array}$ & $\begin{array}{c}\text { Harvester } \\
\text { informants, } \\
\text { personal } \\
\text { communication }\end{array}$ \\
\hline Bivalvia & Donax serra & $\begin{array}{l}\text { White mussel } \\
\text { / Sand mussel }\end{array}$ & 3 Animal & $\begin{array}{c}\text { Food } \\
\text { source }\end{array}$ & Hand & Not listed & $\begin{array}{c}\text { Locally } \\
\text { indigenous }\end{array}$ & $\begin{array}{c}\text { Muizenberg } \\
\text { shoreline }\end{array}$ & $\begin{array}{c}\text { D. Gibbs, } \\
\text { personal } \\
\text { communication }\end{array}$ \\
\hline Reptilia & Duberria lutrix & $\begin{array}{c}\text { Common slug } \\
\text { eater }\end{array}$ & 1 Anima & $\begin{array}{l}\text { Medicine } \\
\text { / Pet trade } \\
\text { Collectors }\end{array}$ & Hand & $\begin{array}{c}\text { Least } \\
\text { Concern }\end{array}$ & $\begin{array}{c}\text { Locally } \\
\text { indigenous }\end{array}$ & $\begin{array}{l}\text { Cape Town } \\
\text { general }\end{array}$ & $\begin{array}{c}\text { Harvester } \\
\text { informants, } \\
\text { personal } \\
\text { communication }\end{array}$ \\
\hline Aves & Estrilda astrild & $\begin{array}{c}\text { Common } \\
\text { waxbill }\end{array}$ & 1 Animal & $\begin{array}{l}\text { Pet trade / } \\
\text { collectors }\end{array}$ & Net & $\begin{array}{c}\text { Least } \\
\text { Concern }\end{array}$ & $\begin{array}{c}\text { Locally } \\
\text { indigenous }\end{array}$ & $\begin{array}{l}\text { Cape Town } \\
\text { general }\end{array}$ & $\begin{array}{c}\text { D. Gibbs, } \\
\text { personal } \\
\text { communication }\end{array}$ \\
\hline Mammalia & Felis caracal & $\begin{array}{l}\text { Caracal / } \\
\text { Rooicat }\end{array}$ & 1 Animal & $\begin{array}{l}\text { Gambling } \\
\text { / sport }\end{array}$ & $\begin{array}{c}\text { Trap / } \\
\text { snare / } \\
\operatorname{dog}\end{array}$ & Not listed & $\begin{array}{c}\text { Locally } \\
\text { indigenous }\end{array}$ & $\begin{array}{l}\text { Cape Town } \\
\text { general }\end{array}$ & $\begin{array}{c}\text { C. Dorse, } \\
\text { personal } \\
\text { communication }\end{array}$ \\
\hline Aves & Fulica cristata & $\begin{array}{c}\text { Red-knobbed } \\
\text { coot or } \\
\text { Crested coot }\end{array}$ & 1 Animal & $\begin{array}{c}\text { Food } \\
\text { source }\end{array}$ & $\begin{array}{l}\text { Trap / } \\
\text { snare }\end{array}$ & $\begin{array}{l}\text { Least } \\
\text { Concern }\end{array}$ & $\begin{array}{c}\text { Locally } \\
\text { indigenous }\end{array}$ & $\begin{array}{c}\text { All } \\
\text { waterways }\end{array}$ & $\begin{array}{c}\text { L. Isaacs, } \\
\text { personal } \\
\text { communication }\end{array}$ \\
\hline Gastropoda & Haliotis midae & Abalone & 1 Animal & $\begin{array}{c}\text { Food } \\
\text { source / } \\
\text { Medicine }\end{array}$ & Boat & Not listed & $\begin{array}{c}\text { Locally } \\
\text { indigenous }\end{array}$ & Coastline & $\begin{array}{c}\text { Harvester } \\
\text { informants, } \\
\text { personal } \\
\text { communication }\end{array}$ \\
\hline Arachnida & $\begin{array}{c}\text { Harpactira } \\
\text { lightfooti }\end{array}$ & $\begin{array}{l}\text { Baboon } \\
\text { spiders }\end{array}$ & 1 Animal & $\begin{array}{l}\text { Pet trade / } \\
\text { collectors }\end{array}$ & Hand & Not listed & $\begin{array}{c}\text { Locally } \\
\text { indigenous }\end{array}$ & $\begin{array}{c}\text { Table } \\
\text { Mountain } \\
\text { National } \\
\text { Park }\end{array}$ & $\begin{array}{c}\text { C. Dorse, } \\
\text { personal } \\
\text { communication }\end{array}$ \\
\hline Gastropoda & Hipponix conicus & Hoof limpets & 1 Animal & $\begin{array}{l}\text { Food } \\
\text { source / } \\
\text { Bait }\end{array}$ & Hand & Not listed & $\begin{array}{c}\text { Locally } \\
\text { indigenous }\end{array}$ & $\begin{array}{l}\text { False Bay } \\
\text { Coastline } \\
\text { (TMNP) }\end{array}$ & $\begin{array}{c}\text { Harvester } \\
\text { informants, } \\
\text { personal } \\
\text { communication }\end{array}$ \\
\hline Reptilia & $\begin{array}{l}\text { Homopus } \\
\text { areolatus }\end{array}$ & $\begin{array}{c}\text { Parrotbeaked } \\
\text { tortoise }\end{array}$ & 1 Anima & $\begin{array}{l}\text { Medicine } \\
\text { / Pet trade } \\
\text { Collectors }\end{array}$ & Hand & Not listed & $\begin{array}{c}\text { Locally } \\
\text { indigenous }\end{array}$ & $\begin{array}{c}\text { Kenilworth } \\
\text { Racecourse } \\
\text { Conservation } \\
\text { Area } \\
\end{array}$ & $\begin{array}{c}\text { M. Beukes, } \\
\text { personal } \\
\text { n communication }\end{array}$ \\
\hline Reptilia & $\begin{array}{c}\text { Homoroselaps } \\
\text { lacteus }\end{array}$ & $\begin{array}{l}\text { Spotted } \\
\text { harlequin } \\
\text { snake }\end{array}$ & 1 Animal & $\begin{array}{l}\text { Medicine } \\
\text { / Pet trade } \\
\text { / } \\
\text { Collectors }\end{array}$ & Hand & Not listed & $\begin{array}{c}\text { Locally } \\
\text { indigenous }\end{array}$ & $\begin{array}{l}\text { Cape Town } \\
\text { general }\end{array}$ & $\begin{array}{c}\text { Harvester } \\
\text { informants, } \\
\text { personal } \\
\text { communication }\end{array}$ \\
\hline Mammalia & $\begin{array}{c}\text { Hystrix } \\
\text { africaeaustralis }\end{array}$ & $\begin{array}{c}\text { Cape } \\
\text { porcupine }\end{array}$ & 1 Animal & $\begin{array}{c}\text { Food } \\
\text { source }\end{array}$ & $\begin{array}{l}\text { Trap / } \\
\text { snare }\end{array}$ & $\begin{array}{l}\text { Least } \\
\text { Concern }\end{array}$ & $\begin{array}{c}\text { Locally } \\
\text { indigenous }\end{array}$ & $\begin{array}{l}\text { Cape Town } \\
\text { general }\end{array}$ & $\begin{array}{c}\text { H. Mananga, } \\
\text { personal } \\
\text { communication }\end{array}$ \\
\hline Malacostraca & Jasus lalandii & $\begin{array}{l}\text { West Coast } \\
\text { rock lobster }\end{array}$ & 1 Animal & $\begin{array}{c}\text { Food } \\
\text { source }\end{array}$ & Boat & Not listed & $\begin{array}{c}\text { Locally } \\
\text { indigenous }\end{array}$ & Coastline & $\begin{array}{c}\text { Marine and } \\
\text { Coastal } \\
\text { Management } \\
(2008), \\
\text { Harvester } \\
\text { informants, }\end{array}$ \\
\hline
\end{tabular}




\begin{tabular}{|c|c|c|c|c|c|c|c|c|c|}
\hline & & & & & & & & & $\begin{array}{c}\text { personal } \\
\text { communication }\end{array}$ \\
\hline Reptilia & $\begin{array}{l}\text { Lamprophis } \\
\text { aurora }\end{array}$ & $\begin{array}{c}\text { Aurora house } \\
\text { snake }\end{array}$ & 1 Animal & $\begin{array}{l}\text { Medicine } \\
\text { / Pet trade } \\
\text { / } \\
\text { Collectors }\end{array}$ & Hand & $\begin{array}{c}\text { Least } \\
\text { Concern }\end{array}$ & $\begin{array}{c}\text { Locally } \\
\text { indigenous }\end{array}$ & $\begin{array}{c}\text { Cape Town } \\
\text { general }\end{array}$ & $\begin{array}{c}\text { Harvester } \\
\text { informants, } \\
\text { personal } \\
\text { communication }\end{array}$ \\
\hline Reptilia & $\begin{array}{c}\text { Lamprophis } \\
\text { capensis }\end{array}$ & $\begin{array}{c}\text { Brown house } \\
\text { snake }\end{array}$ & 1 Animal & $\begin{array}{l}\text { Medicine } \\
\text { / Pet trade } \\
\text { / } \\
\text { Collectors }\end{array}$ & Hand & Not listed & $\begin{array}{l}\text { Locally } \\
\text { indigenous }\end{array}$ & $\begin{array}{c}\text { Cape Town } \\
\text { general }\end{array}$ & $\begin{array}{c}\text { Harvester } \\
\text { informants, } \\
\text { personal } \\
\text { communication }\end{array}$ \\
\hline Reptilia & $\begin{array}{l}\text { Lamprophis } \\
\text { fuscus }\end{array}$ & $\begin{array}{c}\text { Yellow bellied } \\
\text { house snake }\end{array}$ & 1 Animal & $\begin{array}{l}\text { Medicine } \\
\text { / Pet trade } \\
\text { / } \\
\text { Collectors }\end{array}$ & Hand & $\begin{array}{c}\text { Near } \\
\text { Threatened }\end{array}$ & $\begin{array}{c}\text { Locally } \\
\text { indigenous }\end{array}$ & $\begin{array}{c}\text { Cape Town } \\
\text { general }\end{array}$ & $\begin{array}{c}\text { Harvester } \\
\text { informants, } \\
\text { personal } \\
\text { communication }\end{array}$ \\
\hline Reptilia & $\begin{array}{c}\text { Lamprophis } \\
\text { inornatus }\end{array}$ & $\begin{array}{c}\text { Olive house } \\
\text { snake }\end{array}$ & 1 Animal & $\begin{array}{l}\text { Medicine } \\
\text { / Pet trade } \\
\text { / } \\
\text { Collectors }\end{array}$ & Hand & $\begin{array}{c}\text { Least } \\
\text { Concern }\end{array}$ & $\begin{array}{c}\text { Locally } \\
\text { indigenous }\end{array}$ & $\begin{array}{c}\text { Cape Town } \\
\text { general }\end{array}$ & $\begin{array}{c}\text { Harvester } \\
\text { informants, } \\
\text { personal } \\
\text { communication }\end{array}$ \\
\hline Reptilia & $\begin{array}{l}\text { Leptotyphlops } \\
\text { nigricans }\end{array}$ & $\begin{array}{c}\text { Cape worm } \\
\text { Snake }\end{array}$ & 1 Animal & Medicine & Hand & Not listed & $\begin{array}{c}\text { Locally } \\
\text { indigenous }\end{array}$ & $\begin{array}{c}\text { Cape Town } \\
\text { general }\end{array}$ & $\begin{array}{c}\text { Harvester } \\
\text { informants, } \\
\text { personal } \\
\text { communication }\end{array}$ \\
\hline Mammalia & Lepus capensis & Cape hare & 1 Animal & $\begin{array}{l}\text { Food } \\
\text { source }\end{array}$ & $\begin{array}{c}\text { Trap / } \\
\text { snare / } \\
\text { dog }\end{array}$ & $\begin{array}{c}\text { Least } \\
\text { Concern }\end{array}$ & $\begin{array}{c}\text { Locally } \\
\text { indigenous }\end{array}$ & $\begin{array}{c}\text { Cape Town } \\
\text { general }\end{array}$ & $\begin{array}{c}\text { C. Dorse, } \\
\text { personal } \\
\text { communication }\end{array}$ \\
\hline Mammalia & Lepus saxitilis & Scrub hare & 1 Animal & $\begin{array}{c}\text { Food } \\
\text { source }\end{array}$ & $\begin{array}{c}\text { Trap / } \\
\text { snare / } \\
\text { dog }\end{array}$ & Not listed & $\begin{array}{l}\text { Locally } \\
\text { indigenous }\end{array}$ & $\begin{array}{c}\text { Cape Town } \\
\text { general }\end{array}$ & $\begin{array}{c}\text { D. Gibbs, } \\
\text { personal } \\
\text { communication }\end{array}$ \\
\hline Osteichthyes & Lichia amia & $\begin{array}{l}\text { Garrick / } \\
\text { Leervis }\end{array}$ & 1 Animal & $\begin{array}{c}\text { Food } \\
\text { source }\end{array}$ & Hand & Not listed & $\begin{array}{l}\text { Locally } \\
\text { indigenous }\end{array}$ & $\begin{array}{c}\text { Zandvlei } \\
\text { Estuary }\end{array}$ & $\begin{array}{c}\text { Harvester } \\
\text { informants, } \\
\text { personal } \\
\text { communication }\end{array}$ \\
\hline Osteichthyes & $\begin{array}{l}\text { Lithognathus } \\
\text { lithognathus }\end{array}$ & $\begin{array}{l}\text { White } \\
\text { steenbras } \\
\text { (pignose } \\
\text { grunter) }\end{array}$ & 1 Animal & $\begin{array}{l}\text { Food } \\
\text { source }\end{array}$ & Net & $\begin{array}{c}\text { Near } \\
\text { Threatened }\end{array}$ & $\begin{array}{l}\text { Locally } \\
\text { indigenous }\end{array}$ & $\begin{array}{l}\text { False Bay } \\
\text { Coastline } \\
(\mathrm{TMNP})\end{array}$ & $\begin{array}{c}\text { Harvester } \\
\text { informants, } \\
\text { personal } \\
\text { communication }\end{array}$ \\
\hline Osteichthyes & Liza richardsonii & $\begin{array}{l}\text { Mullets / } \\
\text { harders }\end{array}$ & 1 Animal & $\begin{array}{c}\text { Food } \\
\text { source }\end{array}$ & Net & Not listed & $\begin{array}{l}\text { Locally } \\
\text { indigenous }\end{array}$ & $\begin{array}{l}\text { False Bay } \\
\text { Coastline } \\
(\mathrm{TMNP})\end{array}$ & $\begin{array}{c}\text { Marine and } \\
\text { Coastal } \\
\text { Management } \\
(2008) \\
\end{array}$ \\
\hline Reptilia & $\begin{array}{c}\text { Lycodonomorphus } \\
\text { rufulus }\end{array}$ & $\begin{array}{l}\text { Common } \\
\text { brown water } \\
\text { snake }\end{array}$ & 1 Animal & Medicine & Hand & Not listed & $\begin{array}{l}\text { Locally } \\
\text { indigenous }\end{array}$ & $\begin{array}{c}\text { Cape Town } \\
\text { general }\end{array}$ & $\begin{array}{c}\text { Harvester } \\
\text { informants, } \\
\text { personal } \\
\text { communication }\end{array}$ \\
\hline Bivalvia & Mactra glabrata & $\begin{array}{c}\text { smooth trough } \\
\text { shell }\end{array}$ & 1 Animal & $\begin{array}{c}\text { Food } \\
\text { source / } \\
\text { Bait }\end{array}$ & Hand & Not listed & $\begin{array}{l}\text { Locally } \\
\text { indigenous }\end{array}$ & $\begin{array}{l}\text { False Bay } \\
\text { Coastline } \\
(\mathrm{TMNP})\end{array}$ & $\begin{array}{c}\text { Harvester } \\
\text { informants, } \\
\text { personal } \\
\text { communication }\end{array}$ \\
\hline Bivalvia & $\begin{array}{c}\text { Mytilus } \\
\text { galloprovincialis }\end{array}$ & $\begin{array}{c}\text { Mediterranean } \\
\text { mussel }\end{array}$ & 1 Animal & $\begin{array}{c}\text { Food } \\
\text { source }\end{array}$ & Hand & Not listed & $\begin{array}{c}\text { Alien to South } \\
\text { Africa }\end{array}$ & $\begin{array}{l}\text { Atlantic } \\
\text { Coastline } \\
\text { (TMNP) }\end{array}$ & $\begin{array}{c}\text { Harvester } \\
\text { informants, } \\
\text { personal } \\
\text { communication }\end{array}$ \\
\hline Osteichthyes & Myxus capensis & $\begin{array}{c}\text { Freshwater } \\
\text { mullet }\end{array}$ & 1 Animal & $\begin{array}{l}\text { Food } \\
\text { source }\end{array}$ & Net & $\begin{array}{c}\text { Least } \\
\text { Concern }\end{array}$ & $\begin{array}{c}\text { Locally } \\
\text { indigenous }\end{array}$ & $\begin{array}{c}\text { All } \\
\text { waterways }\end{array}$ & $\begin{array}{c}\text { Harvester } \\
\text { informants, } \\
\text { personal } \\
\text { communication }\end{array}$ \\
\hline
\end{tabular}




\begin{tabular}{|c|c|c|c|c|c|c|c|c|c|}
\hline Reptilia & Naja nivea & Cape cobra & 1 Animal & Medicine & Hand & Not listed & $\begin{array}{c}\text { Locally } \\
\text { indigenous }\end{array}$ & $\begin{array}{c}\text { Cape Town } \\
\text { general }\end{array}$ & $\begin{array}{c}\text { Harvester } \\
\text { informants, } \\
\text { personal } \\
\text { communication }\end{array}$ \\
\hline Aves & $\begin{array}{c}\text { Netta } \\
\text { erythrophthalma }\end{array}$ & $\begin{array}{c}\text { Southern } \\
\text { pochard }\end{array}$ & 1 Animal & $\begin{array}{c}\text { Food } \\
\text { source }\end{array}$ & $\begin{array}{l}\text { Trap / } \\
\text { snare }\end{array}$ & $\begin{array}{c}\text { Least } \\
\text { Concern }\end{array}$ & $\begin{array}{c}\text { Locally } \\
\text { indigenous }\end{array}$ & $\begin{array}{c}\text { All } \\
\text { waterways }\end{array}$ & $\begin{array}{c}\text { L. Isaacs, } \\
\text { personal } \\
\text { communication }\end{array}$ \\
\hline Gastropoda & $\begin{array}{c}\text { Nodilittorina } \\
\text { africana }\end{array}$ & Periwinkle & 1 Animal & $\begin{array}{c}\text { Food } \\
\text { source / } \\
\text { Bait }\end{array}$ & Hand & Not listed & $\begin{array}{c}\text { Locally } \\
\text { indigenous }\end{array}$ & $\begin{array}{l}\text { False Bay } \\
\text { Coastline } \\
(\mathrm{TMNP})\end{array}$ & $\begin{array}{c}\text { Marine and } \\
\text { Coastal } \\
\text { Management } \\
(2008) \\
\end{array}$ \\
\hline Aves & Numida meleagris & Guinea fowl & 1 Animal & $\begin{array}{l}\text { Food } \\
\text { source }\end{array}$ & $\begin{array}{l}\text { Trap / } \\
\text { snare }\end{array}$ & $\begin{array}{c}\text { Least } \\
\text { Concern }\end{array}$ & $\begin{array}{c}\text { South Africa } \\
\text { indigenous }\end{array}$ & $\begin{array}{l}\text { Cape Town } \\
\text { general }\end{array}$ & $\begin{array}{c}\text { P. Glanville, } \\
\text { personal } \\
\text { communication }\end{array}$ \\
\hline Cephalopoda & Octopus vulgaris & Octopus & 1 Animal & $\begin{array}{l}\text { Food } \\
\text { source / } \\
\text { Bait }\end{array}$ & Boat & Not listed & $\begin{array}{c}\text { Locally } \\
\text { indigenous }\end{array}$ & Coastline & $\begin{array}{c}\text { Marine and } \\
\text { Coastal } \\
\text { Management } \\
(2008) \\
\end{array}$ \\
\hline Aves & Oxyura maccoa & Maccoa duck & 1 Animal & $\begin{array}{c}\text { Food } \\
\text { source }\end{array}$ & $\begin{array}{l}\text { Trap / } \\
\text { snare }\end{array}$ & $\begin{array}{c}\text { Least } \\
\text { Concern }\end{array}$ & $\begin{array}{c}\text { Locally } \\
\text { indigenous }\end{array}$ & $\begin{array}{c}\text { All } \\
\text { waterways }\end{array}$ & $\begin{array}{c}\text { L. Isaacs, } \\
\text { personal } \\
\text { communication }\end{array}$ \\
\hline Osteichthyes & $\begin{array}{c}\text { Pachymetopon } \\
\text { blochii }\end{array}$ & Hottentot & 1 Animal & $\begin{array}{c}\text { Food } \\
\text { source }\end{array}$ & Net & Not listed & $\begin{array}{c}\text { Locally } \\
\text { indigenous }\end{array}$ & $\begin{array}{l}\text { False Bay } \\
\text { Coastline } \\
\text { (TMNP) }\end{array}$ & $\begin{array}{c}\text { Marine and } \\
\text { Coastal } \\
\text { Management } \\
(2008)\end{array}$ \\
\hline Gastropoda & Patella spp & Limpets & 13 Animal & $\begin{array}{l}\text { Food } \\
\text { source / } \\
\text { Bait }\end{array}$ & Hand & Not listed & $\begin{array}{l}\text { Locally } \\
\text { indigenous }\end{array}$ & $\begin{array}{l}\text { False Bay } \\
\text { Coastline } \\
\text { (TMNP) }\end{array}$ & $\begin{array}{c}\text { Marine and } \\
\text { Coastal } \\
\text { Management } \\
\text { (2008), } \\
\text { Harvester } \\
\text { informants, } \\
\text { personal } \\
\text { communication }\end{array}$ \\
\hline Reptilia & $\begin{array}{l}\text { Pelomedusa } \\
\text { subrufa }\end{array}$ & $\begin{array}{l}\text { Marsh } \\
\text { terrapin }\end{array}$ & 1 Animal & $\begin{array}{l}\text { Medicine } \\
\text { / Pet trade } \\
\text { / } \\
\text { Collectors }\end{array}$ & Hand & Not listed & $\begin{array}{c}\text { Locally } \\
\text { indigenous }\end{array}$ & $\begin{array}{l}\text { Cape Town } \\
\text { general }\end{array}$ & $\begin{array}{c}\text { D. Gibbs, } \\
\text { personal } \\
\text { communication }\end{array}$ \\
\hline Osteichthyes & Petrus rupestris & $\begin{array}{l}\text { Red steenbras } \\
\text { (Copper } \\
\text { steenbras) }\end{array}$ & 1 Animal & $\begin{array}{c}\text { Food } \\
\text { source }\end{array}$ & Net & Not listed & $\begin{array}{l}\text { Locally } \\
\text { indigenous }\end{array}$ & $\begin{array}{l}\text { False Bay } \\
\text { Coastline } \\
\text { (TMNP) }\end{array}$ & $\begin{array}{c}\text { Harvester } \\
\text { informants, } \\
\text { personal } \\
\text { communication }\end{array}$ \\
\hline Aves & $\begin{array}{l}\text { Plectropterus } \\
\text { gambensis }\end{array}$ & $\begin{array}{l}\text { Spur-winged } \\
\text { Goose }\end{array}$ & 1 Animal & $\begin{array}{c}\text { Food } \\
\text { source }\end{array}$ & $\begin{array}{l}\text { Trap / } \\
\text { snare }\end{array}$ & $\begin{array}{l}\text { Least } \\
\text { Concern }\end{array}$ & $\begin{array}{c}\text { Locally } \\
\text { indigenous }\end{array}$ & $\begin{array}{c}\text { All } \\
\text { waterways }\end{array}$ & $\begin{array}{c}\text { L. Isaacs, } \\
\text { personal } \\
\text { communication }\end{array}$ \\
\hline Aves & Podiceps cristatus & $\begin{array}{l}\text { Great crested } \\
\text { grebe }\end{array}$ & 1 Animal & $\begin{array}{c}\text { Food } \\
\text { source }\end{array}$ & $\begin{array}{l}\text { Trap / } \\
\text { snare }\end{array}$ & $\begin{array}{l}\text { Least } \\
\text { Concern }\end{array}$ & $\begin{array}{l}\text { Locally } \\
\text { indigenous }\end{array}$ & $\begin{array}{c}\text { All } \\
\text { waterways }\end{array}$ & $\begin{array}{c}\text { L. Isaacs, } \\
\text { personal } \\
\text { communication }\end{array}$ \\
\hline Aves & $\begin{array}{c}\text { Podiceps } \\
\text { nigricollis }\end{array}$ & $\begin{array}{c}\text { Black-necked } \\
\text { grebe }\end{array}$ & 1 Animal & $\begin{array}{l}\text { Food } \\
\text { source }\end{array}$ & $\begin{array}{l}\text { Trap / } \\
\text { snare }\end{array}$ & $\begin{array}{c}\text { Least } \\
\text { Concern }\end{array}$ & $\begin{array}{l}\text { Locally } \\
\text { indigenous }\end{array}$ & $\begin{array}{c}\text { All } \\
\text { waterways }\end{array}$ & $\begin{array}{c}\text { L. Isaacs, } \\
\text { personal } \\
\text { communication } \\
\end{array}$ \\
\hline Osteichthyes & $\begin{array}{l}\text { Pomatomus } \\
\text { saltatrix }\end{array}$ & Elf (Shad) & 1 Animal & $\begin{array}{c}\text { Food } \\
\text { source }\end{array}$ & Net & Not listed & $\begin{array}{l}\text { Locally } \\
\text { indigenous }\end{array}$ & $\begin{array}{l}\text { False Bay } \\
\text { Coastline } \\
\text { (TMNP) }\end{array}$ & $\begin{array}{c}\text { Harvester } \\
\text { informants, } \\
\text { personal } \\
\text { communication }\end{array}$ \\
\hline Mammalia & Procavia capensis & Rock dassie & 1 Animal & Medicine & Hand & $\begin{array}{c}\text { Least } \\
\text { Concern }\end{array}$ & $\begin{array}{l}\text { Locally } \\
\text { indigenous }\end{array}$ & $\begin{array}{c}\text { Cape Town } \\
\text { general }\end{array}$ & $\begin{array}{c}\text { Harvester } \\
\text { informants, } \\
\text { personal }\end{array}$ \\
\hline
\end{tabular}




\begin{tabular}{|c|c|c|c|c|c|c|c|c|c|}
\hline & & & & & & & & & communication \\
\hline Reptilia & $\begin{array}{l}\text { Prosymna } \\
\text { sundevallii }\end{array}$ & $\begin{array}{l}\text { Sundevall's } \\
\text { shovel-snout }\end{array}$ & 1 Animal & $\begin{array}{l}\text { Medicine } \\
\text { / Pet trade } \\
\text { / } \\
\text { Collectors }\end{array}$ & Hand & Not listed & $\begin{array}{l}\text { Locally } \\
\text { indigenous }\end{array}$ & $\begin{array}{l}\text { Cape Town } \\
\text { general }\end{array}$ & $\begin{array}{c}\text { Harvester } \\
\text { informants, } \\
\text { personal } \\
\text { communication }\end{array}$ \\
\hline Reptilia & $\begin{array}{l}\text { Psammobates } \\
\text { geometricus }\end{array}$ & $\begin{array}{l}\text { Geometric } \\
\text { tortoise }\end{array}$ & 1 Animal & Medicine & Hand & Endangered & $\begin{array}{l}\text { Locally } \\
\text { indigenous }\end{array}$ & $\begin{array}{c}\text { Table } \\
\text { Mountain } \\
\text { National } \\
\text { Park } \\
\end{array}$ & $\begin{array}{c}\text { H. Mananga, } \\
\text { personal } \\
\text { communication }\end{array}$ \\
\hline Reptilia & $\begin{array}{l}\text { Psammophis } \\
\text { crucifer }\end{array}$ & $\begin{array}{l}\text { Cross marked } \\
\text { whip snake }\end{array}$ & 1 Animal & Medicine & Hand & Not listed & $\begin{array}{l}\text { Locally } \\
\text { indigenous }\end{array}$ & $\begin{array}{l}\text { Cape Town } \\
\text { general }\end{array}$ & $\begin{array}{c}\text { Harvester } \\
\text { informants, } \\
\text { personal } \\
\text { communication }\end{array}$ \\
\hline Reptilia & $\begin{array}{c}\text { Psammophis } \\
\text { leightoni }\end{array}$ & $\begin{array}{l}\text { Cape whip } \\
\text { snake }\end{array}$ & 1 Animal & Medicine & Hand & Not listed & $\begin{array}{l}\text { Locally } \\
\text { indigenous }\end{array}$ & $\begin{array}{l}\text { Cape Town } \\
\text { general }\end{array}$ & $\begin{array}{c}\text { Harvester } \\
\text { informants, } \\
\text { personal } \\
\text { communication }\end{array}$ \\
\hline Reptilia & $\begin{array}{l}\text { Psammophis } \\
\text { notostictus }\end{array}$ & $\begin{array}{l}\text { Karoo whip } \\
\text { snake }\end{array}$ & 1 Animal & Medicine & Hand & Not listed & $\begin{array}{l}\text { Locally } \\
\text { indigenous }\end{array}$ & $\begin{array}{l}\text { Cape Town } \\
\text { general }\end{array}$ & $\begin{array}{c}\text { Harvester } \\
\text { informants, } \\
\text { personal } \\
\text { communication }\end{array}$ \\
\hline Reptilia & $\begin{array}{l}\text { Psammophylax } \\
\text { rhombeatus }\end{array}$ & $\begin{array}{c}\text { Spotted } \\
\text { skaapsteker }\end{array}$ & 1 Animal & Medicine & Hand & Not listed & $\begin{array}{l}\text { Locally } \\
\text { indigenous }\end{array}$ & $\begin{array}{l}\text { Cape Town } \\
\text { general }\end{array}$ & $\begin{array}{c}\text { Harvester } \\
\text { informants, } \\
\text { personal } \\
\text { communication }\end{array}$ \\
\hline Reptilia & Pseudaspis cana & Mole snake & 1 Animal & Medicine & Hand & Not listed & $\begin{array}{l}\text { Locally } \\
\text { indigenous }\end{array}$ & $\begin{array}{l}\text { Cape Town } \\
\text { general }\end{array}$ & $\begin{array}{c}\text { Harvester } \\
\text { informants, } \\
\text { personal } \\
\text { communication }\end{array}$ \\
\hline Aves & $\begin{array}{c}\text { Pternistis } \\
\text { capensis }\end{array}$ & Francolin & 1 Animal & $\begin{array}{c}\text { Food } \\
\text { source }\end{array}$ & $\begin{array}{l}\text { Trap / } \\
\text { snare }\end{array}$ & Not listed & $\begin{array}{l}\text { Locally } \\
\text { indigenous }\end{array}$ & $\begin{array}{l}\text { Cape Town } \\
\text { general }\end{array}$ & $\begin{array}{c}\text { H. Mananga, } \\
\text { personal } \\
\text { communication }\end{array}$ \\
\hline Ascidiacea & Pyura stolonifera & Red bait & 1 Animal & $\begin{array}{c}\text { Food } \\
\text { source }\end{array}$ & Hand & Not listed & $\begin{array}{l}\text { Locally } \\
\text { indigenous }\end{array}$ & $\begin{array}{l}\text { False Bay } \\
\text { Coastline } \\
\text { (TMNP) }\end{array}$ & $\begin{array}{c}\text { Harvester } \\
\text { informants, } \\
\text { personal } \\
\text { communication }\end{array}$ \\
\hline Reptilia & $\begin{array}{l}\text { Ramphotyphlops } \\
\text { braminus }\end{array}$ & $\begin{array}{l}\text { Flowerpot } \\
\text { snake }\end{array}$ & 1 Animal & $\begin{array}{l}\text { Medicine } \\
\text { / Pet trade } \\
\text { / } \\
\text { Collectors }\end{array}$ & Hand & Not listed & $\begin{array}{c}\text { Alien to South } \\
\text { Africa }\end{array}$ & $\begin{array}{l}\text { Cape Town } \\
\text { general }\end{array}$ & $\begin{array}{c}\text { Harvester } \\
\text { informants, } \\
\text { personal } \\
\text { communication }\end{array}$ \\
\hline Mammalia & $\begin{array}{l}\text { Raphicerus } \\
\text { campestris }\end{array}$ & Steenbok & 1 Animal & $\begin{array}{c}\text { Food } \\
\text { source / } \\
\text { Gambling } \\
\text { / Sport }\end{array}$ & $\begin{array}{c}\text { Trap / } \\
\text { snare / } \\
\operatorname{dog}\end{array}$ & $\begin{array}{c}\text { Least } \\
\text { Concern }\end{array}$ & $\begin{array}{l}\text { Locally } \\
\text { indigenous }\end{array}$ & $\begin{array}{l}\text { Cape Town } \\
\text { general }\end{array}$ & $\begin{array}{c}\text { C. Dorse, } \\
\text { personal } \\
\text { communication }\end{array}$ \\
\hline Mammalia & $\begin{array}{l}\text { Raphicerus } \\
\text { melanotis }\end{array}$ & Cape grysbok & 1 Animal & $\begin{array}{c}\text { Food } \\
\text { source / } \\
\text { Gambling } \\
\text { / Sport }\end{array}$ & $\begin{array}{c}\text { Trap / } \\
\text { snare / } \\
\operatorname{dog}\end{array}$ & $\begin{array}{c}\text { Least } \\
\text { Concern }\end{array}$ & $\begin{array}{l}\text { Locally } \\
\text { indigenous }\end{array}$ & $\begin{array}{l}\text { Cape Town } \\
\text { general }\end{array}$ & $\begin{array}{c}\text { L. Isaacs, } \\
\text { personal } \\
\text { communication }\end{array}$ \\
\hline Osteichthyes & Seriola lalandi & Yellowtail & 1 Animal & $\begin{array}{c}\text { Food } \\
\text { source }\end{array}$ & Boat & Not listed & $\begin{array}{l}\text { Locally } \\
\text { indigenous }\end{array}$ & $\begin{array}{l}\text { False Bay } \\
\text { Coastline } \\
\text { (TMNP) }\end{array}$ & $\begin{array}{c}\text { Harvester } \\
\text { informants, } \\
\text { personal } \\
\text { communication }\end{array}$ \\
\hline Gastropoda & Siphonaria spp & False limpets & 4 Animal & $\begin{array}{l}\text { Food } \\
\text { source / } \\
\text { Bait }\end{array}$ & Hand & Not listed & $\begin{array}{l}\text { Locally } \\
\text { indigenous }\end{array}$ & $\begin{array}{l}\text { False Bay } \\
\text { Coastline } \\
\text { (TMNP) }\end{array}$ & $\begin{array}{c}\text { Marine and } \\
\text { Coastal } \\
\text { Management } \\
(2008), \\
\text { Harvester }\end{array}$ \\
\hline
\end{tabular}




\begin{tabular}{|c|c|c|c|c|c|c|c|c|c|}
\hline & & & & & & & & & $\begin{array}{c}\text { informants, } \\
\text { personal } \\
\text { communication }\end{array}$ \\
\hline Bivalvia & $\begin{array}{c}\text { Striostrea } \\
\text { margaritacea }\end{array}$ & $\begin{array}{c}\text { Cape rock } \\
\text { oyster }\end{array}$ & 1 Animal & $\begin{array}{c}\text { Food } \\
\text { source }\end{array}$ & Hand & Not listed & $\begin{array}{c}\text { Locally } \\
\text { indigenous }\end{array}$ & $\begin{array}{l}\text { False Bay } \\
\text { Coastline } \\
(\mathrm{TMNP})\end{array}$ & $\begin{array}{c}\text { Marine and } \\
\text { Coastal } \\
\text { Management } \\
\text { (2008), } \\
\text { Harvester } \\
\text { informants, } \\
\text { personal } \\
\text { communication }\end{array}$ \\
\hline Amphibia & $\begin{array}{l}\text { Strongylopus } \\
\text { grayii }\end{array}$ & $\begin{array}{l}\text { Clicking } \\
\text { stream frog }\end{array}$ & 1 Animal & $\begin{array}{l}\text { Pet trade / } \\
\text { collectors }\end{array}$ & Hand & $\begin{array}{c}\text { Least } \\
\text { Concern }\end{array}$ & $\begin{array}{l}\text { Locally } \\
\text { indigenous }\end{array}$ & $\begin{array}{l}\text { Cape Town } \\
\text { general }\end{array}$ & $\begin{array}{c}\text { L. Isaacs, } \\
\text { personal } \\
\text { communication }\end{array}$ \\
\hline Aves & Struthio camelus & Ostrich & 1 Animal & $\begin{array}{l}\text { Gambling } \\
\text { / sport }\end{array}$ & Dog & $\begin{array}{c}\text { Least } \\
\text { Concern }\end{array}$ & $\begin{array}{c}\text { Locally } \\
\text { indigenous }\end{array}$ & $\begin{array}{l}\text { Cape Town } \\
\text { general }\end{array}$ & $\begin{array}{c}\text { D. Gibbs, } \\
\text { personal } \\
\text { communication }\end{array}$ \\
\hline Mammalia & $\begin{array}{l}\text { Sylvicapra } \\
\text { grimmia }\end{array}$ & $\begin{array}{c}\text { Common } \\
\text { duiker }\end{array}$ & 1 Animal & $\begin{array}{c}\text { Food } \\
\text { source / } \\
\text { Gambling } \\
\text { / Sport } \\
\end{array}$ & $\begin{array}{c}\text { Trap / } \\
\text { snare / } \\
\operatorname{dog}\end{array}$ & $\begin{array}{l}\text { Least } \\
\text { Concern }\end{array}$ & $\begin{array}{l}\text { Locally } \\
\text { indigenous }\end{array}$ & $\begin{array}{l}\text { Cape Town } \\
\text { general }\end{array}$ & $\begin{array}{c}\text { C. Dorse, } \\
\text { personal } \\
\text { communication }\end{array}$ \\
\hline Aves & $\begin{array}{l}\text { Tachybaptus } \\
\text { ruficollis }\end{array}$ & Little grebe & 1 Animal & $\begin{array}{c}\text { Food } \\
\text { source }\end{array}$ & $\begin{array}{l}\text { Trap / } \\
\text { snare }\end{array}$ & $\begin{array}{c}\text { Least } \\
\text { Concern }\end{array}$ & $\begin{array}{c}\text { Locally } \\
\text { indigenous }\end{array}$ & $\begin{array}{c}\text { All } \\
\text { waterways }\end{array}$ & $\begin{array}{c}\text { L. Isaacs, } \\
\text { personal } \\
\text { communication }\end{array}$ \\
\hline Aves & Tadorna cana & $\begin{array}{l}\text { South African } \\
\text { shelduck }\end{array}$ & 1 Animal & $\begin{array}{c}\text { Food } \\
\text { source }\end{array}$ & $\begin{array}{l}\text { Trap / } \\
\text { snare }\end{array}$ & $\begin{array}{c}\text { Least } \\
\text { Concern }\end{array}$ & $\begin{array}{c}\text { Locally } \\
\text { indigenous }\end{array}$ & $\begin{array}{c}\text { All } \\
\text { waterways }\end{array}$ & $\begin{array}{c}\text { L. Isaacs, } \\
\text { personal } \\
\text { communication }\end{array}$ \\
\hline Bivalvia & Tellina alfredensis & $\begin{array}{c}\text { Pink Port } \\
\text { Alfred tellin }\end{array}$ & 1 Animal & Bait & Hand & Not listed & $\begin{array}{c}\text { Locally } \\
\text { indigenous }\end{array}$ & $\begin{array}{l}\text { False Bay } \\
\text { Coastline } \\
\text { (TMNP) }\end{array}$ & $\begin{array}{c}\text { Marine and } \\
\text { Coastal } \\
\text { Management } \\
\text { (2008), } \\
\text { Harvester } \\
\text { informants, } \\
\text { personal } \\
\text { communication }\end{array}$ \\
\hline Osteichthyes & Thyrsites atun & $\begin{array}{c}\text { Snoek (Cape } \\
\text { snoek) }\end{array}$ & 1 Animal & $\begin{array}{c}\text { Food } \\
\text { source }\end{array}$ & Boat & Not listed & $\begin{array}{c}\text { Locally } \\
\text { indigenous }\end{array}$ & $\begin{array}{l}\text { False Bay } \\
\text { Coastline } \\
\text { (TMNP) }\end{array}$ & $\begin{array}{c}\text { Harvester } \\
\text { informants, } \\
\text { personal } \\
\text { communication }\end{array}$ \\
\hline Osteichthyes & $\begin{array}{c}\text { Tilapia } \\
\text { sparrmanii }\end{array}$ & Tilapia & 1 Animal & $\begin{array}{c}\text { Food } \\
\text { source }\end{array}$ & Hand & $\begin{array}{l}\text { Least } \\
\text { Concern }\end{array}$ & $\begin{array}{c}\text { Alien to South } \\
\text { Africa }\end{array}$ & $\begin{array}{c}\text { False Bay } \\
\text { Ecology } \\
\text { Park area } \\
\end{array}$ & $\begin{array}{c}\text { D. Gibbs, } \\
\text { personal } \\
\text { communication }\end{array}$ \\
\hline Gastropoda & Turbo sarmaticus & Allikruekel & 1 Animal & $\begin{array}{c}\text { Food } \\
\text { source / } \\
\text { Bait }\end{array}$ & Hand & Not listed & $\begin{array}{c}\text { Locally } \\
\text { indigenous }\end{array}$ & $\begin{array}{l}\text { False Bay } \\
\text { Coastline } \\
\text { (TMNP) }\end{array}$ & $\begin{array}{c}\text { Marine and } \\
\text { Coastal } \\
\text { Management } \\
(2008), \\
\text { Harvester } \\
\text { informants, } \\
\text { personal } \\
\text { communication }\end{array}$ \\
\hline Gastropoda & Turritella spp. & Screw shells & 3 Animal & $\begin{array}{c}\text { Food } \\
\text { source / } \\
\text { Bait }\end{array}$ & Hand & Not listed & $\begin{array}{c}\text { Locally } \\
\text { indigenous }\end{array}$ & $\begin{array}{l}\text { False Bay } \\
\text { Coastline } \\
\text { (TMNP) }\end{array}$ & $\begin{array}{c}\text { Harvester } \\
\text { informants, } \\
\text { personal } \\
\text { communication }\end{array}$ \\
\hline Reptilia & Typhlops lalandei & $\begin{array}{l}\text { Delalande's } \\
\text { blind snake }\end{array}$ & 1 Animal & Medicine & Hand & Not listed & $\begin{array}{c}\text { Locally } \\
\text { indigenous }\end{array}$ & $\begin{array}{l}\text { Cape Town } \\
\text { general }\end{array}$ & $\begin{array}{c}\text { Harvester } \\
\text { informants, } \\
\text { personal }\end{array}$ \\
\hline
\end{tabular}




\begin{tabular}{|c|c|c|c|c|c|c|c|c|c|}
\hline & & & & & & & & & communication \\
\hline Malacostraca & $\begin{array}{l}\text { Upogebia } \\
\text { africana }\end{array}$ & $\begin{array}{l}\text { Estuarine } \\
\text { mudprawn }\end{array}$ & 1 Animal & Bait & Pump & Not listed & $\begin{array}{c}\text { Locally } \\
\text { indigenous }\end{array}$ & Coastline & $\begin{array}{c}\text { Harvester } \\
\text { informants, } \\
\text { personal } \\
\text { communication }\end{array}$ \\
\hline Arachnida & $\begin{array}{c}\text { Uroplectes } \\
\text { insignus }\end{array}$ & $\begin{array}{c}\text { Lesser thick } \\
\text { tailed } \\
\text { scorpion }\end{array}$ & 1 Animal & $\begin{array}{l}\text { Medicine } \\
\text { / Pet trade } \\
\text { / } \\
\text { Collectors }\end{array}$ & Hand & Not listed & $\begin{array}{c}\text { Locally } \\
\text { indigenous }\end{array}$ & $\begin{array}{c}\text { Table } \\
\text { Mountain } \\
\text { National } \\
\text { Park } \\
\end{array}$ & $\begin{array}{c}\text { Harvester } \\
\text { informants, } \\
\text { personal } \\
\text { communication }\end{array}$ \\
\hline Arachnida & $\begin{array}{c}\text { Uroplectes } \\
\text { lineatus }\end{array}$ & $\begin{array}{c}\text { Lesser thick } \\
\text { tailed } \\
\text { scorpion }\end{array}$ & 1 Animal & $\begin{array}{l}\text { Medicine } \\
\text { / Pet trade } \\
\text { / } \\
\text { Collectors }\end{array}$ & Hand & Not listed & $\begin{array}{c}\text { Locally } \\
\text { indigenous }\end{array}$ & $\begin{array}{c}\text { Table } \\
\text { Mountain } \\
\text { National } \\
\text { Park } \\
\end{array}$ & $\begin{array}{c}\text { Harvester } \\
\text { informants, } \\
\text { personal } \\
\text { communication }\end{array}$ \\
\hline Amphibia & $\begin{array}{l}\text { Xenopus laevis } \\
\text { (Daudin, 1802) }\end{array}$ & $\begin{array}{l}\text { Common } \\
\text { platanna }\end{array}$ & 1 Animal & $\begin{array}{l}\text { Pet trade / } \\
\text { collectors }\end{array}$ & Hand & $\begin{array}{c}\text { Least } \\
\text { Concern }\end{array}$ & $\begin{array}{c}\text { Locally } \\
\text { indigenous }\end{array}$ & $\begin{array}{c}\text { Cape Town } \\
\text { general }\end{array}$ & $\begin{array}{c}\text { C. Dorse, } \\
\text { personal } \\
\text { communication }\end{array}$ \\
\hline Gastropoda & & Alikruekel & 4 Animal & $\begin{array}{c}\text { Food } \\
\text { source / } \\
\text { Bait }\end{array}$ & Hand & Not listed & $\begin{array}{c}\text { Locally } \\
\text { indigenous }\end{array}$ & $\begin{array}{l}\text { False Bay } \\
\text { Coastline } \\
(\mathrm{TMNP})\end{array}$ & $\begin{array}{c}\text { Harvester } \\
\text { informants, } \\
\text { personal } \\
\text { communication } \\
\end{array}$ \\
\hline Gastropoda & & $\begin{array}{l}\text { Keyhole } \\
\text { limpets }\end{array}$ & 5 Animal & $\begin{array}{c}\text { Food } \\
\text { source / } \\
\text { Bait }\end{array}$ & Hand & Not listed & $\begin{array}{c}\text { Locally } \\
\text { indigenous }\end{array}$ & $\begin{array}{l}\text { False Bay } \\
\text { Coastline } \\
\text { (TMNP) }\end{array}$ & $\begin{array}{c}\text { Harvester } \\
\text { informants, } \\
\text { personal } \\
\text { communication }\end{array}$ \\
\hline Gastropoda & & $\begin{array}{l}\text { Slipper } \\
\text { limpets }\end{array}$ & 4 Animal & $\begin{array}{c}\text { Food } \\
\text { source / } \\
\text { Bait }\end{array}$ & Hand & Not listed & $\begin{array}{c}\text { Locally } \\
\text { indigenous }\end{array}$ & $\begin{array}{l}\text { False Bay } \\
\text { Coastline } \\
(\mathrm{TMNP})\end{array}$ & $\begin{array}{c}\text { Harvester } \\
\text { informants, } \\
\text { personal } \\
\text { communication }\end{array}$ \\
\hline Gastropoda & & Top snails & 8 Animal & $\begin{array}{c}\text { Food } \\
\text { source / } \\
\text { Bait }\end{array}$ & Hand & Not listed & $\begin{array}{c}\text { Locally } \\
\text { indigenous }\end{array}$ & $\begin{array}{l}\text { False Bay } \\
\text { Coastline } \\
\text { (TMNP) }\end{array}$ & $\begin{array}{c}\text { Harvester } \\
\text { informants, } \\
\text { personal } \\
\text { communication }\end{array}$ \\
\hline Gastropoda & & Tritons & 3 Animal & $\begin{array}{c}\text { Food } \\
\text { source / } \\
\text { Bait }\end{array}$ & Hand & Not listed & $\begin{array}{c}\text { Locally } \\
\text { indigenous }\end{array}$ & $\begin{array}{l}\text { False Bay } \\
\text { Coastline } \\
(\mathrm{TMNP})\end{array}$ & $\begin{array}{c}\text { Harvester } \\
\text { informants, } \\
\text { personal } \\
\text { communication } \\
\end{array}$ \\
\hline Maxillopoda & & Barnacles & 3 Animal & $\begin{array}{c}\text { Food } \\
\text { source / } \\
\text { Bait }\end{array}$ & Hand & Not listed & $\begin{array}{c}\text { Locally } \\
\text { indigenous }\end{array}$ & $\begin{array}{l}\text { False Bay } \\
\text { Coastline } \\
(\mathrm{TMNP})\end{array}$ & $\begin{array}{c}\text { Harvester } \\
\text { informants, } \\
\text { personal } \\
\text { communication }\end{array}$ \\
\hline
\end{tabular}

